Revue des patrimoines

16 | 2011

Le patrimoine militaire et la question urbaine

\title{
Découverte à Paris d'un plafond peint à décor de singeries attribué à Claude III Audran, Antoine Watteau et Nicolas Lancret
}

\section{Christelle Inizan}

\author{
(2) OpenEdition \\ Journals \\ Édition électronique \\ URL : http://journals.openedition.org/insitu/805 \\ DOI : 10.4000/insitu.805 \\ ISSN : 1630-7305 \\ Éditeur \\ Ministère de la Culture \\ Référence électronique \\ Christelle Inizan, « Découverte à Paris d'un plafond peint à décor de singeries attribué à Claude III \\ Audran, Antoine Watteau et Nicolas Lancret », In Situ [En ligne], 16 | 2011, mis en ligne le 22 août 2011, \\ consulté le 10 décembre 2020. URL : http://journals.openedition.org/insitu/805 ; DOI : https://doi.org/ \\ 10.4000/insitu.805
}

Ce document a été généré automatiquement le 10 décembre 2020.

\section{(c) (1) (9)}

In Situ Revues des patrimoines est mis à disposition selon les termes de la licence Creative Commons Attribution - Pas d'Utilisation Commerciale - Pas de Modification 4.0 International. 


\title{
Découverte à Paris d'un plafond peint à décor de singeries attribué à Claude III Audran, Antoine Watteau et Nicolas Lancret
}

\author{
Christelle Inizan
}

La Conservation Régionale des Monuments Historiques d'île-de-France (CRMH) a entrepris voici plusieurs années le recensement systématique de son parc immobilier francilien de monuments protégés, tant public que privé ${ }^{1}$. C'est précisément lors d'une visite approfondie de l'immeuble du numéro 26 de la rue de Condé, dans le 6e arrondissement de Paris (dont la façade sur rue et sa toiture correspondante sont inscrites au titre des Monuments historiques depuis le 20 mars 1964) que fut découvert, en juin 2009, ce remarquable plafond peint une cinquantaine d'années après la construction de l'édifice, qui remonte au milieu du XVII ${ }^{\mathrm{e}}$ siècle ${ }^{2}$. 
Figure 1

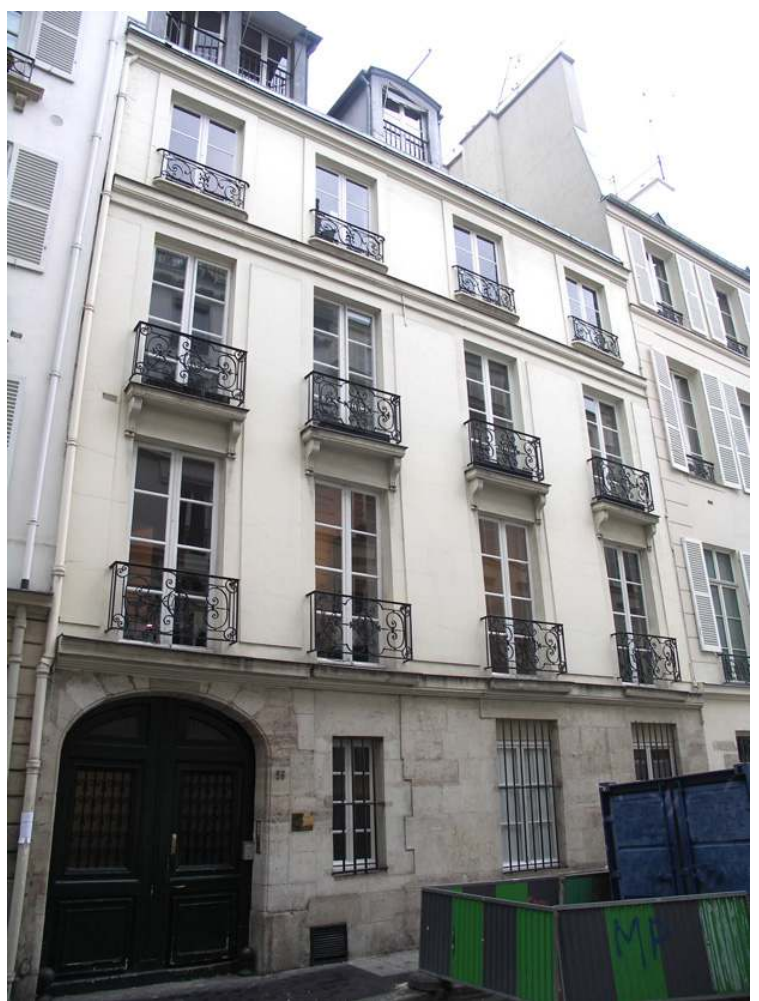

Façade sur rue du 26 rue de Condé à Paris 6e. Phot. Christelle Inizan.

(c) CRMH Île-de-France, 2009.

2 Rien ne distingue singulièrement cette maison (fig. $\left.\mathbf{n}^{\circ} \mathbf{1}\right)$ (fig. $\mathbf{n}^{\circ} \mathbf{2}$ ) des autres constructions environnantes (fig. $\mathbf{n}^{\circ} \mathbf{3}$ ), l'immeuble n'appartenant pas aux illustres hôtels parisiens, les chercheurs ont ignoré son importance artistique. Côté pair de la rue de Condé, certains édifices ont été protégés dans le souci de conserver des séquences de ce front bâti de l'Ancien Régime ${ }^{3}$. Côté impair, à l'emplacement de l'Hôtel de Condé détruit en 1764 , des constructions de la fin du XVIII ${ }^{\text {e }}$ siècle bénéficient également d'une protection au titre des Monuments historiques ${ }^{45}$. 
Figure 2

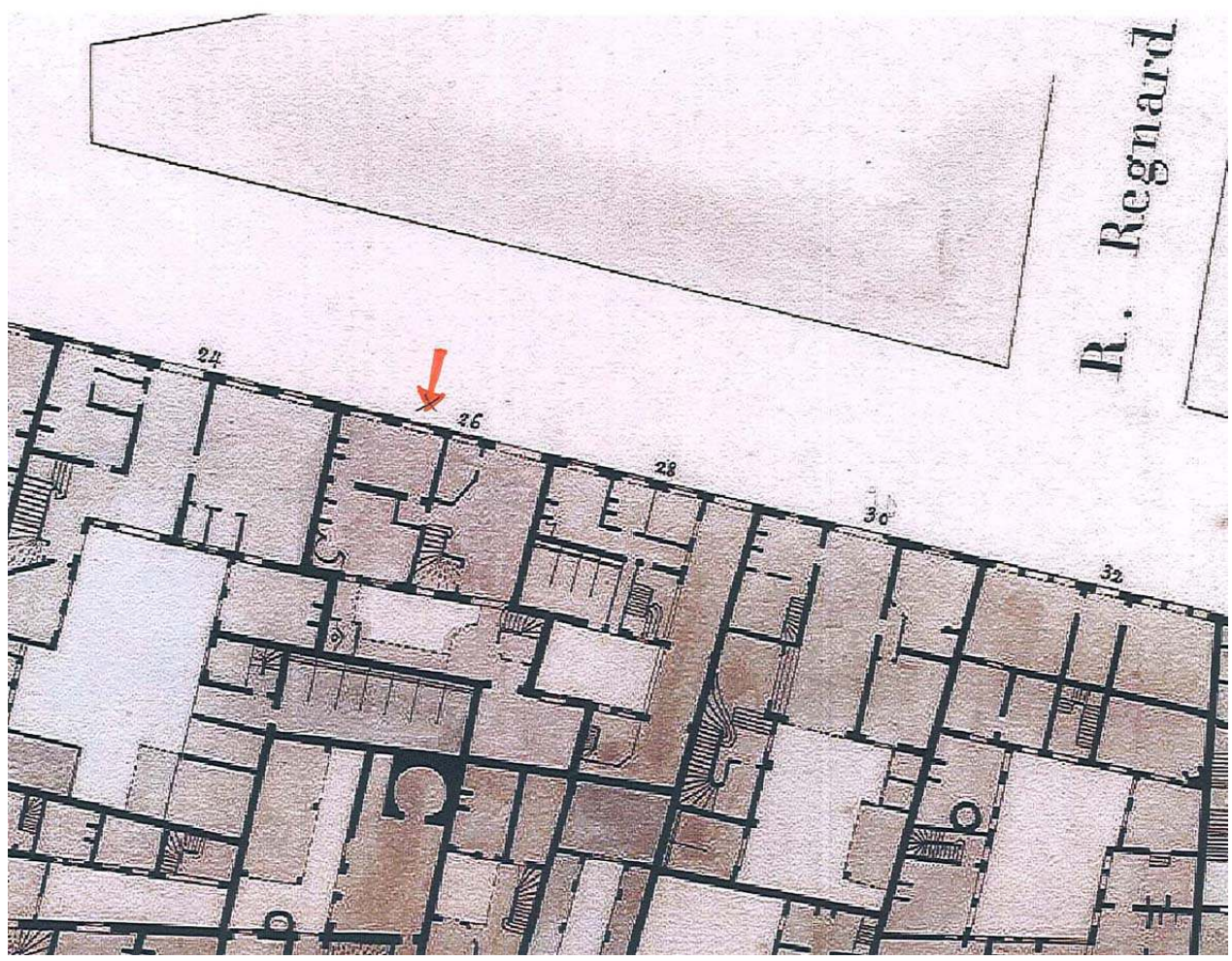

Plan Vasserot 1810-1836, îlot $n^{\circ} 16$ du quartier du Luxembourg, ancien 11e arrondissement F/31/93/17. Flèche signalant la parcelle de l'immeuble sis 26 rue de Condé.

(c) Archives Nationales. 
Figure 3

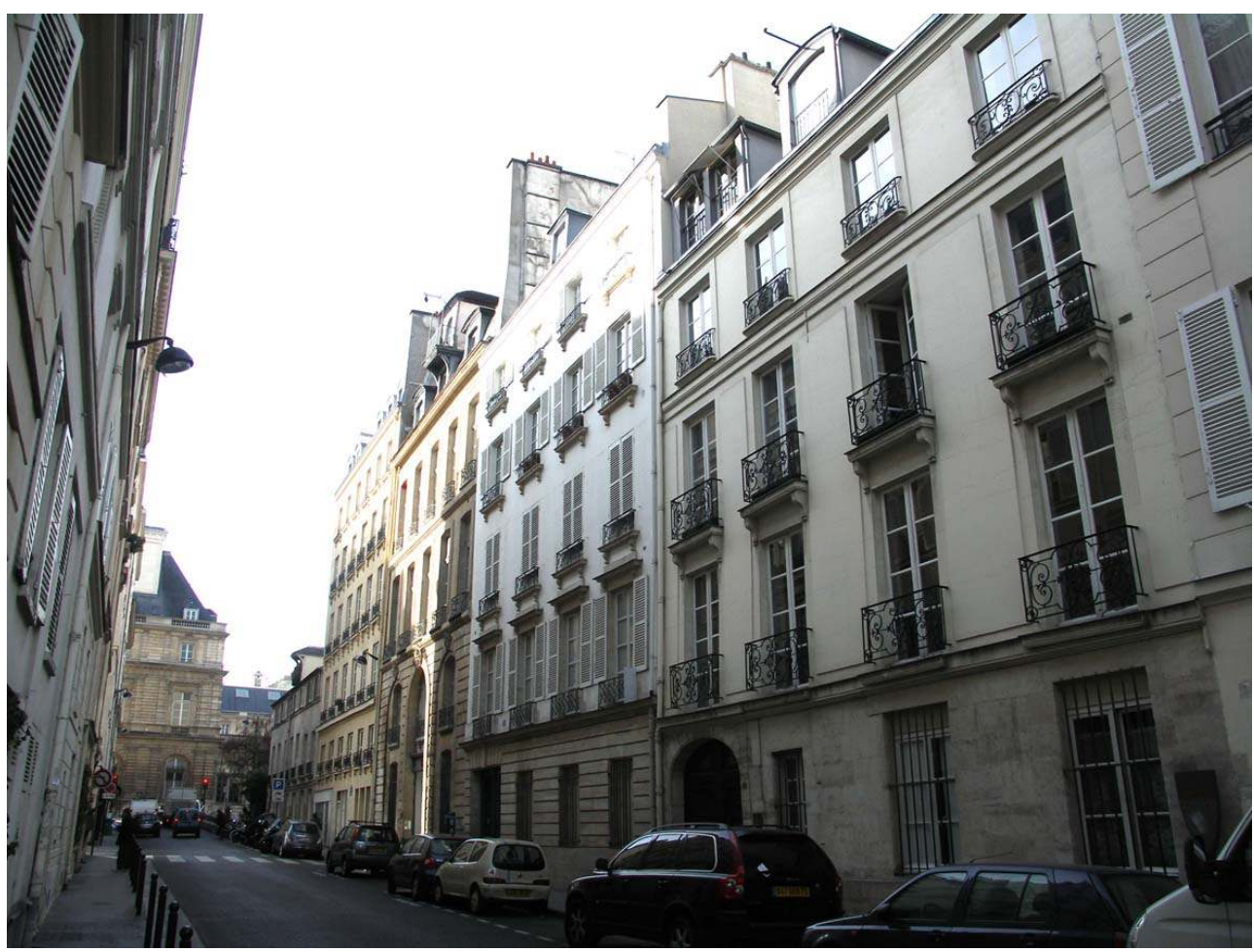

Côté pair de la rue de Condé, vers le Palais du Luxembourg. Phot. Christelle Inizan.

(c) CRMH île-de-France, 2010

\section{Rareté d'un décor peint dans le premier quart du XVIIle siècle encore en place}

La conservation in situ du plafond de la maison du 26 rue de Condé est une grande chance. Beaucoup de décors parisiens ont en effet été démontés et remontés, perdant ainsi toute lisibilité historique. Fait heureux, ce plafond peut être replacé dans son contexte architectural et géographique. Son existence confirme du même coup la tradition orale suivant laquelle ce boudoir aurait été celui des sœurs de Beaumarchais.

Le commanditaire probable de l'œuvre a pu être identifié : Joseph Le Gendre d'Armény ${ }^{67}$, beau-père de la plus grosse fortune de France de l'époque, Antoine Crozat, qui comme son frère Pierre, était collectionneur d'art et mécène des artistes les plus novateurs de la fin du règne de Louis XIV et de la Régence.

5 La charge de directeur général de l'île de Saint-Domingue de Le Gendre d'Armény est un indice des liens économiques que pouvaient entretenir le beau-père et le gendre. Au-delà de l'exotisme fort apprécié en ce début du XVIII ${ }^{e}$ siècle, le plafond pourrait bien receler quelques allusions à cette île des Antilles, place forte stratégique et commerciale pour la France ${ }^{8}$.

6 L'achat de la maison par Le Gendre d'Armény face aux jardins de l'hôtel parisien des princes de Condé n'est certainement pas le fruit du hasard. Le rattachement à la maison Crozat s'affiche ostensiblement sur les garde-corps avec monogrammes (L pour le nom de 
Legendre, A pour Armény, et $\mathrm{C}$ pour Crozat) au vu et au su des puissants du royaume résidant dans le faubourg Saint-Germain.

7 La présence en ces murs de Marie Angélique Maxime de la Motte d'Aulnay, protégée de Le Gendre d'Armény occupante de la maison «pour sa vie durant de l'usufruit et de la jouissance $"{ }^{9}$, est également riche d'informations ${ }^{10}$. Nous savons qu'un des cousins de sa mère, grand aumônier de la Dauphine, était l'abbé de la Luzerne (était-il apparenté à Catherine de la Luzerne, épouse d'Adrien du Bosc, propriétaire de la maison entre 1703-1710 ?). Quant au père de Marie Angélique, il fut à la fin de sa vie pourvoyeur et contrôleur du prince de Condé et décéda le 21 août 1700 en sa maison parisienne de la rue Neuve Saint-Lambert (ancien nom de la rue de Condé). Mademoiselle de la Motte d'Aulnay, qui n'a guère pu échapper à la vie tumultueuse de sa mère - puisqu'elle vécut avec elle à la cour d'Espagne -, fut certainement durablement affectée par des épisodes familiaux douloureux ${ }^{11}$. Cela pourrait peut-être expliquer certaines métaphores animalières présentes sur le plafond et qui semblent empruntées à plusieurs ouvrages d'Ovide.

\section{Iconographie générale et présentation physique du plafond}

$8 \quad\left(\right.$ fig. $\left.\mathbf{n}^{\circ} \mathbf{4}\right)$

Figure 4

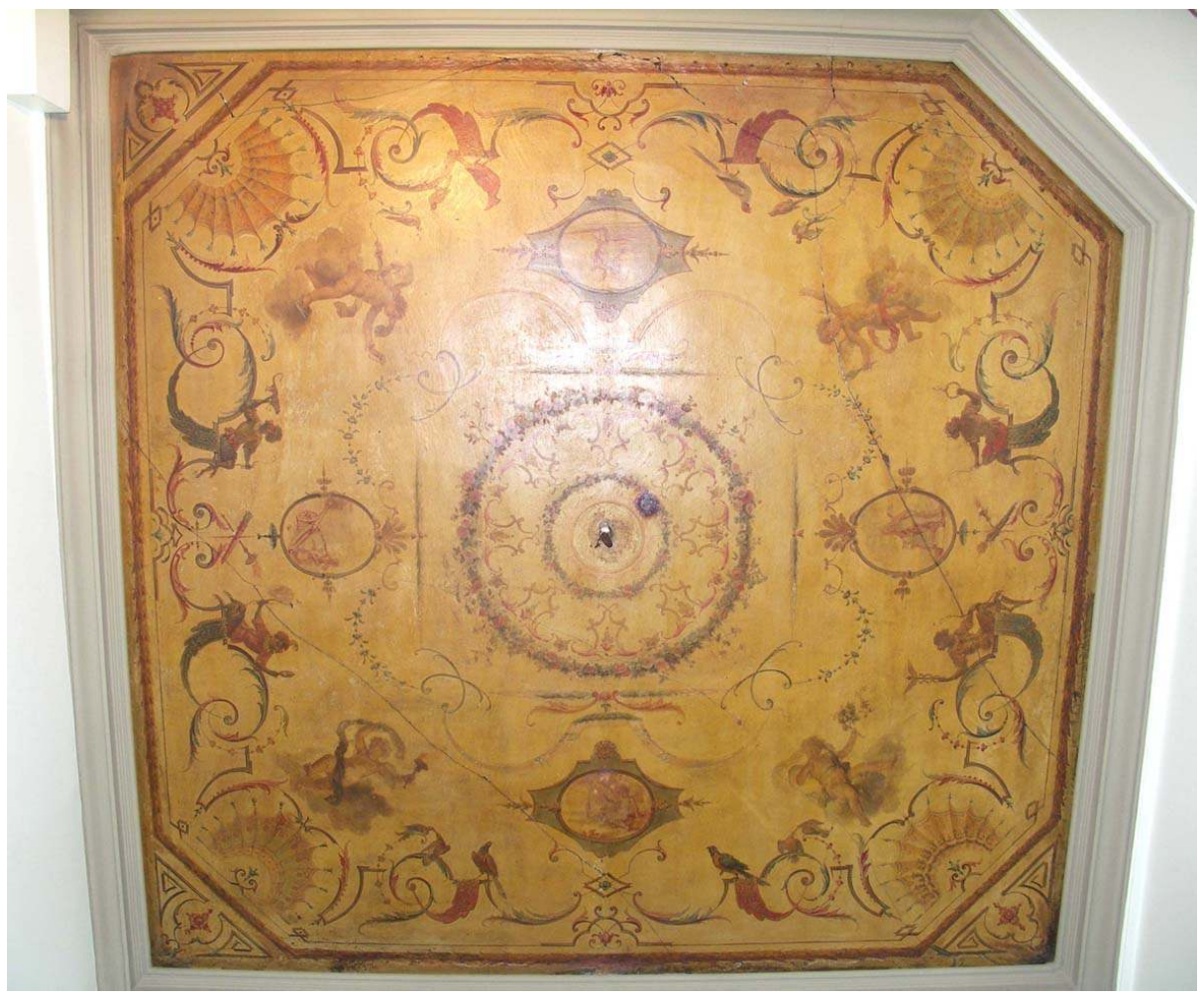

Plafond aux singes du 26 rue de Condé. Phot. Christelle Inizan.

(c) CRMH île-de-France, 2010 

octogonale est parfaite, permettant une répartition équilibrée des figures fonctionnant par paire, distribuées autour d'un axe central (une grande couronne de fleurs champêtres tressées et une plus petite à l'intérieur) et qui se répondent sur chaque face opposée.

Les quatre coins accueillent des éventails déployés (l'un des angles est tronqué pour accueillir le conduit de cheminée). Une tresse de blé encadre l'ensemble de la composition, excluant les angles décorés. Surmontant les éventails, quatre amours ailés émergent de nuages (leurs sexes sont plus ou moins dissimulés par des rubans).

11 Deux binômes de singes se font face de chaque côté de la pièce. Ils sont surmontés de deux médaillons ornés chacun de palmettes (des guirlandes florales donnent l'impression de servir d'accroche à ces médaillons). Au-dessous, des trophées sont composés de torches enflammées et de carquois croisés. Les deux autres faces du plafond accueillent des volatiles que surplombent deux cartouches, eux-mêmes surmontés de dais au léger voilage.

\section{Les singes et leurs attributs}

Figure 5

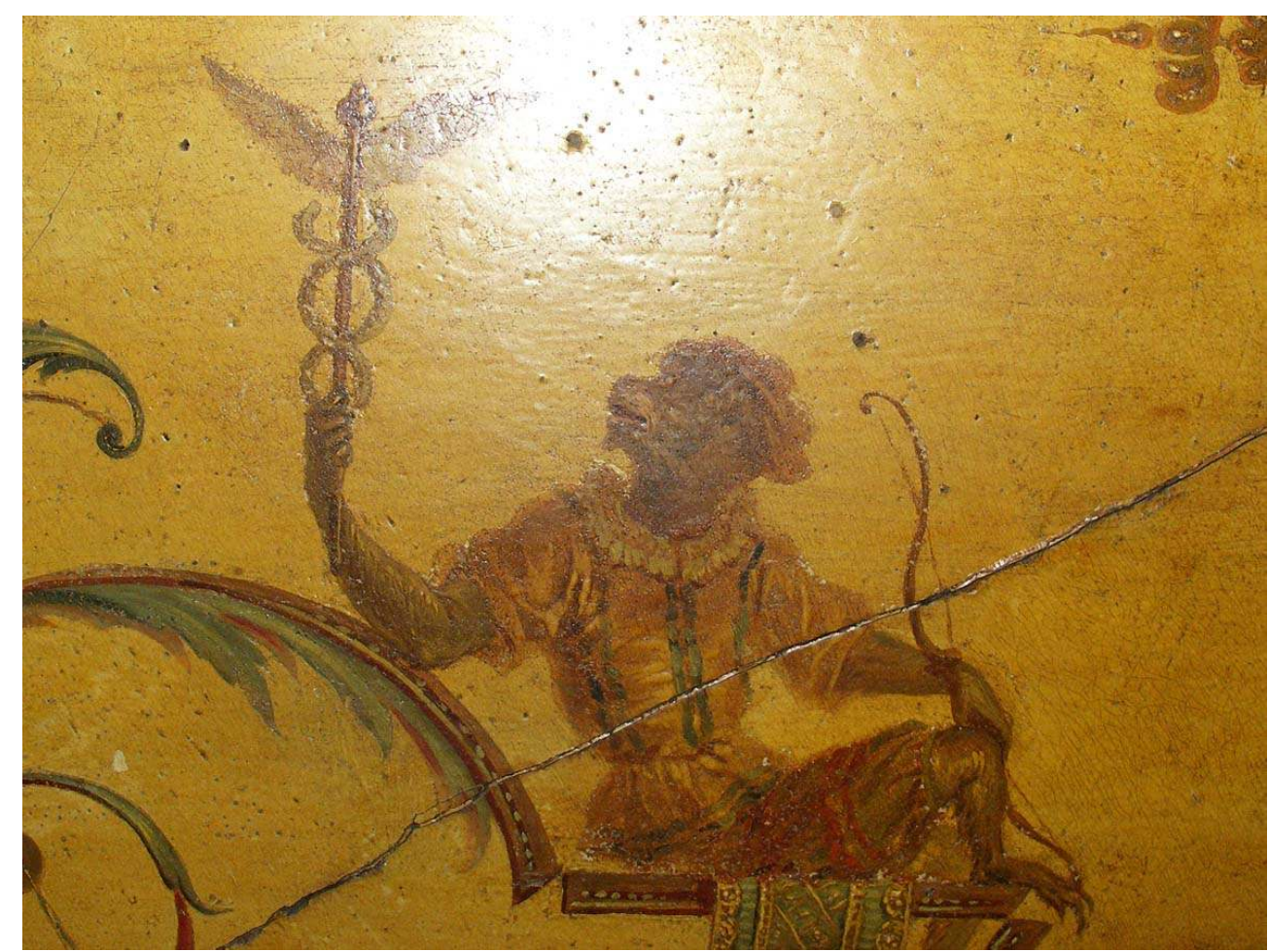

Singe au caducée. Phot. Christelle Inizan.

(c) CRMH île-de-France, 2010. imiter ici les actions humaines et non pas parodier les vices des hommes, comme c'est souvent le cas. Outre des arcs, ils tiennent chacun un attribut :

Le caducée (fig. $\mathbf{n}^{\circ}$ ) : Jean de La Fontaine dans sa fable «L'Éléphant et le singe de Jupiter » ${ }^{12}$ évoque un personnage de singe, nommé Gille, envoyé par Mercure qui lui a confié son 
caducée (emblème de paix). L'allusion est burlesque et les paroles distillées par l'animal ironiques. Quand il s'agit des affaires des hommes, c'est Mercure qui est député par Jupiter pour l'aider dans ses conquêtes amoureuses ${ }^{13}$, quand il s'agit des animaux, c'est le singe, messager divin qui porte alors un caducée et parfois des ailes aux talons, puisqu'il paraît dans l'air. Mercure, c'est enfin une petite planète, la plus proche du soleil (du roi ?).

Figure 6

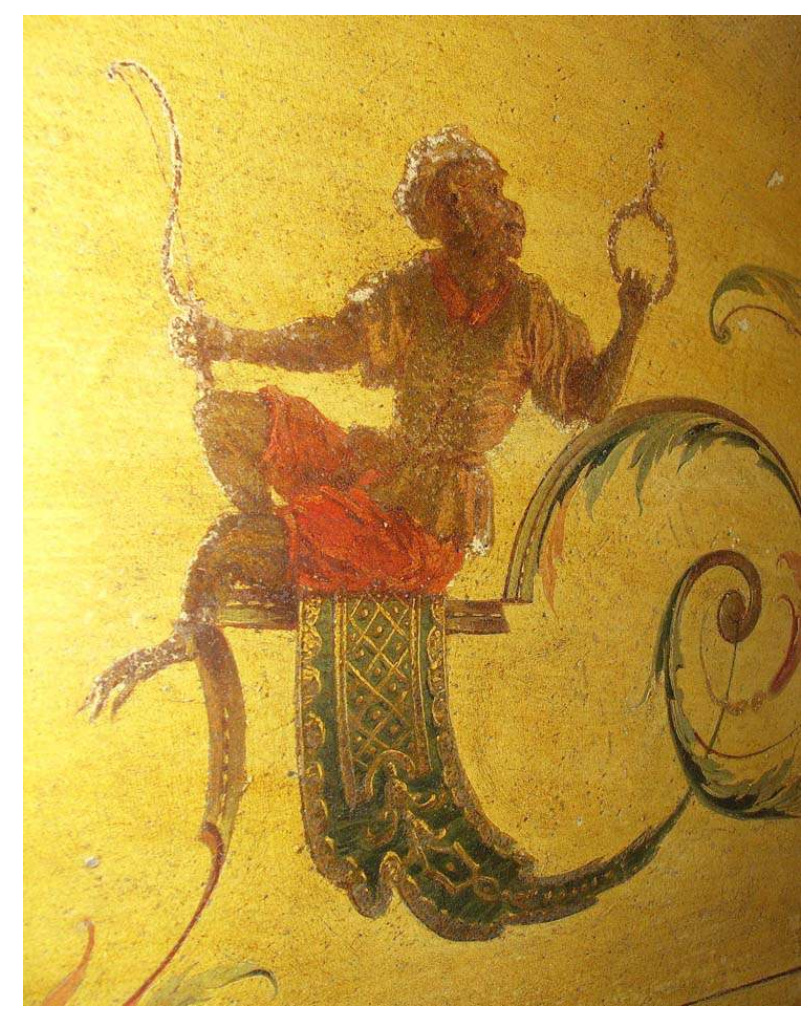

Singe au collier. Phot. Christelle Inizan.

(c) CRMH Île-de-France, 2010.

Le collier d'esclave (dont le bout enflammé se consume) (fig. $\left.\mathbf{n}^{\circ} \mathbf{6}\right)$ : ôté, c'est la fin de l'asservissement, la liberté! (Allusion au commerce triangulaire ou à l'esclavage amoureux qui nous consume et nous libère?). 


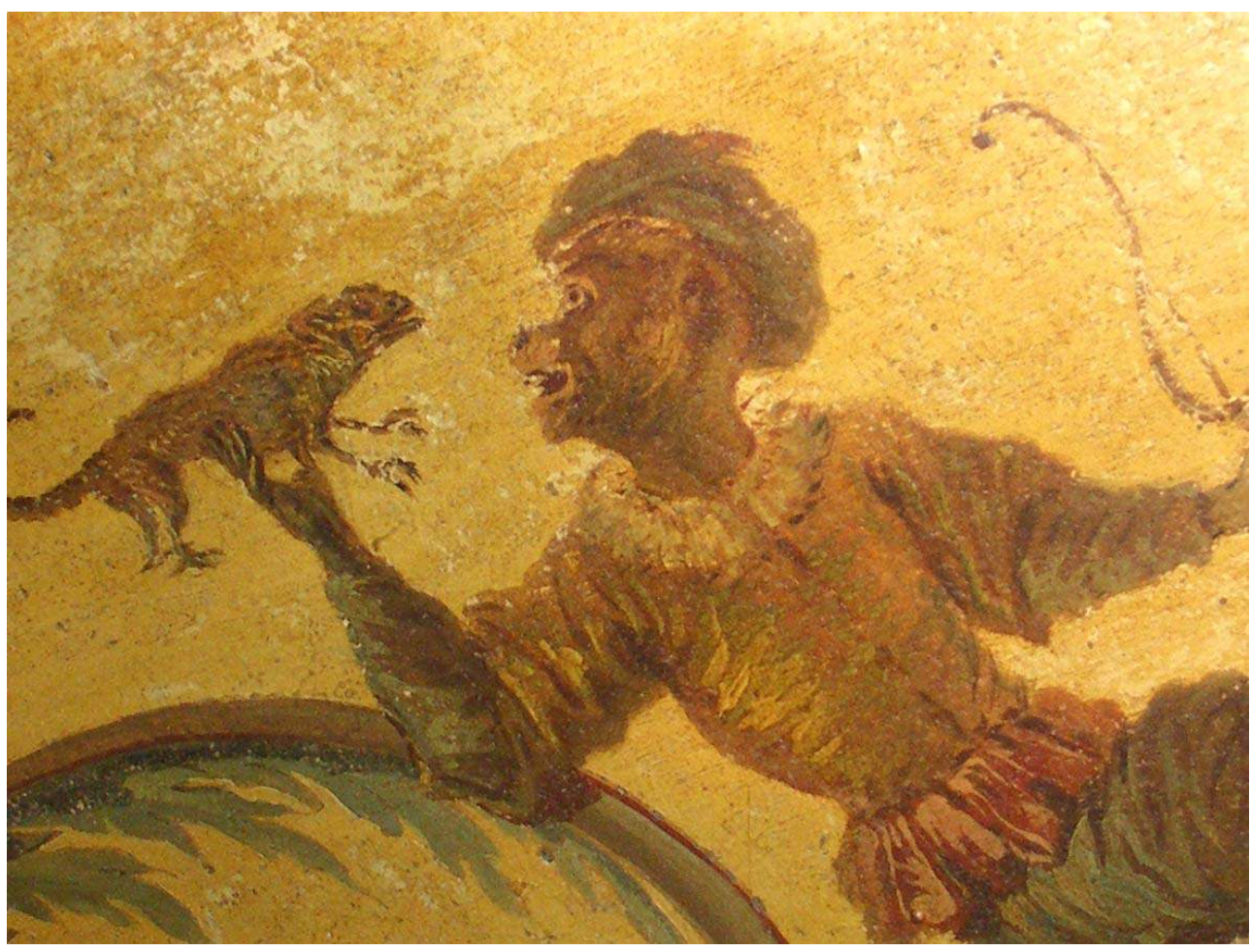

Singe à l'iguane. Phot. Christelle Inizan.

(c) CRMH Île-de-France, 2010.

15 L'iguane (fig. $\mathbf{n}^{\circ}$ ) : L'Ancien Testament fait rarement allusion au lézard sinon dans la phrase : « le lézard que l'on a capturé avec la main, mais qui hante les palais des rois » (Prov. 30, 28). L'interprétation en paraît hasardeuse, mais du moins y voit-on attestée sa familiarité avec l'homme et son indifférence aux hiérarchies terrestres, dont on pourrait induire que ses longues heures d'immobilité au soleil sont le symbole d'une extase contemplative. Il est d'ailleurs cité dans la Bible comme l'un de ces êtres minuscules sur la terre, mais « sage entre les sages » (Prov. 30, 24) ${ }^{1415}$.

Le miroir (fig. $\mathbf{n}^{\circ} \mathbf{8}$ ) (qui donne de la réalité une image inversée) : mais que reflète-t-il dans le contexte de ce plafond : la vérité, la sincérité, le contenu du cœur et de la conscience? En vérité, apparaît nettement dans les reflets du miroir un portrait en buste d'une femme, décolleté à la grecque et cape rouge (qui évoque les portraits aristocratiques des XVII et XVIII $^{\mathrm{e}}$ siècles où les femmes aimaient paraître en Diane chasseresse). La femme porte partiellement un masque et une coiffure à la fontange (clin d'œil au tableau de claude Gillot «Les Deux carrosses" où Arlequin travesti en femme porte les mêmes accoutrements). 
Figure 8

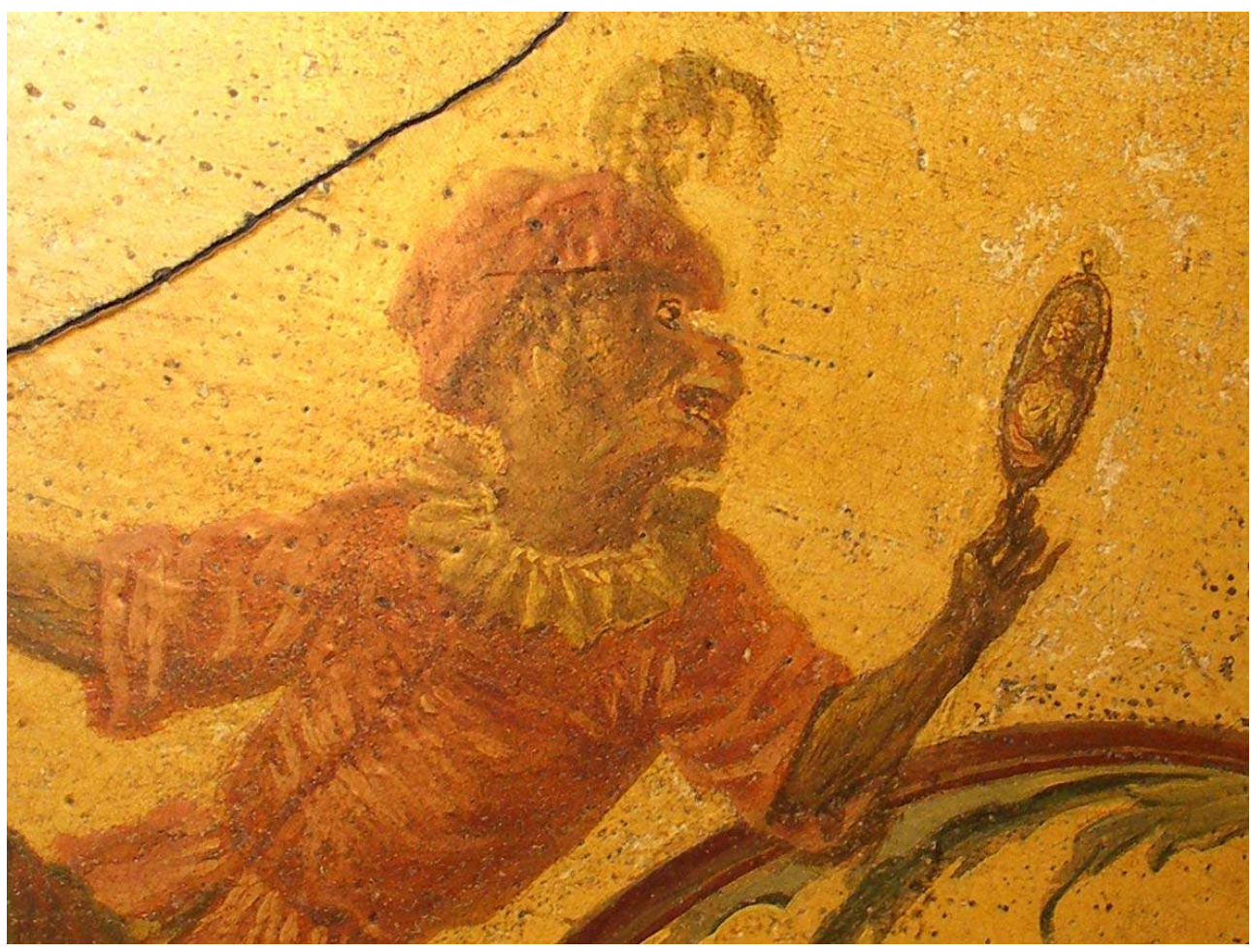

Singe au miroir. Phot. Christelle Inizan.

(c) CRMH Île-de-France, 2010.

\section{Les oiseaux}


Figure 9

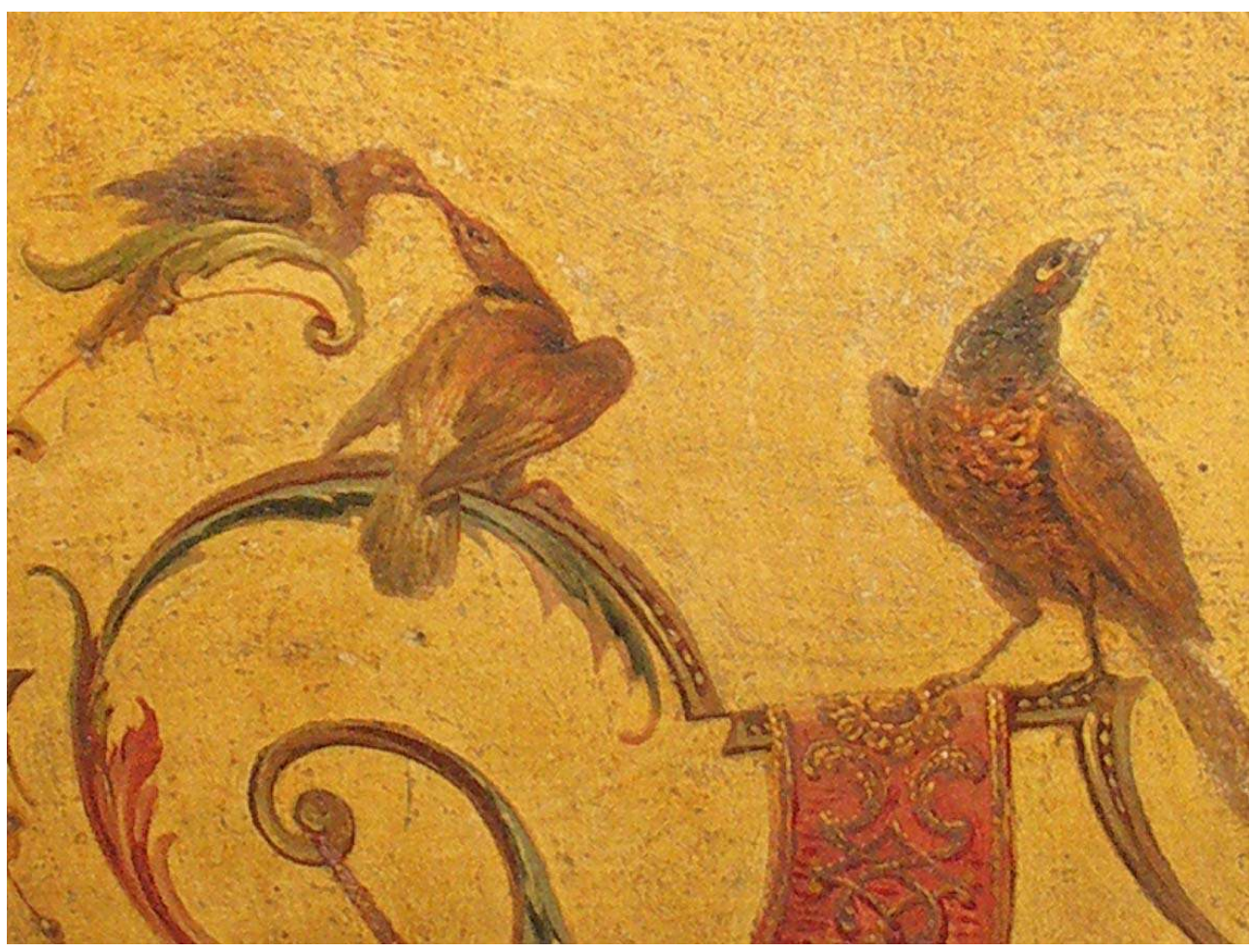

Oiseaux du plafond. Phot. Christelle Inizan.

(c) CRMH Île-de-France, 2010. 
Figure 10

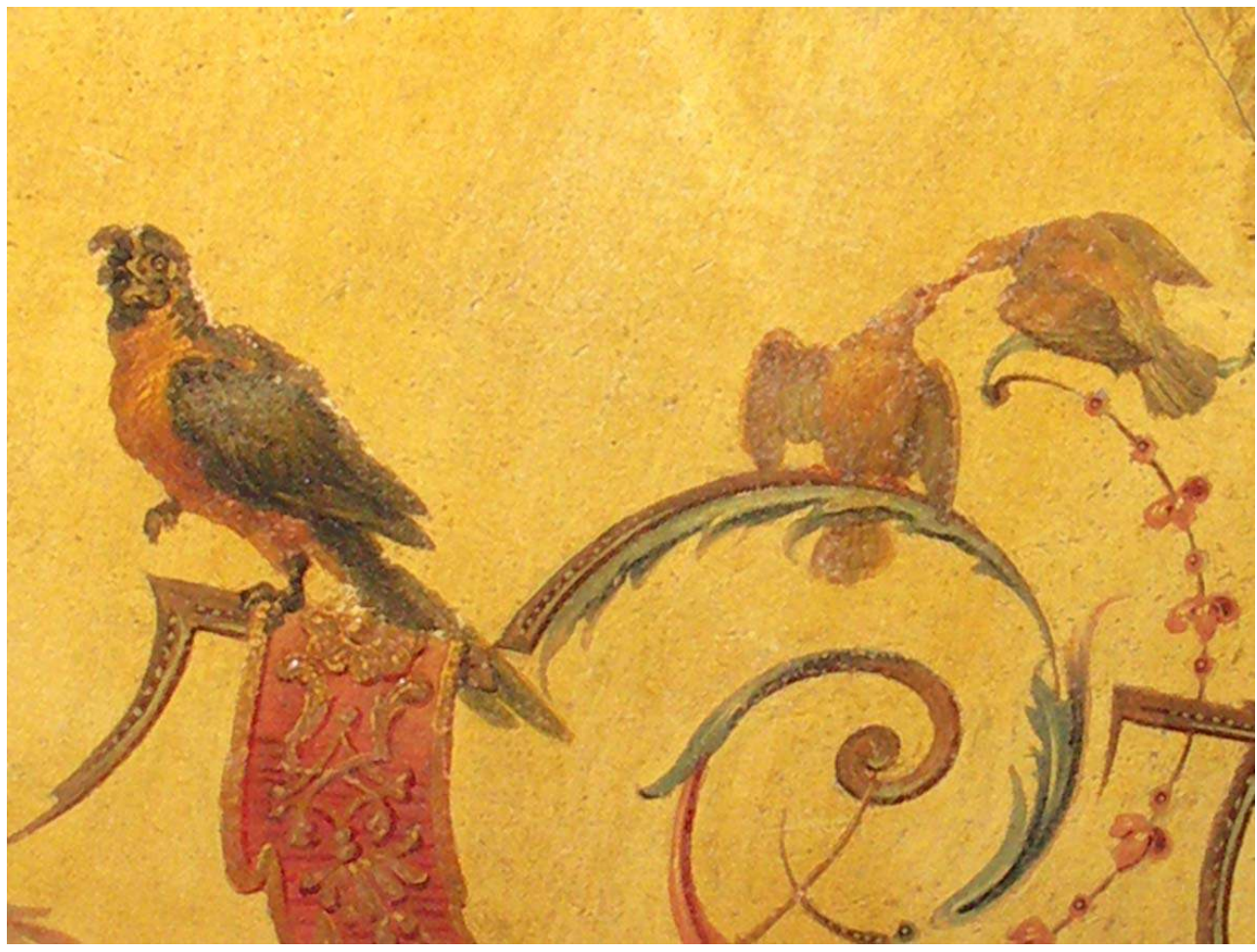

Oiseaux du plafond. Phot. Christelle Inizan.

(c) CRMH Île-de-France, 2010

17 Sur les deux faces opposées aux singes paradent des oiseaux : un faisan (fig. $\left.\mathbf{n}^{\circ} \mathbf{9}\right)$; un ara bleu (fig. $\left.\mathbf{n}^{\circ} 10\right)$; une espèce de perruche à tête rose (trois oiseaux figurant souvent dans les tableaux du peintre animalier Alexandre-François Desportes); un cardinal rouge ${ }^{16}$; deux couples de tourterelles turques ou de ramiers s'effleurant du bec (l'amour ! $\left.{ }^{17}\right)$; deux chardonnerets $^{18}$; deux serins ${ }^{19}$ (fig.n $\left.{ }^{\circ} 11\right)$ (fig. $\left.{ }^{\circ}{ }^{12}\right)$ (fig. $n^{\circ}{ }^{13}$ ). 
Figure 11

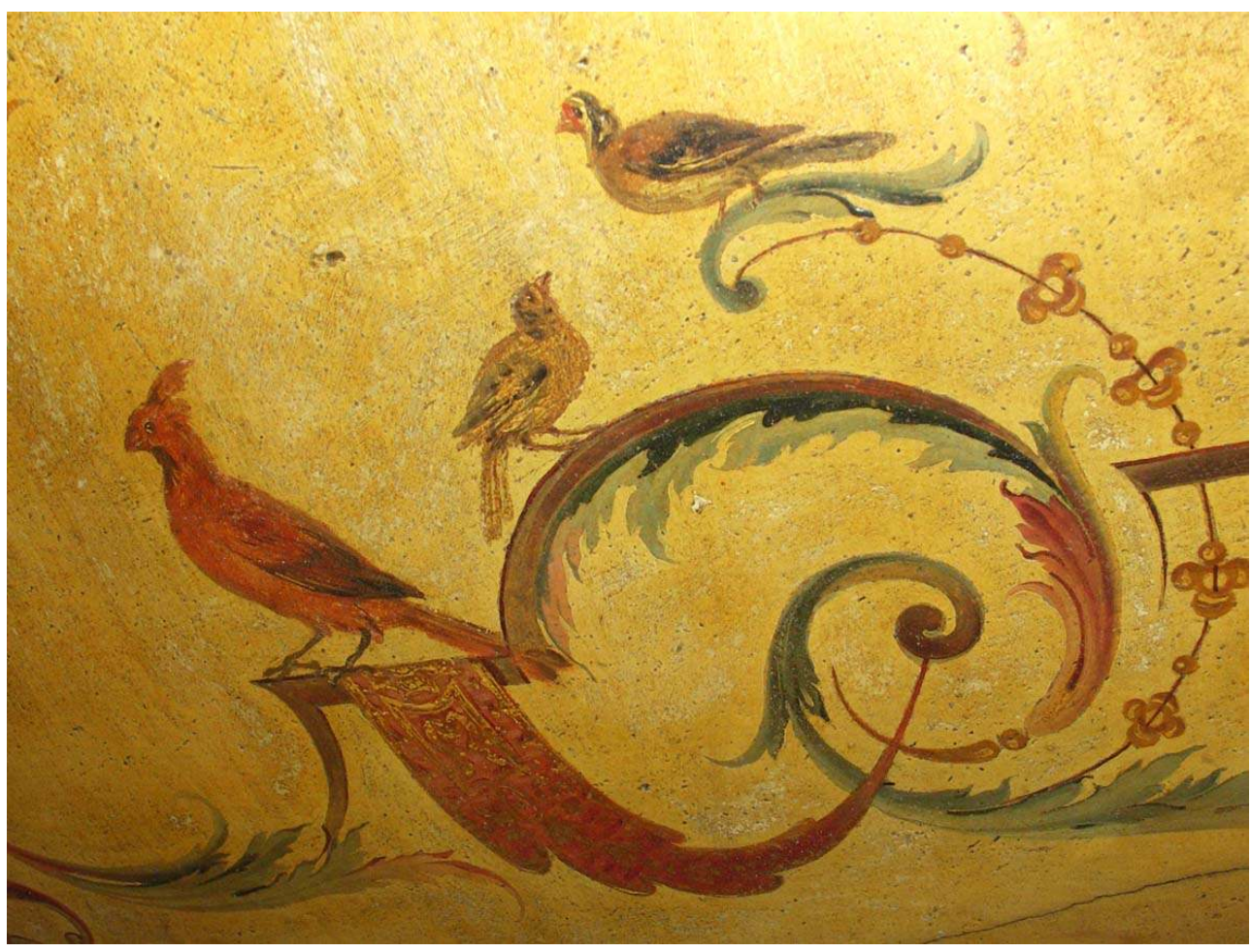

Oiseaux du plafond. Phot. Christelle Inizan.

(c) CRMH Île-de-France, 2010. 
Figure 12

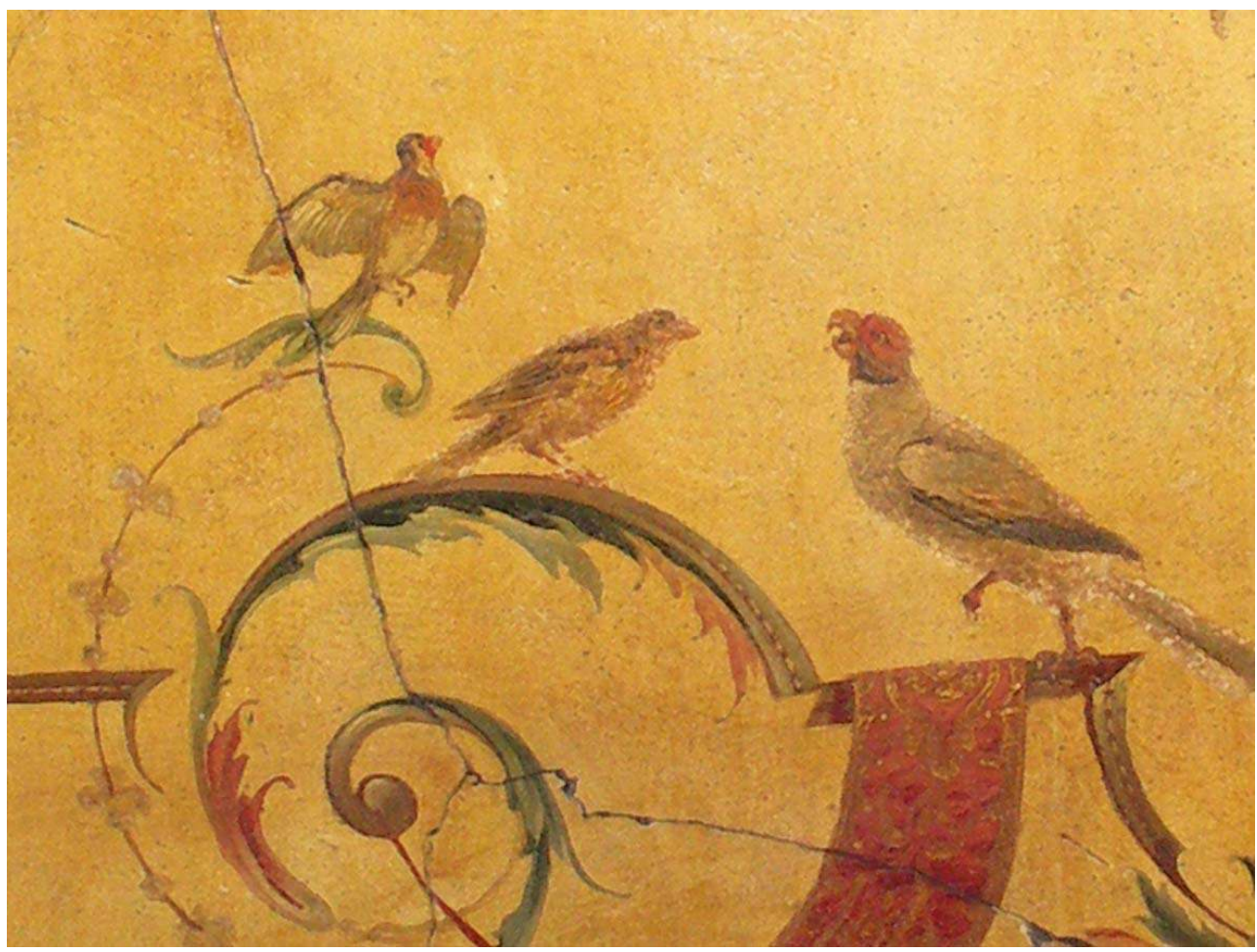

Oiseaux du plafond. Phot. Christelle Inizan.

(c) CRMH île-de-France, 2010.

\section{FIgURE 13}

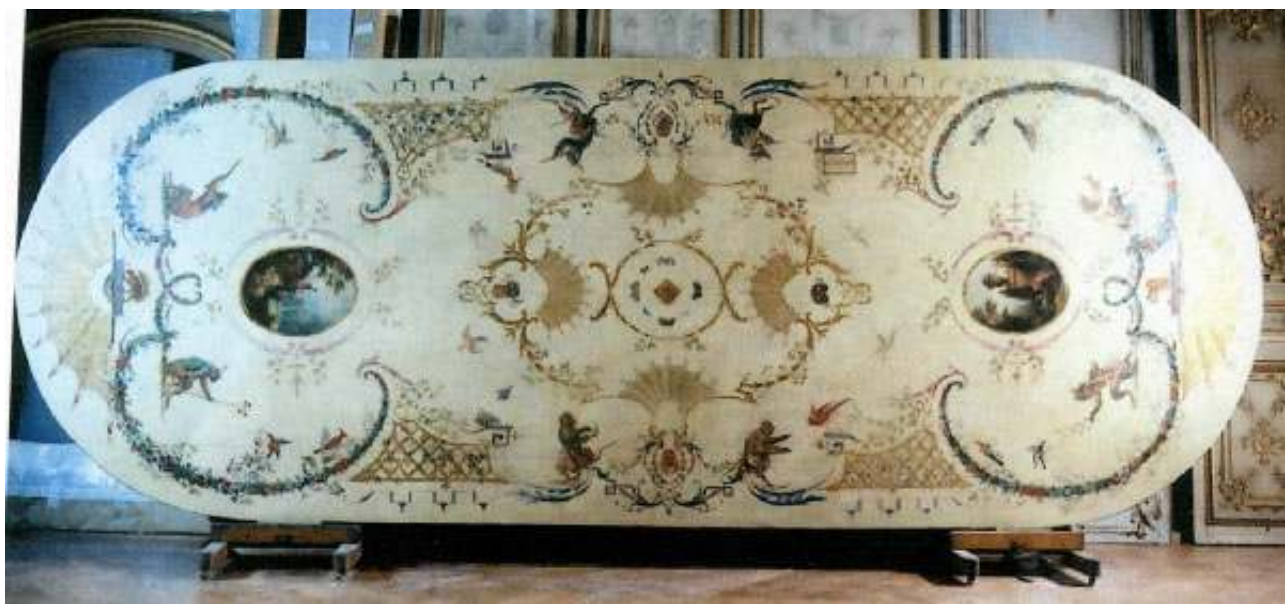

Cardinal rouge présent sur le plafond de l'Hôtel de Verrüe, remonté au musée des Arts Décoratifs, Paris.

(C) Les Arts Décoratifs, Paris/Jean Tholance (Tous droits réservés).

La présence de ces oiseaux n'est en rien fortuite. Ces sujets d'apparence purement ornementale appartiennent en vérité à une iconographie symbolique faisant référence à des textes familiers aux lettrés de l'âge classique ${ }^{20}$. 


\section{Cartouches et médaillons}

Figure 14

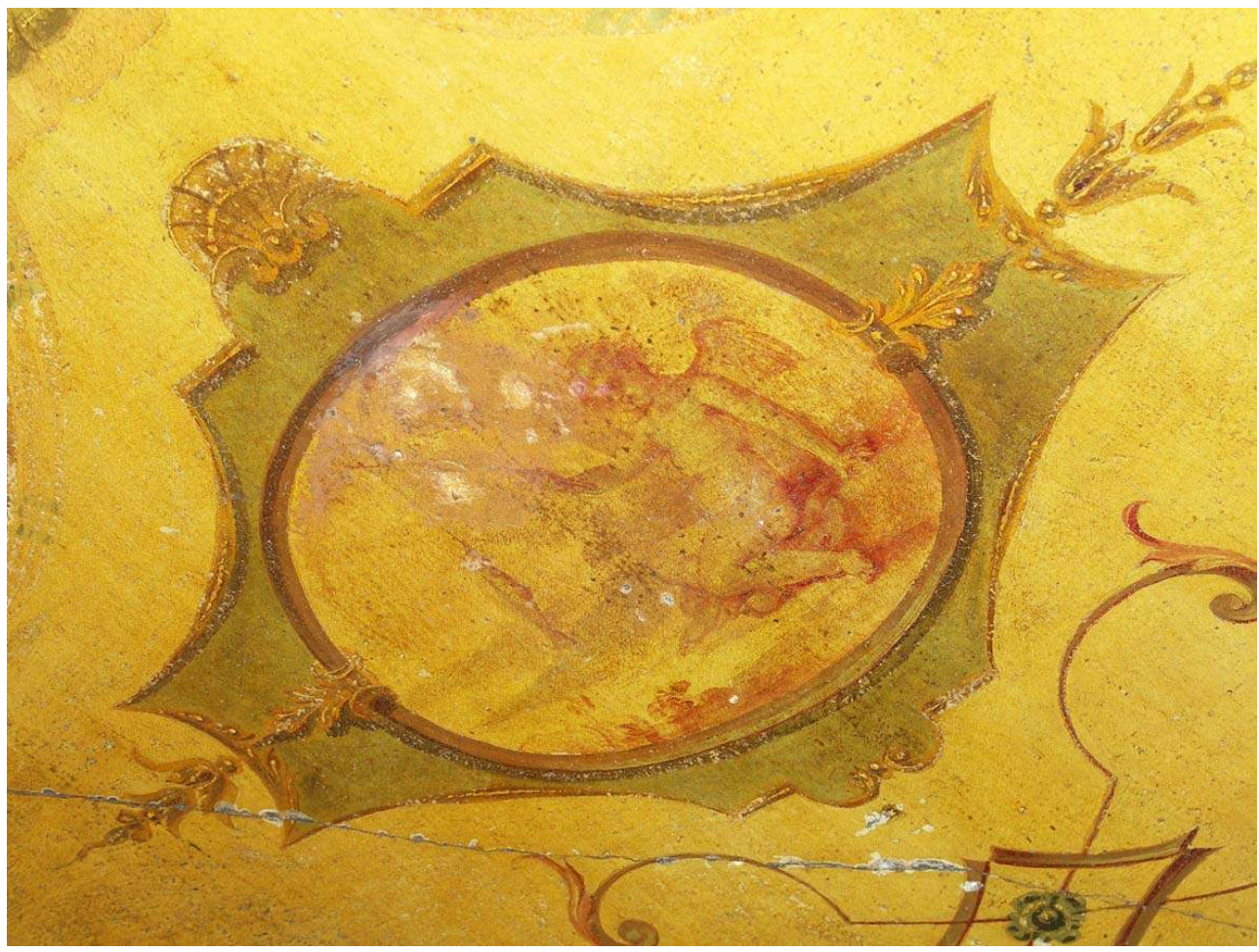

Cartouche aux amours à la canne à pêche. Phot. Christelle Inizan.

(c) CRMH Île-de-France, 2010 


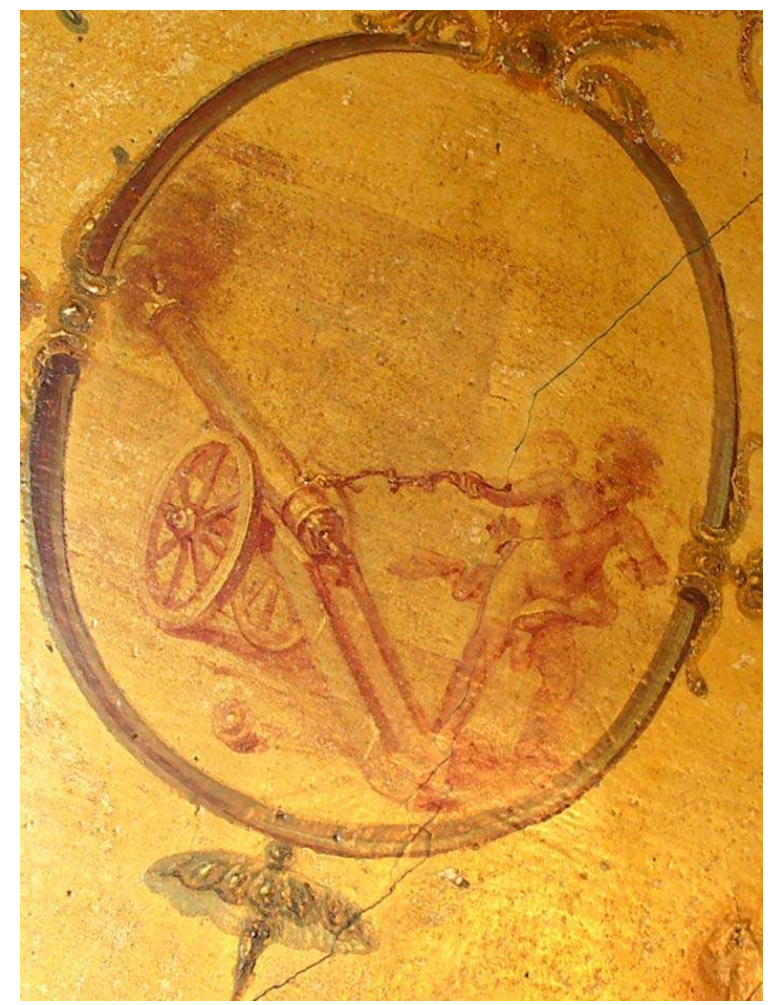

Cartouche aux amours au canon. Phot. Christelle Inizan.

(c) CRMH Île-de-France, 2010.

Les personnages représentés dans les deux médaillons et les deux cartouches sont traités en monochromie de bistre, en camaïeu. Illustrent-ils les devoirs humains?

Dans le premier, un amour ailé pêche et tient un poisson au bout de sa ligne (fig. $\left.\mathbf{n}^{\circ} \mathbf{1 4}\right)$. La pêche serait ici le symbole de la prédication et de l'apostolat (le poisson pris, c'est l'homme converti, ou encore le salut, la pêche miraculeuse...). Dans le second, un autre amour ailé tire au canon (en référence à l'art de la guerre) (fig. $\mathbf{n}^{\circ} \mathbf{1 5}$ ). Dans le troisième, un putto oriente l'aiguille d'une boussole (allusion à la nécessité de garder le cap ?) (fig. $\mathbf{n}$ •16). Dans le quatrième, une vestale ailée garde le feu sur un autel (évocation d'Hestia, personnification romaine du feu sacré, du foyer domestique, de la cité ou même de l'empire. Tout accomplissement, toute prospérité, toute victoire sont placés sous le signe de cette absolue pureté) (fig. $\left.\mathbf{n}^{\circ} \mathbf{1 7}\right)$. 


\section{Figure 16}

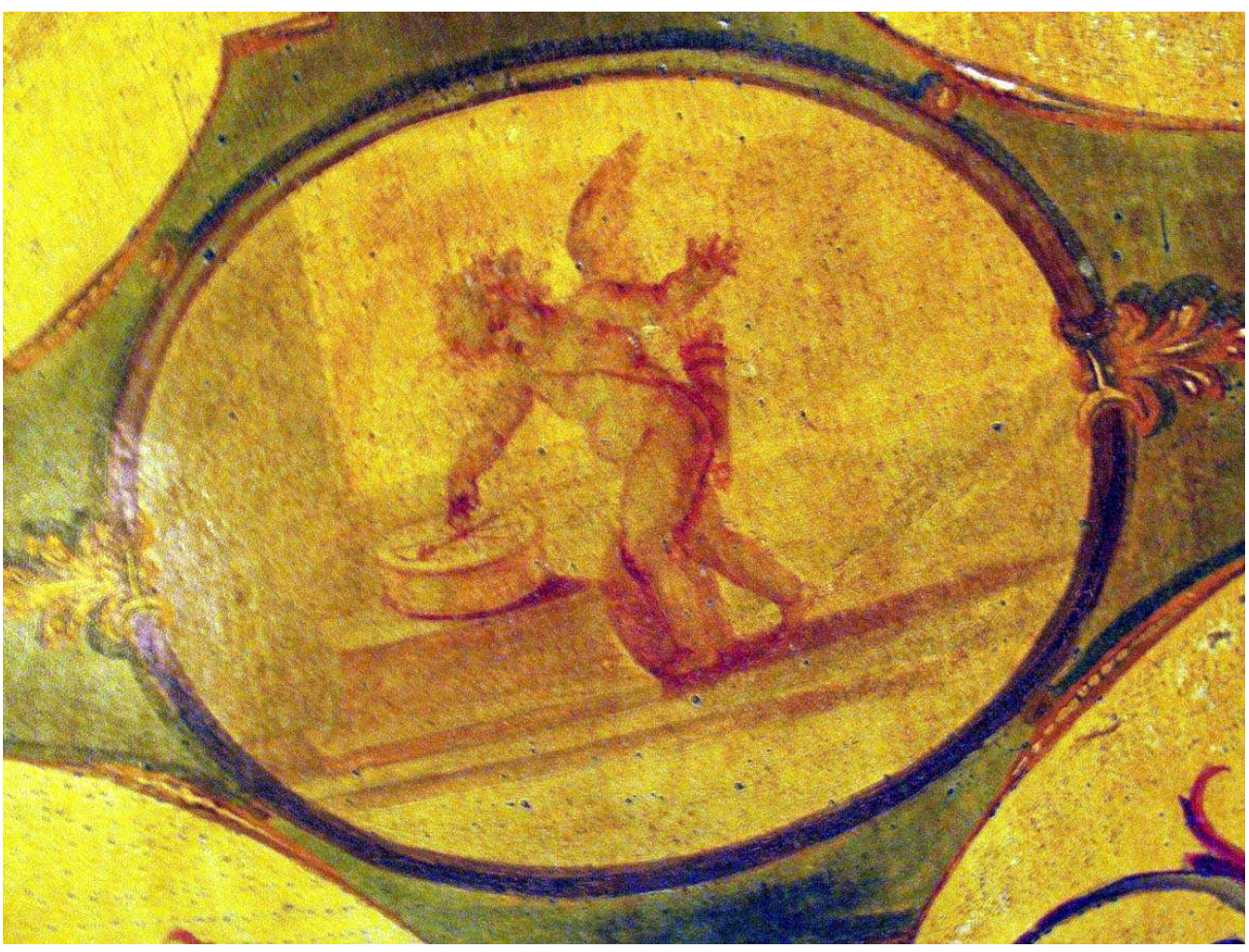

Cartouche aux amours à la boussole. Phot. Christelle Inizan.

(c) CRMH Île-de-France, 2010 
Figure 17

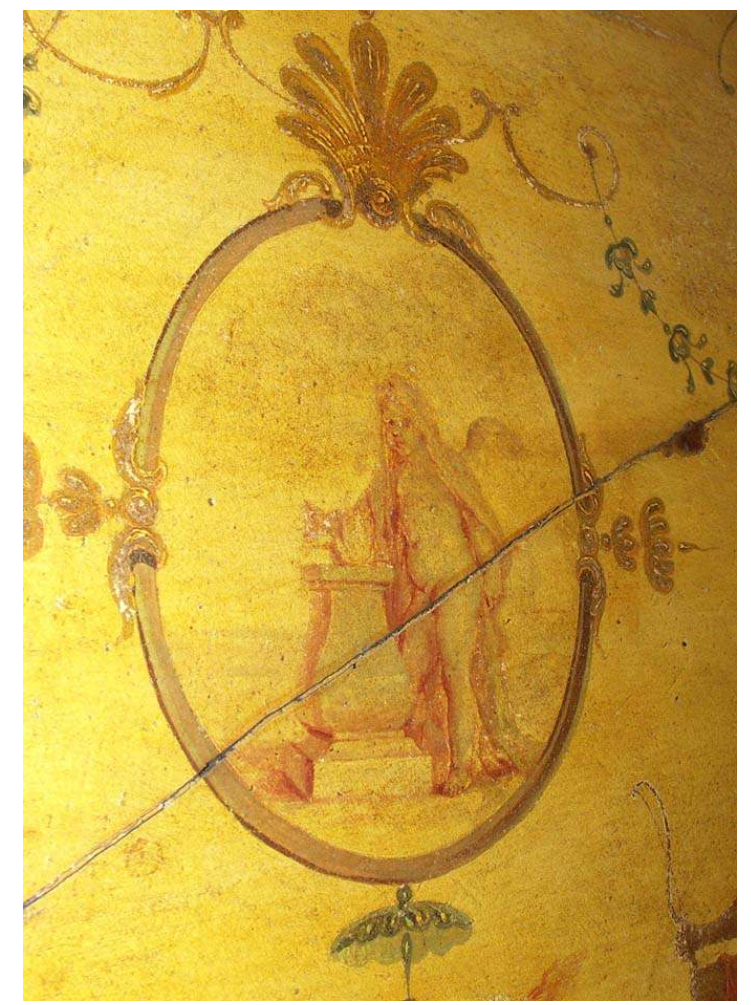

Cartouche aux amours et vestale entretenant le feu sacré. Phot. Christelle Inizan. (c) CRMH Île-de-France, 2010.

21 Les quatre grands amours sont, quant à eux, issus de scènes mythologiques illustrant l'amour et pourraient évoquer les quatre saisons :

22 L'éphéméride (fig. $\mathbf{n}^{\circ}{ }^{18}$ ) évoque le temps qui passe « Dum loquimur, fugerit inuida aetas: carpe diem, quam minimum credula postero ${ }^{21}$ _ l'hiver (feuillet indiquant le premier jour de l'année). 
Figure 18

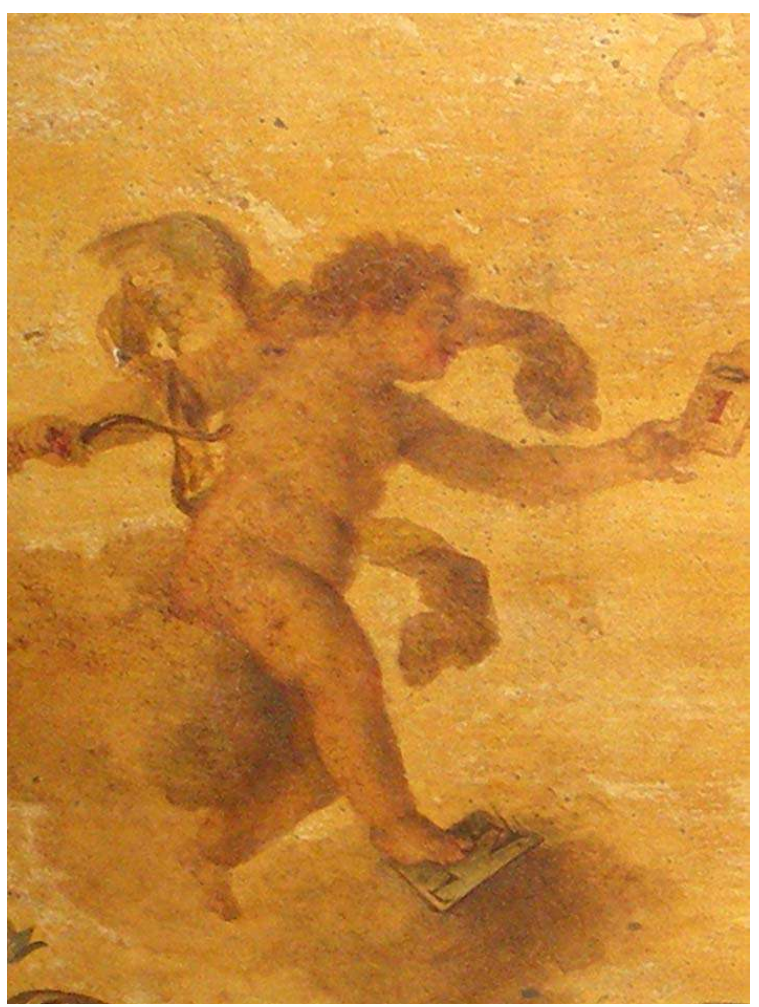

Amour à l'éphéméride. Phot. Christelle Inizan.

(c) CRMH île-de-France, 2010. 
Figure 19

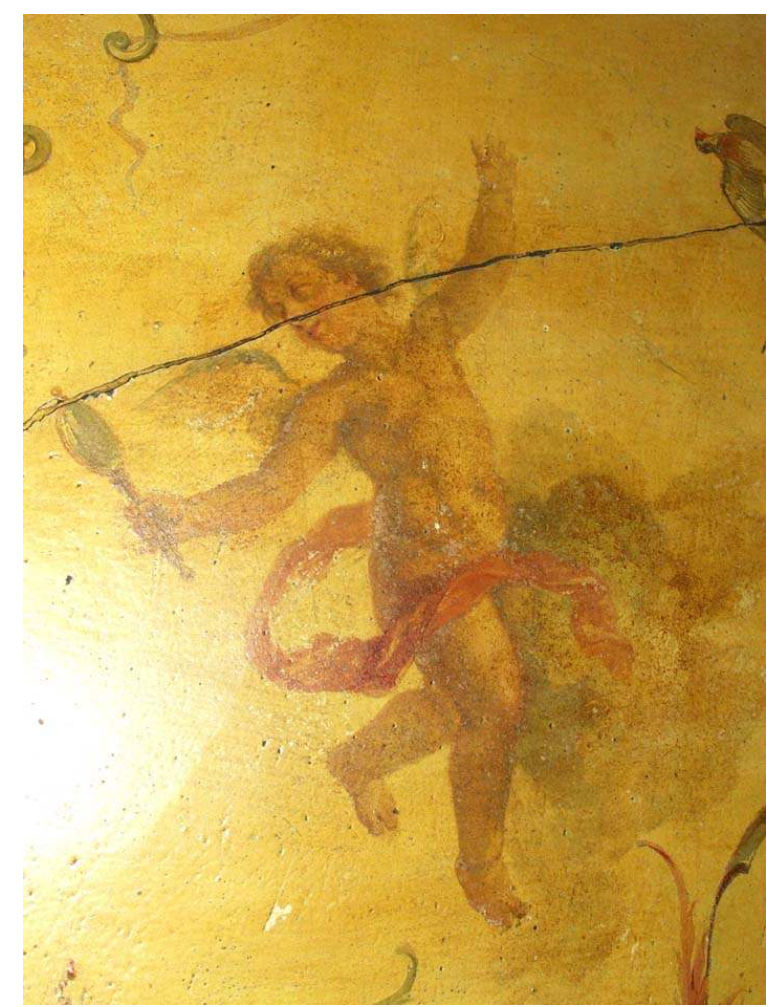

Amour au miroir. Phot. Christelle Inizan.

(c) CRMH Île-de-France, 2010.

Le miroir d'Aphrodite est brandi par Éros (fig. $\mathbf{n}^{\circ} \mathbf{1 9}$ ) - le printemps (qui était assimilé au XVIII ${ }^{\mathrm{e}}$ siècle au matin donc à la toilette et à son principal accessoire de beauté).

La branche d'oranger fait certainement référence au don de trois pommes d'or par Vénus à Hippomène $^{22}$ (fig. $\mathbf{n}^{\circ} \mathbf{2 0}$ ) (cette branche fait-elle encore référence au conte de Mme d'Aulnay «L'oranger et l'abeille » où un prince amoureux est métamorphosé en oranger ? ) - l'automne.

La torche (fig. $\mathbf{n}^{\circ} \mathbf{2 1}$ ) est l'attribut de Cupidon ${ }^{23}$ - des feux de l'amour à la chaleur de l'été... 
Figure 20

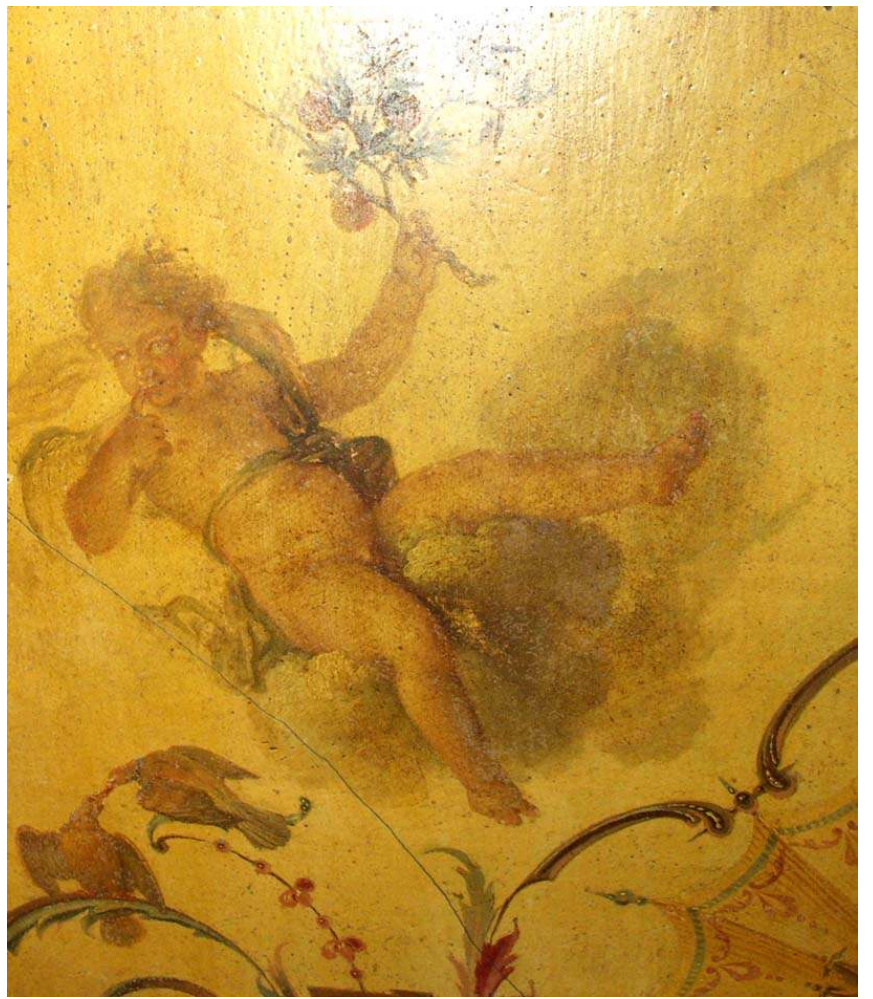

Amour à la branche d'oranger. Phot. Christelle Inizan.

(c) CRMH île-de-France, 2010. 


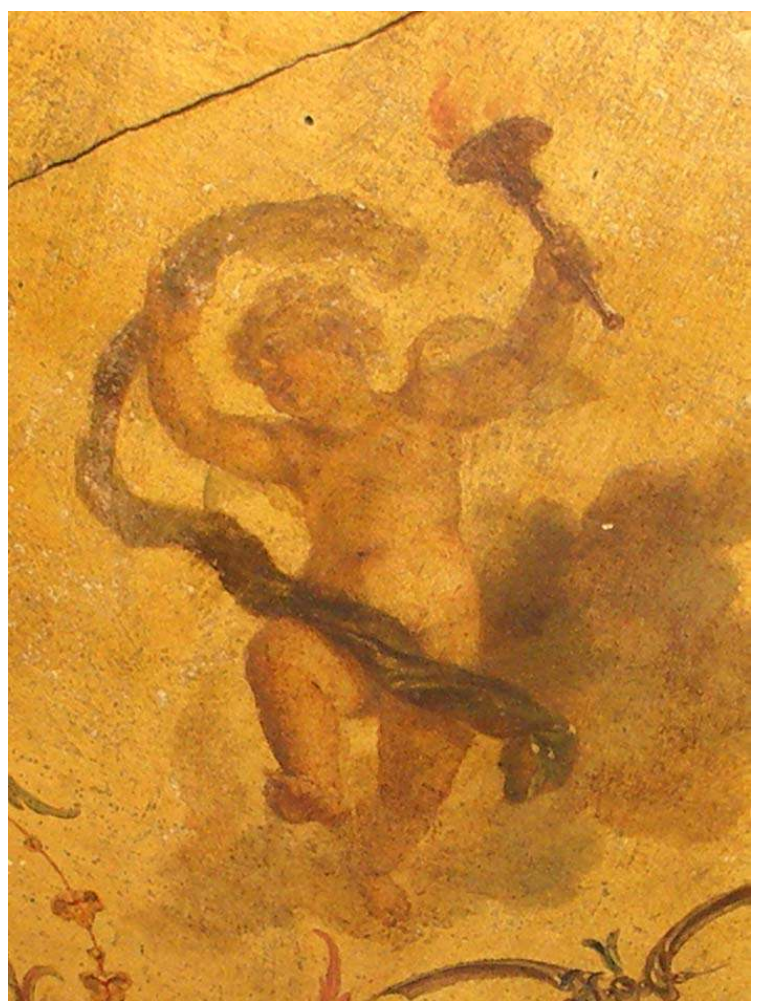

Amour à la torche. Phot. Christelle Inizan.

(c) CRMH Île-de-France, 2010.

La peinture du plafond est réalisée à l'huile, directement appliquée sur l'enduit. Le fond de la composition est couleur or. Le plafond très encrassé présente quelques fissures, quelques trous et manques. La trace de brûlure au niveau de l'éclairage central est récente. Les pertes de matières picturales sont assez réduites, souvent concentrées sur les motifs dorés. Les parties latérales ont été enduites sur au moins deux centimètres afin de se raccorder à la corniche actuelle.

Le pan coupé dissimulant le conduit de la cheminée d'angle du cabinet, légèrement asymétrique par rapport au décor, prouve qu'on a adapté ce plafond à une pièce préexistante. Un interstice conséquent existe entre la corniche actuelle et le plafond proprement dit.

\section{Une réalisation décorative de Claude III Audran (1658-1734)}

L'attribution du plafond de la rue de Condé à l'ornemaniste Claude III Audran s'est révélée relativement aisée, tant ses réalisations sont reconnaissables et grande la réputation de son atelier en ce début du XVIIIe siècle. Cette position de quasi-monopole sur le décor parisien s'explique par le nombre important de collaborateurs qu'Audran fit travailler, offrant ainsi à une clientèle prestigieuse une grande variété d'exécution tout en garantissant par sa seule signature la qualité artistique et le bon suivi. 

qui s'observe dans le pourtour du plafond : ruban de gerbe de blé formant frise continue, cartouches, entrelacs et volutes végétales, trophées, cuirs estampés (lambrequins) servant de supports aux figures. Le trait est affirmé. Dans les cartouches se trouvent évoquées les actions vertueuses par des représentations d'usage. Tous ces éléments rattachent stylistiquement ce décor à la fin du XVII ${ }^{e}$ siècle $^{24}$. Pourtant, le dais à peine esquissé, la couronne de fleurs centrale, les éventails, les amours sont traités de manière plus souple, presque vaporeuse. À l'inverse, le traitement très naturaliste des oiseaux évoque la rigueur et la sensibilité d'exécution d'un peintre comme Desportes. Ces motifs appartiennent déjà à un nouveau style émergent, qui s'épanouira sous la Régence avant de devenir le style Louis XV proprement dit, où pointent la jeunesse et la fraîcheur si ardemment appelées de ses vœux par Louis XIV vieillissant ${ }^{25} 26$. (ancien numéro 17 de la rue Neuve Saint-Lambert) est un indice significatif de l'implication de Claude III Audran dans cette commande (fig.n²2). Du 5 juillet 1704 à 1720 , Audran reçut en effet la charge de concierge (c'est-à-dire de conservateur) du Palais $\mathrm{du}$ Luxembourg. Il y résidait et n'avait par conséquent que quelques pas à faire pour superviser le chantier du plafond ou y intervenir personnellement.

Figure 22

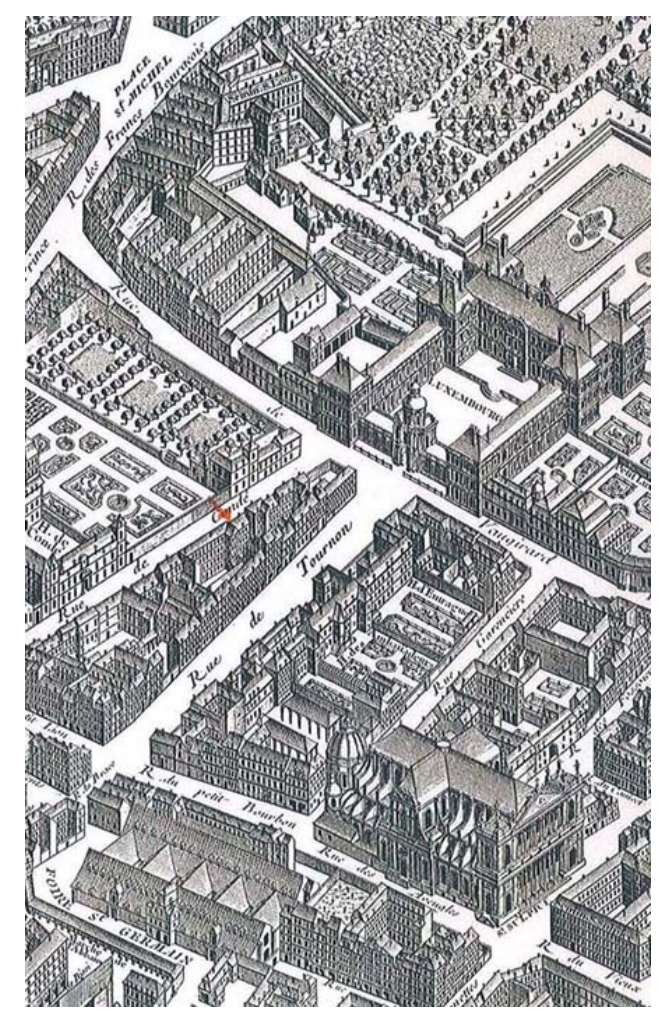

Plan de Turgot (1734-1739). Repro. Christelle Inizan. (c) CRMH île-de-France, 2010.

La période durant laquelle Audran exerça dans la résidence royale du Luxembourg correspond à deux dates de mutation de propriétés de la maison: celle du conseiller Antoine Auger (propriétaire de 1710 à 1713) et celle de Joseph Le Gendre d'Armény (propriétaire de 1713 à 1740) qui l'avait acquise pour y loger Mademoiselle de la Motte 
d'Aulnay alors âgée de trente-six ans (le portrait féminin masqué, en buste, pourrait-il être le sien?).

Ces dates permettent de proposer une fourchette plausible de datation du plafond, entre 1713 et 1720, tranche chronologique parfaitement compatible avec le style et les réalisations de l'ornemaniste à cette période ${ }^{27}$. D'autres éléments nous permettront plus avant de resserrer cette datation grâce à l'analyse croisée d'autres indices biographiques.

\section{Audran, peintre de grotesques et d'ornements}

Né à Lyon le 25 août 1658 et décédé le 27 ou le 28 mai 1734 à Paris ${ }^{28}$, Claude III Audran est le fils aîné de Germain Audran, graveur de son état (lui-même fils du graveur Claude I Audran). Il fut l'élève de son père et de son oncle Claude II.

"Il se présente devant ses contemporains comme entrepreneur de "grosse peinture " en huile et en détrempe, travaillant indifféremment les fonds clairs ou dorés. Membre de l'Académie Royale de peinture et de sculpture en 1675, il connut le succès dès l'âge de 35 ans. En 1692, lors de sa réception de maître pour chef d'œuvre, il est désigné comme " peintre, sculpteur, graveur, enjoliveur ».

Rapidement, il est recruté pour les bâtiments royaux. En 1706, il travaille à Fontainebleau à la "réparation" des peintures de la galerie de Diane et aux appartements du Roi et du Grand Dauphin, conservant parallèlement des chantiers privés parisiens. En 1716, les comptes des bâtiments du roi le qualifient de "peintre et sculpteur». En attendant d'importants travaux à Versailles, à Marly, à Sceaux, il crée pour la duchesse du Maine de nouvelles peintures à Anet, vers 1690, et décorera, en 1699, la Ménagerie de Versailles (plafond du cabinet octogone) à l'intention de la duchesse de Bourgogne. À Meudon, pour le Grand Dauphin toujours, il réalise des plafonds, des lambris, des ornements tant admirés par ses contemporains qu'en 1717 l'électeur de Cologne lui commande des décors pour son petit palais de Buen Retiro à Bonn ${ }^{29}$.

Claude III Audran était un inventeur ingénieux et abondant doublé d'un praticien fort habile.

Germain Brice, dans sa " Description de Paris », édition de 1752, écrit que "Claude Audran, est regardé avec justice comme un des premiers dessinateurs qui aient jamais paru, pour les arabesques et pour les grotesques. Ce sont des compositions d'ornements légers et agréablement distribués, qui étaient en usage chez les anciens, et qui ont été renouvelés par le fameux Raphaël. Ils sont devenus fort en vogue; on en orne les lambris et les plafonds des plus petites pièces et ils produisent un effet charmant lorsqu'ils sont imaginés avec goût et qu'ils sont exécutés avec autant de soin que tout ce qui l'a été en ce genre par Claude Audran (...) On peut en juger par plusieurs de ses ouvrages qui sont répandus dans plusieurs endroits, particulièrement dans le Château de Meudon, dans celui d'Anet, dans la ménagerie de Versailles et dans le château de la Muette, où il a fait des choses dignes d'admiration, plus belles et plus ingénieuses, que tout ce qui s'était encore vu jusqu'ici en France en ce genre singulier. Il a aussi inventé une nouvelle fabrique de tapisserie, dont le fond est une toile cirée, sur laquelle on applique des laines hachées ou broyées de différentes nuances et couleurs, suivant que le sujet le demande. Ces tapisseries ont été bien reçues, la beauté des dessins a beaucoup contribué à en relever le mérite ${ }^{30}$.

38 Nous connaissons les noms des assistants de Claude III Audran (1658-1734) grâce aux écrits de l'architecte suédois Carl Hårleman (1700-1753) : à côté de peintres en bâtiments, de doreurs comme Paul Chéron, Claude Guignebault, Nivelon, Audran eut aussi sous sa direction Pierre Nicolas Huilliot (1674-1751) peintre d'attributs et de décorations (d'animaux, de fleurs et de fruits, de légumes et paysages décoratifs), un peintre de fleurs, 
Fontenay le Père, François Taraval (1665-1715) et Antoine Watteau. L'artiste fit également appel à Christophe Huet (pour le décor du château d'Anet), à Bon de Boullogne, à Claude Simpol. Il collabora de même avec Jean-Baptiste Pater et Jean-Baptiste Oudry.

Dès sa jeunesse, le peintre animalier Alexandre-François Desportes (1661-1743) avait aussi secondé Audran. Les deux artistes travaillèrent côte à côte à maintes reprises (notamment au château d'Anet et à la Ménagerie de Versailles).

La vogue dont Audran jouit durant sa vie est attestée non seulement par l'abondance des commandes dont le gratifièrent le roi, les princes et les «simples » particuliers (la duchesse de Lude - dame d'honneur de la duchesse de Bourgogne -, le maréchal de Villars, le peintre Jean-Baptiste Massé, conseiller de l'Académie Royale de peinture et de sculpture) mais aussi par les témoignages de ses contemporains.

Figure 23

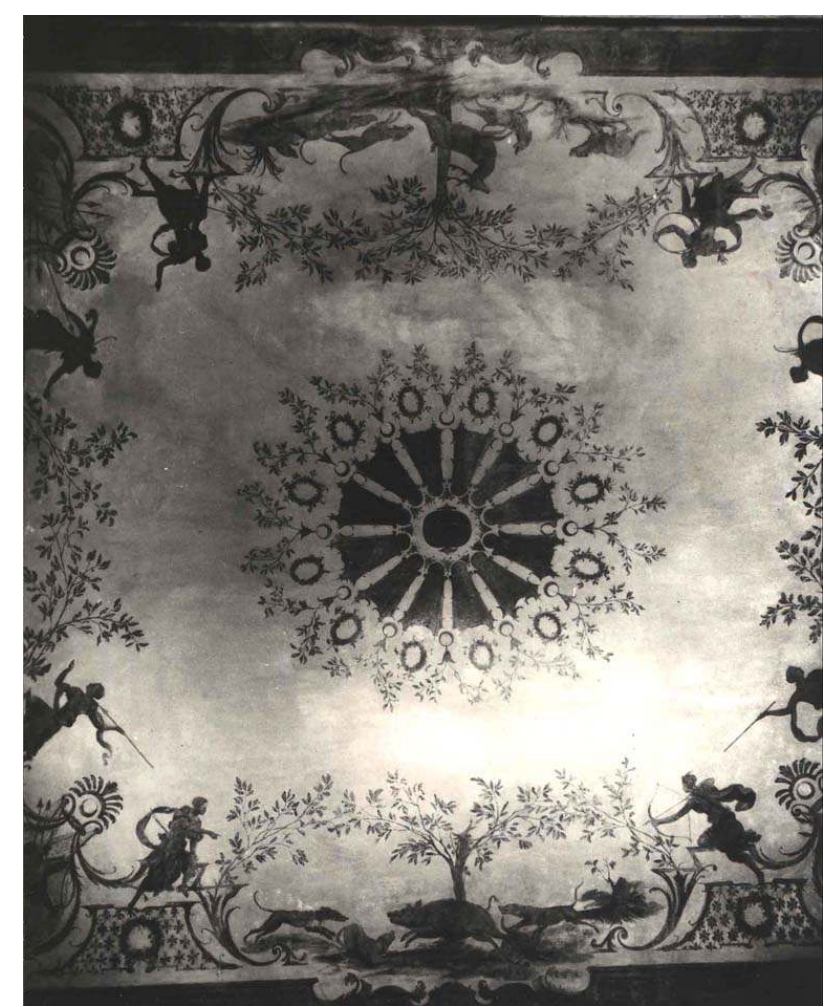

Pavillon Vendôme à Clichy (Hauts-de-Seine), plafond du grand salon du rez-de-chaussée, vers 1697-1702, classé au titre des Monuments historiques.

(c) CRMH île-de-France, 1983. 


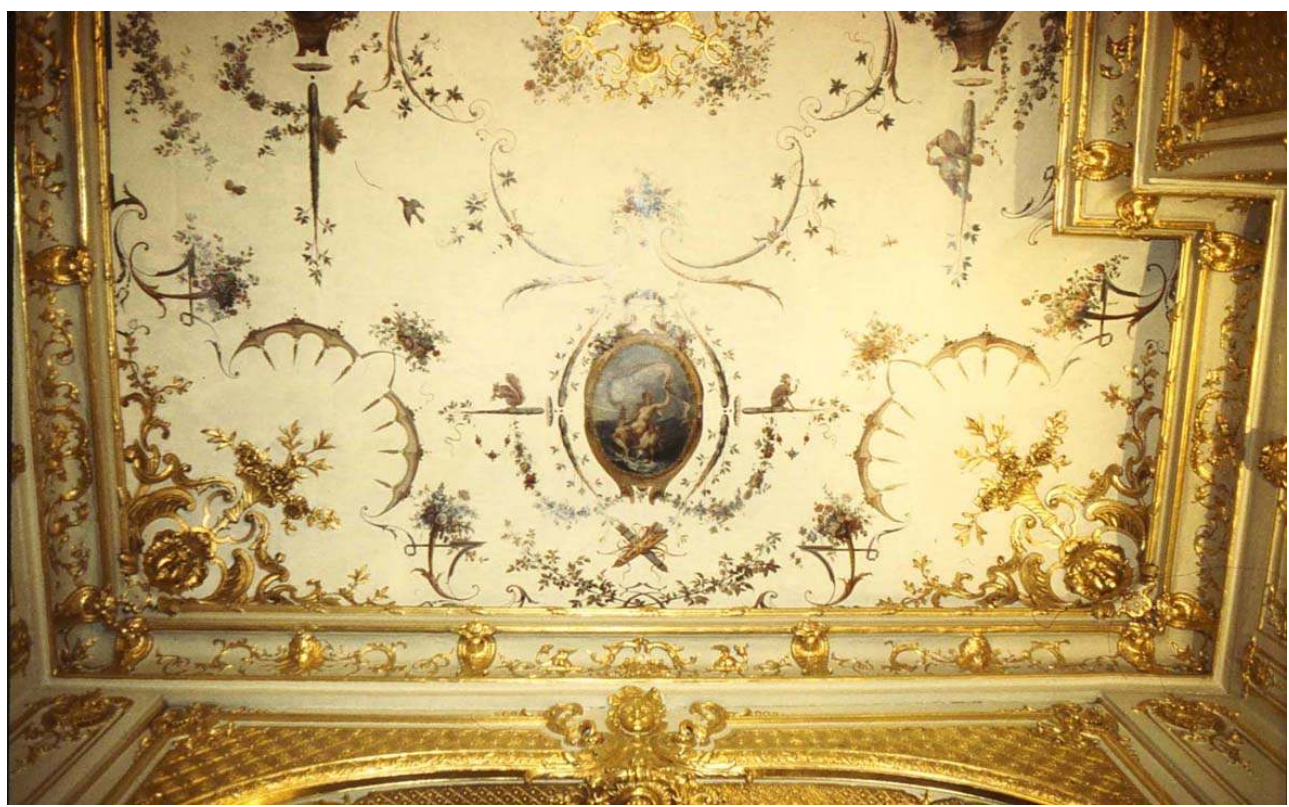

Plafond de l'Hôtel Darnay ou Angran de Fontpertuis, ou de Bonvalet, 21 place Vendôme à Paris 1er, petit cabinet du premier étage, vers 1723-1724, inscrit au titre des Monuments historiques. Phot. Valérie Gaudard.

(c) CRMH Île-de-France, 2003.

41 Que reste-t-il aujourd'hui des nombreuses réalisations de Claude III Audran, exception faite des deux plafonds de la rue de Condé et de la rue de Poitiers (hôtel de Nointel) que nous étudierons plus loin? Plusieurs plafonds nous sont malgré tout parvenus : celui du pavillon Vendôme à Clichy (fig.n ${ }^{\circ} \mathbf{2 3}$ ); celui de l'hôtel Darnay sis 21 place Vendôme à Paris 1er (fig. $\mathbf{n}^{\circ} \mathbf{2 4}$ ); deux autres ont été remontés au musée des Arts Décoratifs: le plafond de l'hôtel de Verrüe ${ }^{31}$, réalisé vers 1720 , et le plafond dit de l'hôtel de Flesselles ${ }^{32}$, daté de 1727.

En France, trois de ses dessins sont exposés au musée des Arts Décoratifs à Paris (dont un décor de plafond, pour le château de Meudon ou la Ménagerie de Versailles) ${ }^{33}$ (fig. $\mathbf{n}^{\circ}$ 25) et quelques croquis d'après ses plafonds sont conservés au cabinet des Estampes de la Bibliothèque nationale de France. L'essentiel des dessins d'Audran est conservé au National Museum de Stockholm ${ }^{34} 35$. 


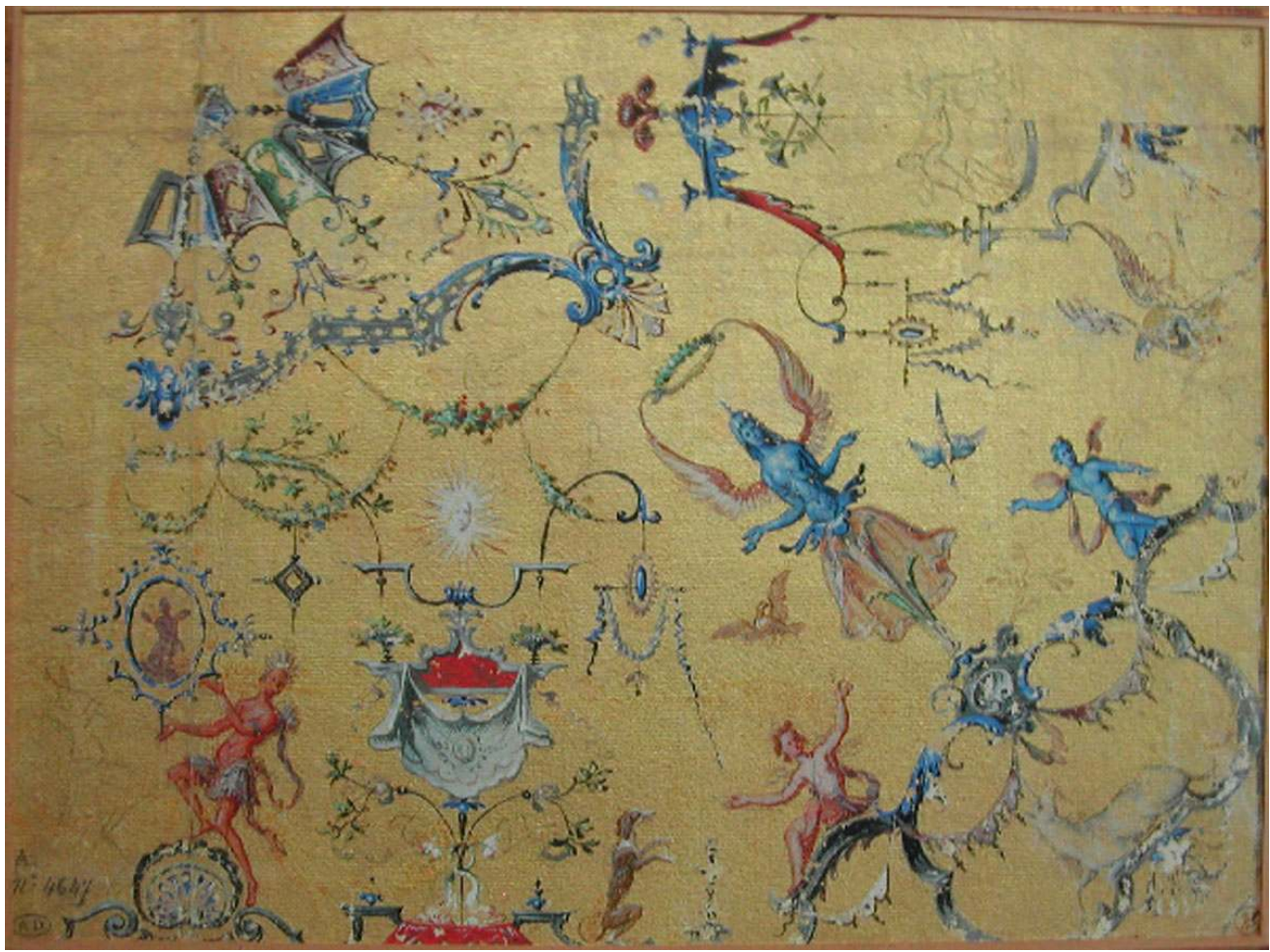

Décoration de plafond, gouache sur fond or, 450 × 370 mm, musée des Arts Décoratifs, Paris

(c) Les Arts Décoratifs, Paris (Tous droits réservés).

Il n'existe pas de gravures reproduisant les compositions décoratives d'Audran, sinon celles pour tapisseries des «Portières des dieux » et des "Douze mois grotesques », gravées par son frère Jean Audran (1699).

Les rapprochements iconographiques les plus probants de notre plafond sont précisement à chercher du côté des multiples compositions pour tapisseries d'Audran exécutées par la Manufacture des Gobelins - collections du Mobilier National ${ }^{37}$ - (fig. $\mathbf{n}^{\circ}$ 26), notamment «Les Douze mois grotesques » (fig. $\mathbf{n}^{\circ} \mathbf{2 7}$ ) commencés en 1708 et achevés en 1710. Cette tenture unique à fils d'argent avait été exécutée pour l'appartement de Monseigneur le Dauphin à Meudon (il existe d'autres séries réalisées pour des particuliers et un certain nombre de pièces isolées). Elle illustre les figures mythologiques des douze mois surmontées chacune par un signe du zodiaque. Dans le bas, des animaux ou des allégories rappellent les attributs de la divinité. Watteau, âgé de 23 ans, travaillait alors pour Audran. Il est probable qu'il collabora à ce projet. 


\section{Figure 26}

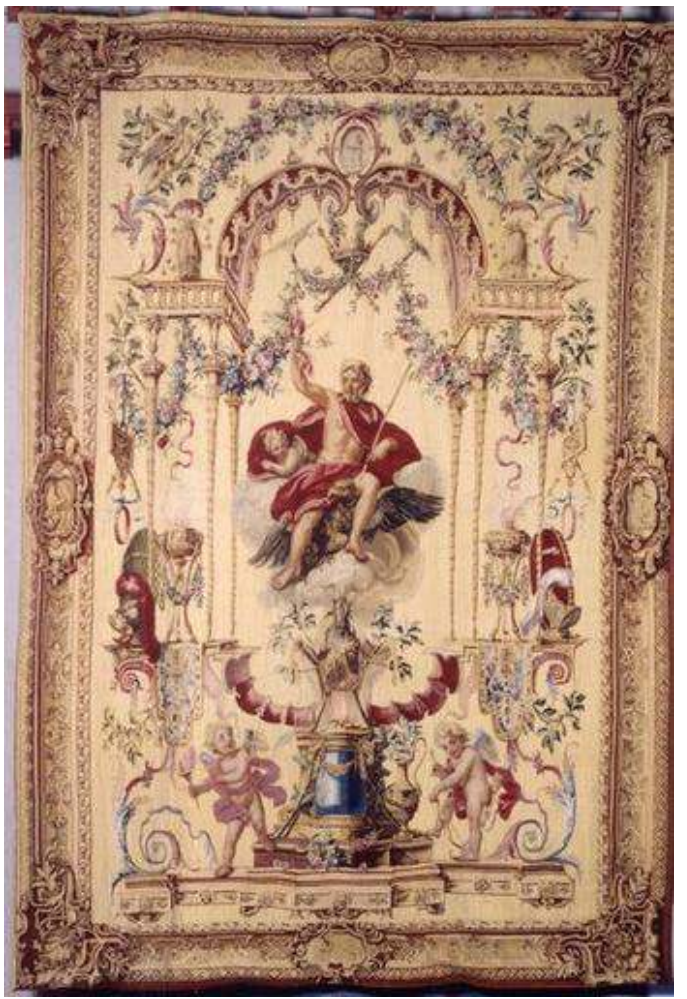

Tapisseries d'Audran exécutées par la Manufacture des Gobelins. Tenture de la « Portière des Dieux » Jupiter ou le feu, GMTT 167/1, tapisserie, H 333 x L 243 cm. Paris, Mobilier national.

(c) Mobilier National. (c) Direction des musées de France. 


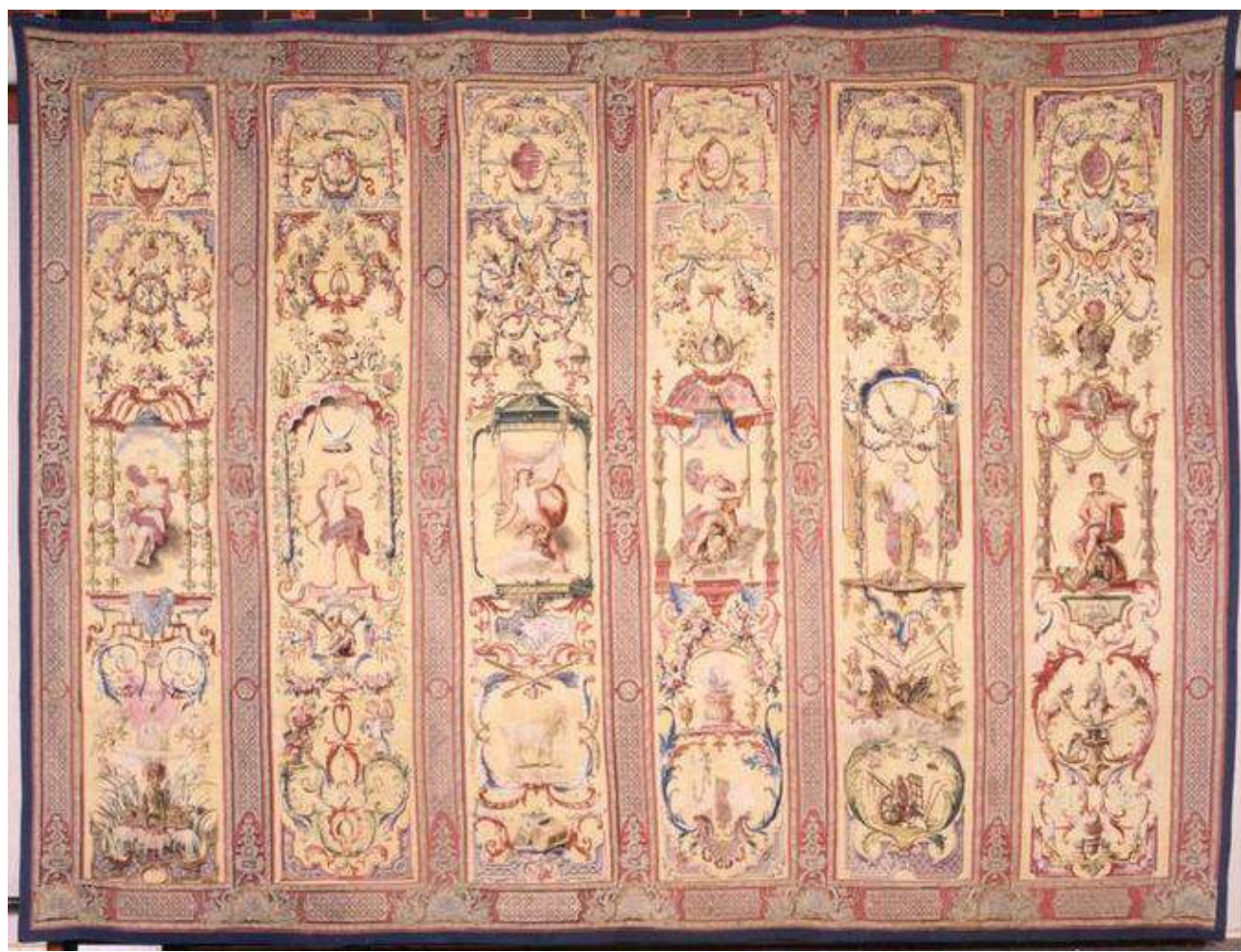

Tapisseries d'Audran exécutées par la Manufacture des Gobelins. Tenture « Les Douze mois grotesques ». Avril à septembre, GMTT 183/2, tapisserie, H 380 x L 500 cm. Paris, Mobilier national. (c) Mobilier National. () Direction des musées de France.

Certains mois ont inspiré des motifs ou des figures allégoriques qui se retrouvent sur le plafond de la rue de Condé: le mois de mai (Apollon portant un arc, les singes, le caducée); juillet (des représentations d'autel ou de brûle-parfums fumants) ; août (Cérès portant une torche) ; octobre (une figure d'Arachné masquée au métier à broder et des éventails déployés).

On découvre encore dans ces compositions, ou dans leurs dessins préparatoires, des dieux comme Jupiter et Mercure, des trophées, des amours, des cartouches, des lettres romaines apposées au pied d'une figure.

47 "Les Douze mois grotesques» et « les Portières des dieux » furent en leur temps des œuvres célébrées, maintes fois rééditées, même au siècle suivant. Ces tapisseries s'inscrivaient clairement dans un projet commercial visant à toucher un public élargi d'amateurs d'art, auquel ne pouvait manquer de faire partie Le Gendre d'Armény, qui a bien pu passer commande d'un décor peint dans l'esprit des fameuses tapisseries.

\section{La collaboration de Claude III AUDRAN avec Antoine WATTEAU (1684-1721)}

Nous l'avons évoqué brièvement, Audran avait requis l'aide de Watteau lors de sa commande des "Mois grotesques" pour Meudon, pour lesquels l'Albertina de Vienne possède un dessin de Watteau. C'est en quittant Claude Gillot, au cours de l'année 1707, que Watteau serait entré au Palais du Luxembourg chez Claude III Audran. Ce dernier lui 
confiera également une partie de la décoration du château de la Muette (décors du cabinet du roi réalisés vers 1708-1715 et connus grâce aux gravures reproduites dans " Trente figures chinoises » publiées dans le Mercure Galant en juillet 1731).

Gersaint, dans la notice qu'il a consacrée au peintre Watteau ${ }^{38}$ indique que :

"Watteau entra ensuite (en sortant de l'atelier de Claude Gillot) chez M. Audran au Luxembourg qui se trouvait très occupé à des camaïeux et à des arabesques dans lesquels on donnait beaucoup en ce temps-là et que l'on plaçait tant dans les plafonds que sur la boiserie des grands cabinets. Il se procura chez lui une vie plus douce et $M$. Audran qui trouvait son compte dans la facilité et l'exécution prompte du pinceau de notre jeune peintre, lui rendit la vie plus aisée à proportion du bénéfice que ses ouvrages lui occasionnaient. Ce fut chez lui qu'il prit goût pour les ornements dont nous avons plusieurs échantillons dans les morceaux de ce genre que l'on a gravés d'après lui. Watteau cependant qui ne voulait pas en demeurer là, ni passer sa vie à travailler pour autrui qui se sentait en état d'imaginer, hasarda un tableau de génie (...). Le sieur Audran (...) de crainte de perdre un sujet qui lui était utile et sur lequel il se reposait assez souvent pour l'aménagement et même pour la composition des morceaux qu'il avait à exécuter, lui conseilla légèrement de ne point passer son temps à ces sortes de pièces libres et de fantaisies qui ne pourraient que lui faire perdre le goût dans lequel il donnait. Watteau n'en fut point dupe. Le parti ferme qu'il avait pris de sortir, joint à un petit désir de revoir Valenciennes, le déterminèrent totalement. Le prétexte d'aller voir ses parents lui servit de moyen honnête (... $)^{39}$ 》.

Le comte de Caylus parlait en ces termes de la pratique des peintures d'arabesques de Watteau dans l'atelier d'Audran : "Ce fut là que Watteau forma son goût pour l'ornement et qu'il acquit une légèreté de pinceau qu'exigent les fonds blancs ou les fonds dorés sur lesquels Audran faisait exécuter ses ouvrages $»^{40}$.

51 Louis de Fourcaud accrédita l'hypothèse selon laquelle Watteau, qui contribuait aux éléments figuratifs des dessins d'Audran, aurait continué à collaborer avec lui longtemps après avoir pris son indépendance ${ }^{41}$ reprenant en cela les remarques consignées par le premier biographe de Watteau (et sans doute le plus sérieux) l'abbé Leclerc pour qui le jeune peintre avait repris le travail avec Audran quand il revint à Paris ${ }^{42}$.

52 Grâce à l'existence d'un plafond peint aux singes à l'hôtel de Nointel - ou de Poulpry (aujourd'hui Maison des Polytechniciens, située 12 rue de Poitiers à Paris 7e), qu'il nous a été autorisé de voir, nous pouvons, sans contestation possible, associer le nom d'Antoine Watteau à la réalisation de notre plafond. Ce décor ressemble en bien des points à celui du 26 rue de Condé43.

53 La restauration récente du plafond de l'hôtel de Nointel, effectuée en juillet 2009 par l'atelier Meriguet-Carrère, en a restitué la qualité plastique (fig. $\mathbf{n}^{\circ} \mathbf{2 8}$ ). 


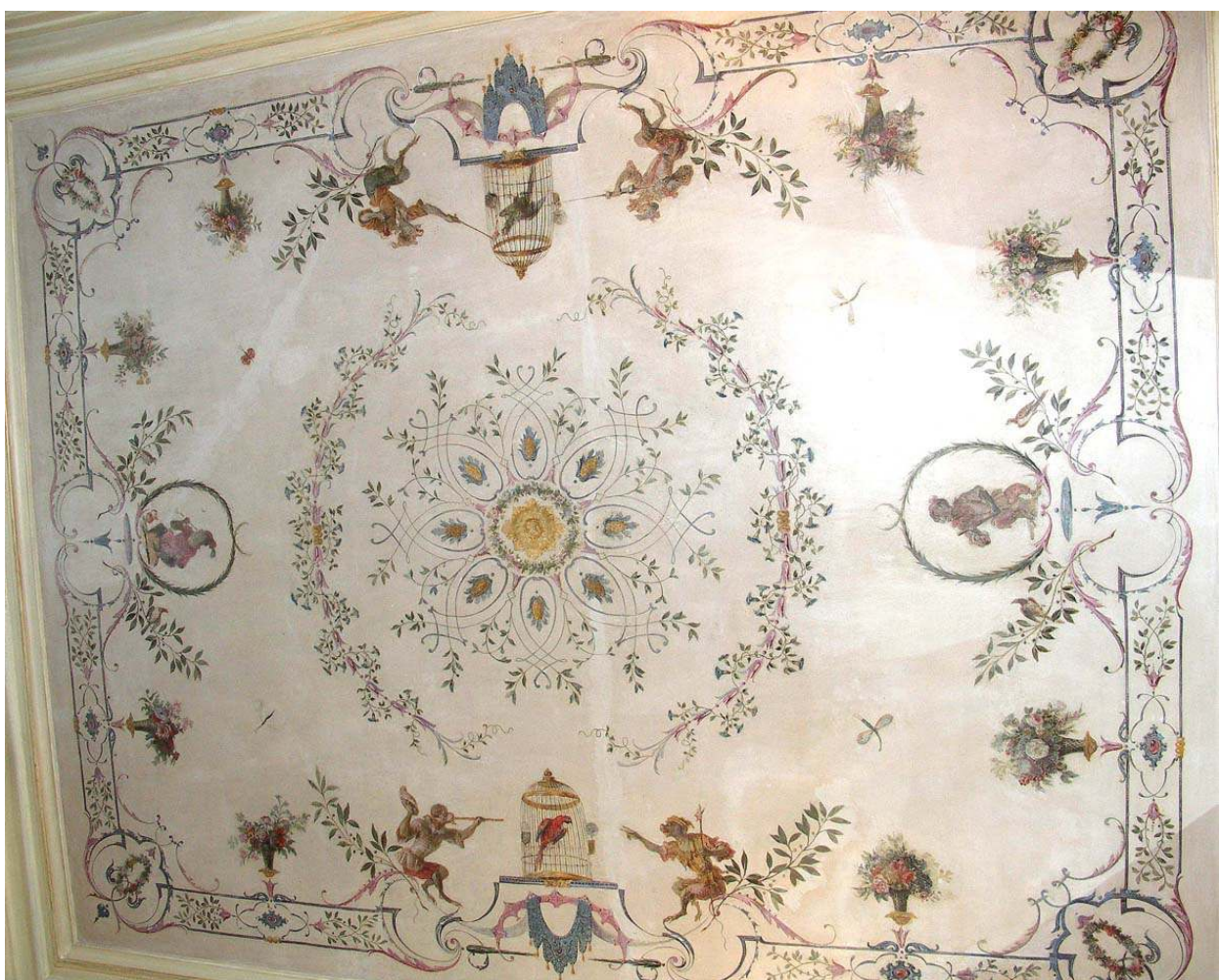

Hôtel de Nointel ou de Poulpry, 12 rue de Poitiers à Paris 7e, plafond du petit cabinet du premier étage. Phot. Christelle Inizan. (c) CRMH Île-de-France, 2010. x $3 \mathrm{~m}$, rectangulaire et sensiblement plus grand que celui du 26 rue de Condé) met également en scène des singes, au nombre de quatre, vêtus comme des comédiens italiens, qui importunent des perroquets dans des cages (à l'aide d'une épée, d'une sarbacane, d'une seringue à lavement ou en faisant des gestes obscènes et agitant une marotte). Deux singes ont été ajoutés dans deux médaillons latéraux: l'un souffle des bulles de savon, l'autre tient une longue-vue.

S'y déploient les éléments traditionnels de l'arabesque : feuillage, lambrequins et vases remplis de fleurs qui servent de motifs de séparation aux singes. Une autre frise court dans la zone centrale. Elle est constituée d'une rose et d'une guirlande. La signification symbolique de ce plafond est encore plus absconse que celle du plafond du 26 rue de Condé.

Mais il est certain qu'il fait également référence aux théâtres des tréteaux si chers à Watteau, nouveau répertoire de scènes des théâtres de foires découvert chez Claude Gillot. Ses singes endossent les habits des comédiens italiens ou ceux de la farce française comme le fou à la marotte, personnage récurrent des tableaux de Watteau. directement peinte sur plâtre. Elle se distingue de la technique employée par Christophe Huet à la Grande Singerie de Chantilly (1737); à savoir un enduit de préparation à peinture de faible épaisseur, posé sur un encollage qui isole cette couche de la structure sous-jacente plâtre sur lattis. 
La question de l'attribution de ce plafond est ici essentielle puisqu'elle entraîne dans son sillage celle du 26 rue de Condé, tant le rapprochement stylistique des deux plafonds est incontestable.

9 On sait, de façon certaine, qu'Antoine Watteau a travaillé à la décoration de cet hôtel. Deux panneaux de la salle à manger de l'hôtel de Nointel étaient de la main de l'artiste valenciennois puisqu'Aveline les grava l'un et l'autre, en 1731 et 1738, en précisant qu'il reproduisait des tableaux de l'artiste.

En 1984, à l'occasion de la célébration du tricentenaire de Watteau, Pierre Rosenberg se déclara en faveur de l'attribution du plafond du petit cabinet au célèbre peintre ${ }^{44}$. Edmond de Goncourt, le premier à avoir proposé cette attribution, s'appuyait pour sa part sur une information importante : l'existence de trois panneaux, mis en vente les 18/30 mai 1885 par le Comte de la Béraudière, descendant du propriétaire de l'hôtel de Nointel et protecteur de Watteau, dont un de $25 \times 36 \mathrm{~cm}$, représentant « une couronne de fleurs traversée par deux thyrses en sautoir. Le motif central est encadré d'arabesques déliées et de feuilles d'acanthes. Le tout ressortant sur fond blanc » ${ }^{45}$. Les deux autres motifs «le faune » et "l'enjôleur ", qui décoraient autrefois l'une des portes du grand salon sous une épaisse couche de peinture à la colle, sont les deux panneaux évoqués par Pierre Rosenberg et aujourd'hui conservés au musée de Valenciennes ${ }^{4647}$.

Martin Eidelberg, dans son remarquable article «Watteau and Audran at the Hotel de Nointel », offre une synthèse des différentes recherches publiées sur le sujet, compare les différents points de vue des chercheurs et fait part de leurs interrogations. Eidelberg y pressent que Watteau, débutant sa carrière, a probablement dû passer par le patronage et la caution d'Audran. Il confirme que nous en savons fort peu sur la manière dont Watteau travaillait en tant qu'assistant d'Audran, l'abbé Leclerc précisant juste qu'il employait le jeune artiste à « faire de petites figures dans ses ouvrages $»^{4849}$.

Eidelberg se réfère aux réflexions de Roger-Armand Weigert pour qui «le plafond de Nointel possède clairement un style rococo qui s'accorde avec la simplification croissante de plusieurs travaux d'Audran après $1710 »^{50}$. Il conclut en penchant pour l'hypothèse d'une séparation progressive des deux hommes et opte pour une datation du plafond de l'Hôtel de Nointel plus tardive que les années 1709-1710, souvent avancées, "qu'il faudrait reconsidérer au $v u$ du contexte de création des arabesques présentes dans les différentes réalisations d'Audran et Watteau $»^{51}$.

L'activité artistique de Watteau entre 1712 et 1715 est effectivement très mal connue. Durant cette période, le peintre ne semble pas rechercher de grandes commandes mais vouloir plutôt se perfectionner. Vers 1715, on sait simplement qu'il fit la connaissance du frère aîné d'Antoine Crozat, le trésorier Pierre Crozat, lequel le missionna pour la décoration de la salle à manger de son hôtel de la rue de Richelieu à Paris, décor inspiré des quatre saisons ${ }^{52}$.

Si l'on considère, par ailleurs, qu'à l'automne 1719, Watteau se rendit en Angleterre ${ }^{53}$ pour y séjourner de longs mois, la fourchette de datation du plafond du 26 rue de Condé se réduit aux années 1713-1719. 


\section{Lecture comparative du plafond avec les œuvres de Watteau}

On retrouve dans les créations de Watteau (c'est particulièrement vrai dans les gravures réalisées d'après ses dessins) des motifs similaires à ceux présents sur le plafond du 26 rue de Condé.

Figure 29

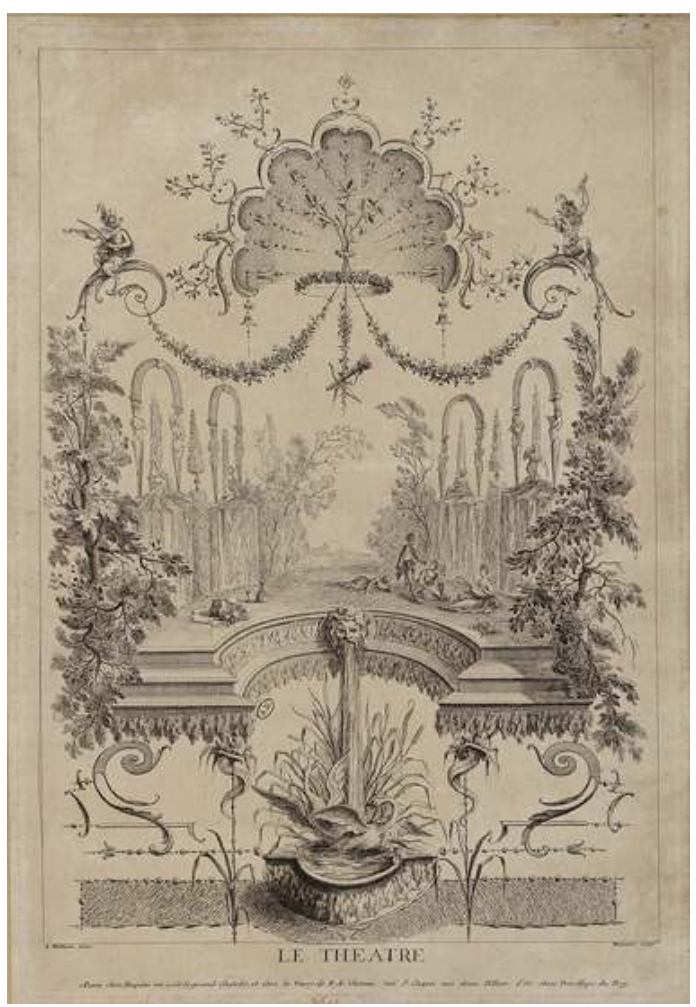

"Le Théâtre », chez G. Huquier, Watteau pinxit, collection MACIET «WATTEAU - Réserve » ORN/14/13, bibliothèque des arts décoratifs, Paris.

(C) Bibliothèque des Arts Décoratifs, Paris (Tous droits réservés). 


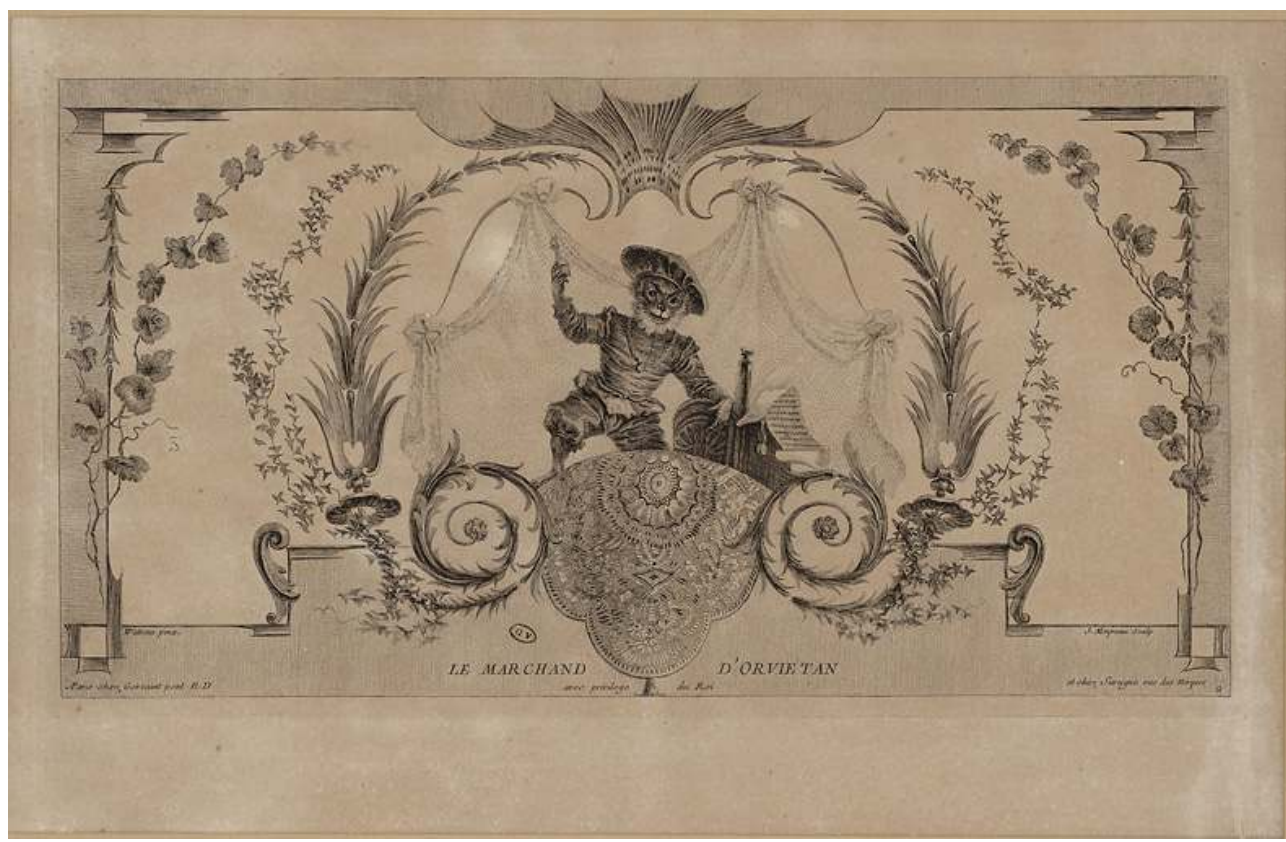

«Le Marchand d'Orvietan », collection MACIET « WATTEAU », collection MACIET « Graveurs ornemanistes des XVIe au XVIIIe siècles » ORN/14/5 - bibliothèque des Arts Décoratifs, Paris.

(C) Bibliothèque des Arts Décoratifs, Paris (Tous droits réservés).

Des éventails ouverts : ornements récurrents que l'on retrouve à la fois dans les tapisseries et le projet de plafond pour le château de Meudon; dans le dessin de plafond de la " Naissance de Vénus " conservé au musée de l'Ermitage à Saint-Pétersbourg (qui daterait également du séjour de Watteau chez Audran) et dans des gravures : le frontispice des " Figures de mode" gravé par Watteau lui-même; «le Théâtre» (fig. n²9); "la Pélerine altérée », gravées par Huquier ainsi que dans les dessus-de-porte peints suivants «le Marchand d'Orvietan » (fig. $\left.\mathbf{n}^{\circ} \mathbf{3 0}\right)$ ou « la Favorite de Flore». 


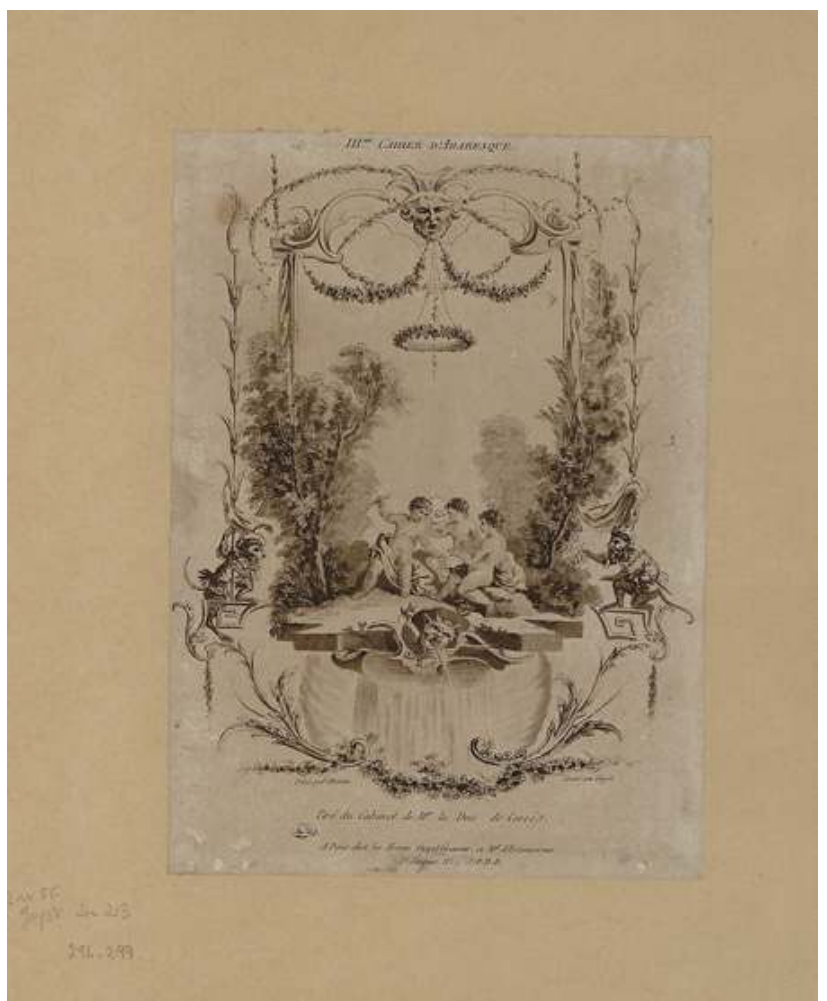

«Ille cahier d'arabesques tiré du cabinet de Monseigneur le duc de Cossé à Paris, chez les frères Guyot graveurs, peint par Watteau », collection MACIET «WATTEAU - Réserve » ORN/15/23, bibliothèque des Arts Décoratifs, Paris.

(C) Bibliothèque des Arts Décoratifs, Paris (Tous droits réservés).

Une couronne de fleurs sommitale visible notamment dans les gravures "le Théâtre ", "les Saisons ovales", «les Saisons Cossé » (fig. $\left.\mathbf{n}^{\mathbf{0} 31}\right)$ ou encore dans le tableau "le Contrat de mariage » conservé au musée du Prado à Madrid.

Des profils féminins figurant dans des médaillons et des trophées, dans les panneaux des « $\mathrm{S}$ aisons ovales » reproduites dans les gravures réalisées par Huquier.

Des amours présents dans la série de quatre gravures «les Saisons Cossé » exécutées par P. Guyot $^{54}$ dont les historiens de l'art acceptent l'attribution au peintre valenciennois et datent autour de 1708. Les différentes saisons y sont représentées illustrées par l'action d'amours, très semblables dans leur apparence générale, à ceux présents sur notre plafond.

Le dais à voilage fin qui apparaît dans la gravure de "Vénus et l'amour» (fig. $\mathbf{n}^{\circ} \mathbf{3 2}$ ) et les tapisseries des « Mois grotesques». 


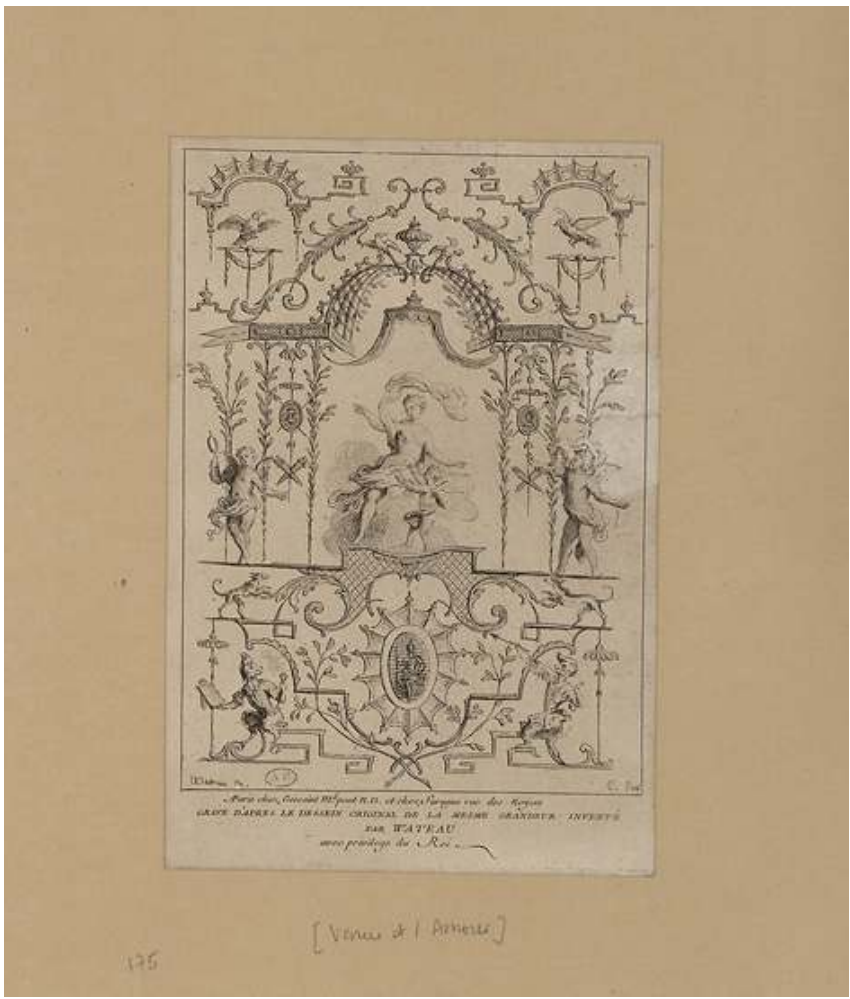

« Vénus et l'Amour », gravé d'après le dessin original de la même grandeur inventé par WATTEAU, à Paris chez Gersaint et chez Suruque, collection MACIET «WATTEAU - Réserve » ORN/14/ 36 bibliothèque des Arts Décoratifs, Paris.

(C) Bibliothèque des Arts Décoratifs, Paris (Tous droits réservés).

71 Au contraire, deux autres motifs semblent appartenir exclusivement au répertoire formel d'Audran : il s'agit des palmettes situées au-dessus des médaillons (visibles notamment dans le projet d'un plafond conservé à Stockholm, sur les plafonds de l'hôtel de Flesselles et du Pavillon Vendôme) et les cartouches (présents sur les plafonds de l'hôtel de Nointel et de l'hôtel de Darnay et antérieurement dans les « Mois grotesques »).

Quant aux lambrequins, ils figurent en bonne place sur les tentures et les tapisseries d'Audran (série de tapisseries des «Portières des dieux»: Jupiter le feu, Jupiter) mais paraissent avoir été repris à son compte par Watteau qui en a simplifié la forme en épurant les détails d'ornementation (comme dans la gravure de Caylus d'après Watteau : " couvercle de clavecin" (fig. $\mathbf{n}^{\circ} \mathbf{3 3}$ ) ou sur le plafond de l'hôtel de Nointel, sous les cages des perroquets). 


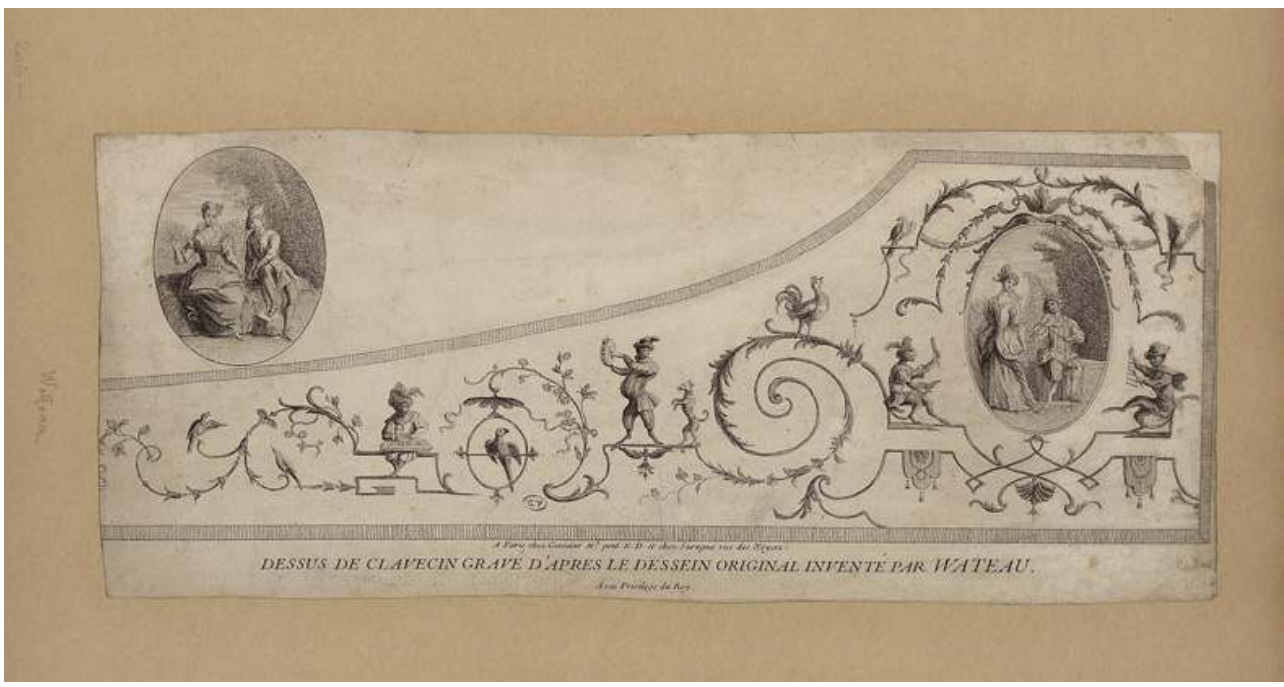

"Couvercle de clavecin » gravé par Caylus d'après le dessin original inventé par WATTEAU, à Paris chez Gersaint, et chez Surugue, collection MACIET « WATTEAU - Réserve » ORN/15/2, bibliothèque des Arts Décoratifs, Paris.

(C) Bibliothèque des Arts Décoratifs, Paris (Tous droits réservés).

\section{Jeux simiesques sur plafond}

Une comparaison entre les singes des plafonds de Nointel et du 26 rue de Condé s'impose. Leur composition en binôme, la posture générale, enfin la physionomie et l'expression faciale très expressive des singes sont en tous points semblables.

Les costumes de ces animaux sont largement inspirés par les types italiens de la Commedia dell'arte qui fixent les personnages comiques par leur costume caractérisé et invariable (valet, aventurier, amoureux, etc...).

Le singe au miroir du 26 rue de Condé porte les habits rose satiné de Mezzetin (plus souvent représenté, il est vrai, dans un costume à raies à plusieurs couleurs) mais visible comme tel dans le tableau de Claude Gillot «Le tombeau de maitre André» conservé au musée du Louvre (fig. $\mathbf{n}^{\circ} \mathbf{3 4}$ ). C'est bien ce type de valet amoureux et sentimental qui est ici dépeint, cherchant sa belle dans le miroir. Une certaine souffrance amoureuse est clairement perceptible sur le visage de ce singe ${ }^{55}$. 


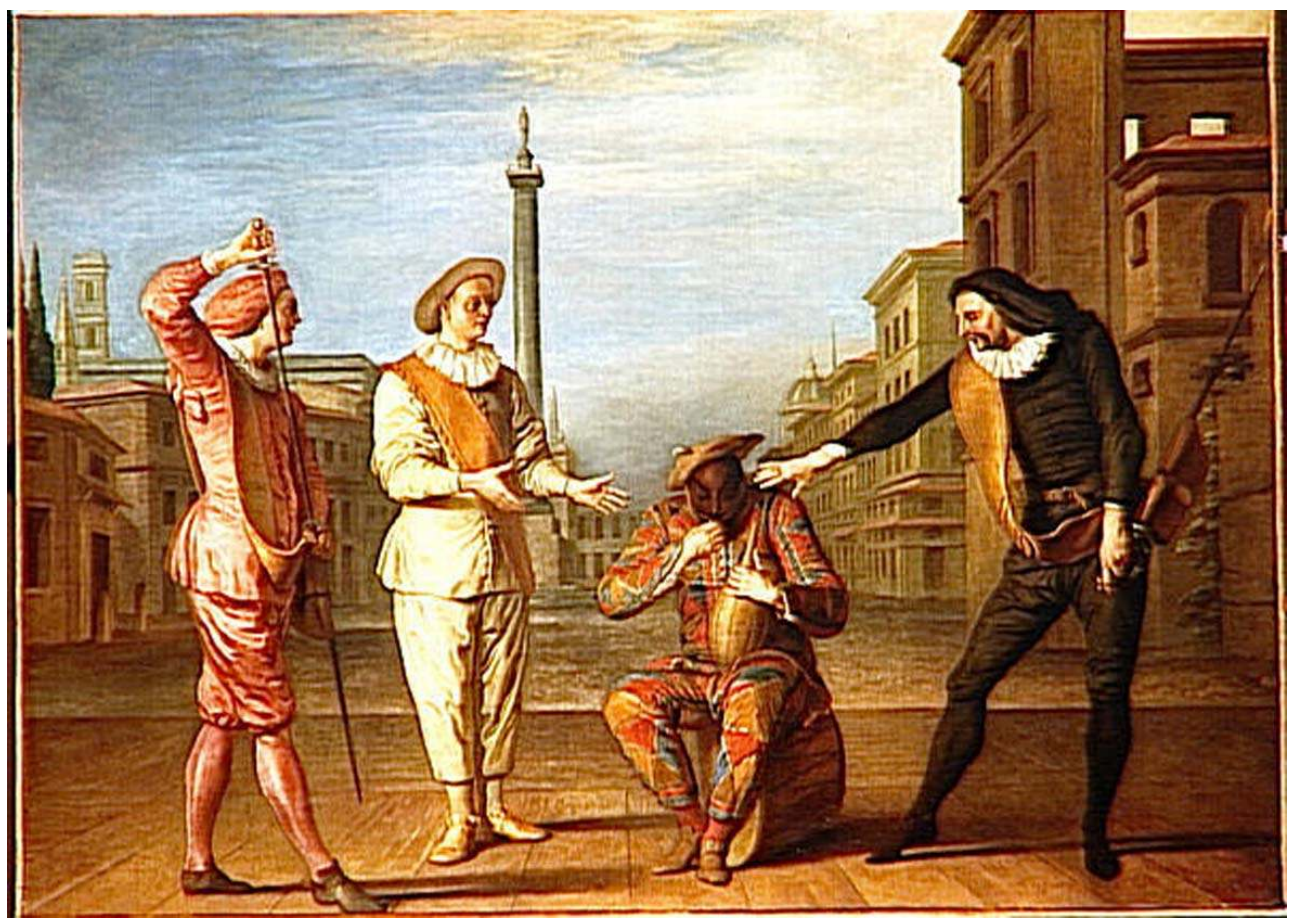

Claude Gillot « Le Tombeau de Maître André », R.F.1945-26. Toile. H 100 x L 138 cm. Paris, musée du Louvre.

(c) RMN

Sur la face du singe à l'iguane se dégage davantage l'expression d'une exaltation mystique. De son côté, le singe au collier tourne son regard vers son attribut, tenu à hauteur de regard, à hauteur d'homme. Quant au singe au caducée, il suit des yeux son objet solaire, brandi haut. Il porte une parure similaire au singe à la marotte de l'hôtel de Nointel, n'était que sa collerette qui diffère (les rayures vertes et jaunes sont les emblèmes traditionnels du fol).

Une importante source d'inspiration iconographique de notre plafond est donc à chercher dans le voisinage de la maison de la rue Neuve Saint-Lambert avec la Foire Saint-Germain, lieu d'effervescence théâtrale avec la foire Saint-Laurent ${ }^{56}$. De 1697 à 1716, les comédiens italiens animèrent exclusivement ces théâtres forains. Une grande partie du répertoire théâtral de ces années a malheureusement disparu (avant 1715, il était pour l'essentiel manuscrit et beaucoup de ces textes ont été perdus). Mais c'est précisément dans ces pièces d'accès difficile ${ }^{57}$, même aux spécialistes, que l'on pourrait trouver les meilleures sources de l'iconographie théâtrale de Watteau. Ce qui nous paraît aujourd'hui une construction, des sujets à clé, avait la même lisibilité pour les contemporains de l'artiste que la fable pour un peintre d'histoire.

La démonstration de cet emprunt iconographique de Watteau au théâtre de foire est encore plus probante sur le plafond de la rue de Condé que sur celui de l'hôtel de Nointel, nous renvoyant avec force à l'univers de Claude Gillot.

Une clef de lecture permettant d'interpréter ce plafond se trouve dans l'intéressant ouvrage de Robert Tomlinson « La fête galante : Watteau et Marivaux $»^{58}$. 


\section{La technique picturale de Watteau}

80 L'analyse de la technique picturale de Watteau a été récemment détaillée par élisabeth Martin et Claudia Sindaco-Domas ${ }^{59}$. Les auteurs confirment que les hachures de Watteau sont « quelquefois un peu couchées de droite à gauche » comme l'a écrit Dezallier d'Argenville ${ }^{60}$. "Le traitement des carnations de ce peintre est très caractéristique: réalisé par de petites touches compactes très chargées de blanc, avec assez peu de passage (...) Les lèvres ou certains détails expressifs sont accentués par des rehauts vifs, de vermillon le plus souvent (...) Mais surtout Watteau surpasse ses suiveurs par la liberté de son écriture dont les caractéristiques ont été définies en 1984 : travail de la hampe du pinceau pour accentuer certains plis; accent de couleurs vives pour les rehauts, variété de matière et grande économie de moyens. On ne constate pas chez les suiveurs la même diversité, la même rapidité d'écriture, ni des raccourcis aussi audacieux $»^{61}$.

81 "Le vermillon est présent chez Watteau dans de nombreux accessoires vestimentaires, sans que soit exclu le mélange avec d'autres pigments (...) Le jaune de Naples, dont les procédés de fabrication à base de plomb et d'antimoine ne sont publiés en France qu'en 1766 par Fougeroux dans un mémoire à l'Académie des Sciences est très sollicité par Watteau dès ses premières compositions $»^{62}$.

82 Nous ne pouvons qu'espérer lors d'une future restauration du plafond de la maison du 26 rue de Condé une analyse poussée des couches picturales, en particulier des costumes des singes et de leurs têtes effectivement rehaussées de rouge.

\section{Audran, Watteau et .... Lancret (1690-1743)}

83 Le traitement pictural très particulier des quatre amours (proches de ceux figurant dans «Le Printemps » des Saisons Cossé de Watteau gravées par Guyot) est une sérieuse source d'interrogation tant leur facture diffère nettement du reste de la composition. Divers arguments semblent plaider pour une attribution à Nicolas Lancret.

La matière y est peu chargée, fine et transparente. Or Élisabeth Martin et Claudia Sindaco-Domas précisent que «chez Lancret, la couleur de la préparation en demi-teinte peut également servir de fond tonal comme dans les quatre Saisons où la couleur chaude de la préparation affleure à de nombreux endroits sous la finesse de la matière picturale et contribue ainsi à unifier l'harmonie colorée " $"$.

Les historiens de l'art connaissent de surcroît le goût de Lancret à peindre les tableaux par séries, surtout par quatre. "Nicolas Lancret s'est toujours distingué par une grande vérité, une belle exécution, de riches compositions, des groupes bien ménagés, des figures gracieuses, une légèreté de pinceau surprenante: quelle variété n'a-t-il pas mise dans des sujets aussi usés, aussi rebattus que les éléments, les saisons, les quatre parties du monde, les heures du jour, les douze mois de l'année, les cinq sens! " ${ }^{64}$. 
Figure 35

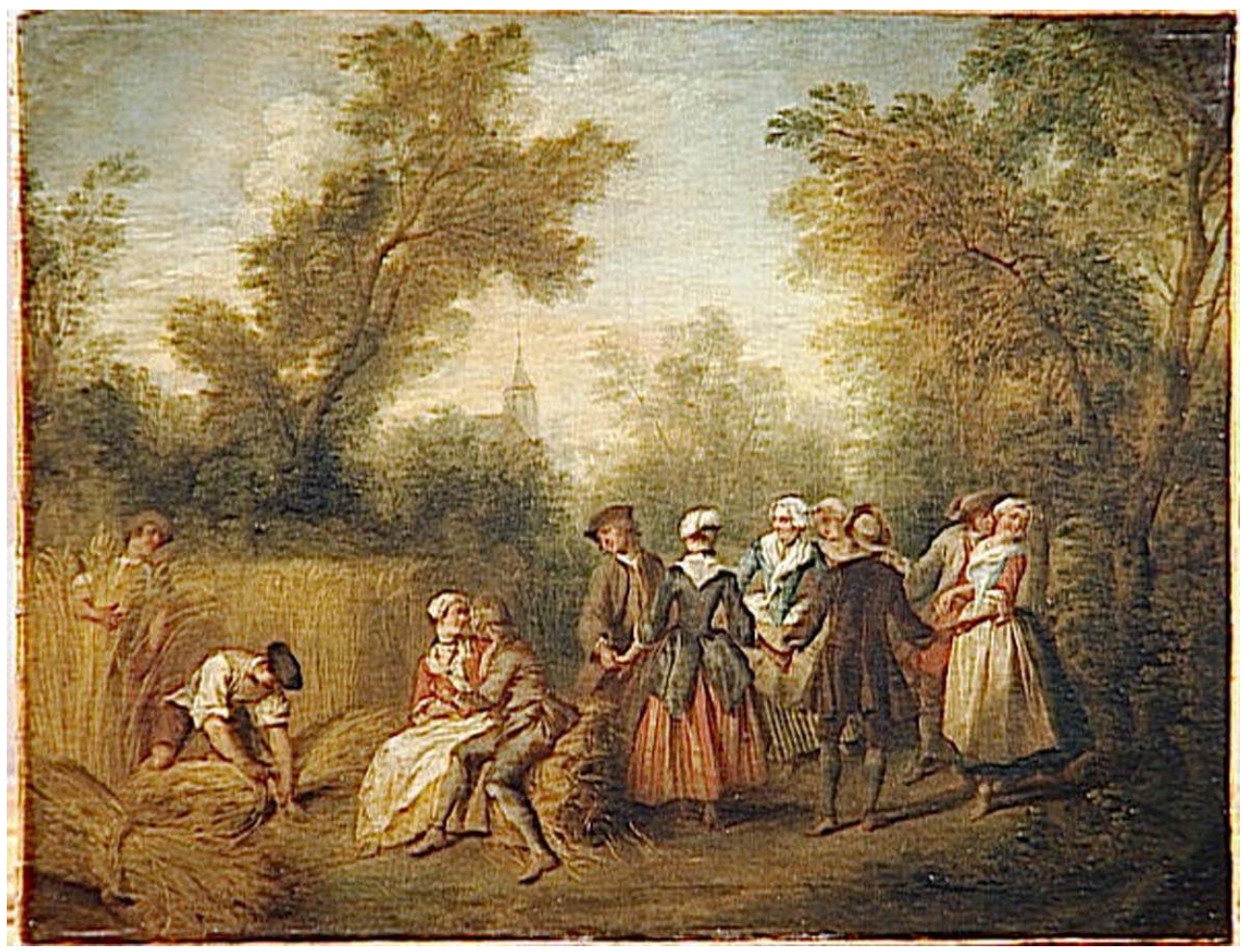

Nicolas Lancret « l'Été », vers 1738, INV.5598. Paris, musée du Louvre. (c) RMN/ Gérard Blot.

Figure 36

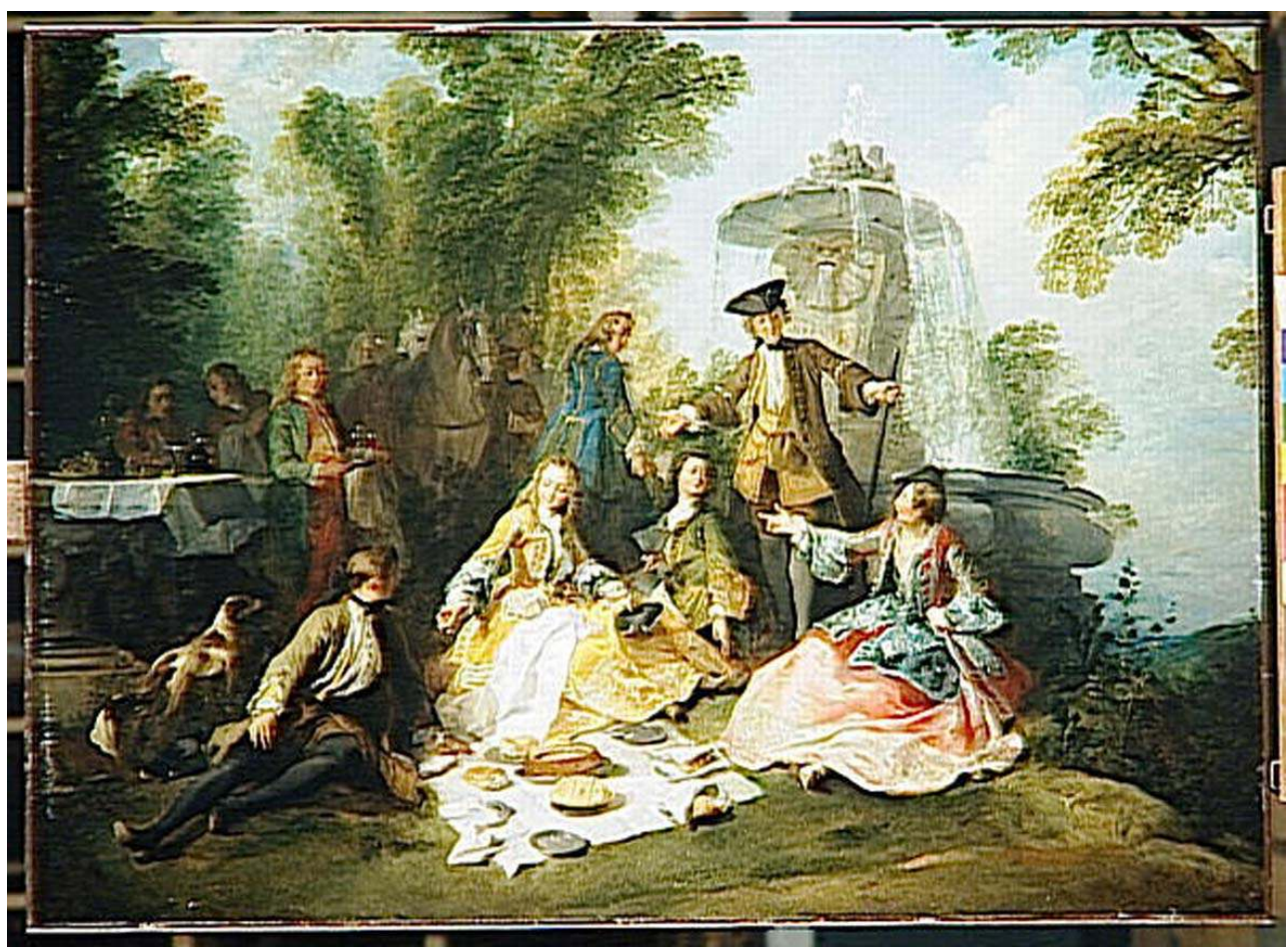

Nicolas Lancret « Le Repas de chasse », R.F.1990-19. Paris, musée du Louvre. (c) RMN 
La confrontation des quatre amours avec certains personnages des tableaux de l'artiste s'avère également éclairante : "L'été » (fig. $\mathbf{n}^{\circ} \mathbf{3 5}$ ), «Le repas de chasse » (fig. $\mathbf{n}^{\circ}{ }^{36}$ ), " L'innocence " (fig. $\mathbf{n}^{\circ}{ }^{37}$ ), conservés au musée du Louvre, «Avant le bal masqué » (fig. $\mathbf{n}^{\circ}{ }^{38}$ ) du musée des Beaux-Arts de Nantes, "Une femme dans un jardin prenant un café » de la National Gallery de Londres, «Le miroir ardent » conservé au château de Charlottenburg à Berlin. Mêmes profils, yeux aux paupières mi-closes, même implantation des oreilles, cheveux flous, gestuelle très large des membres, mains potelées aux doigts ouverts.

Figure 37

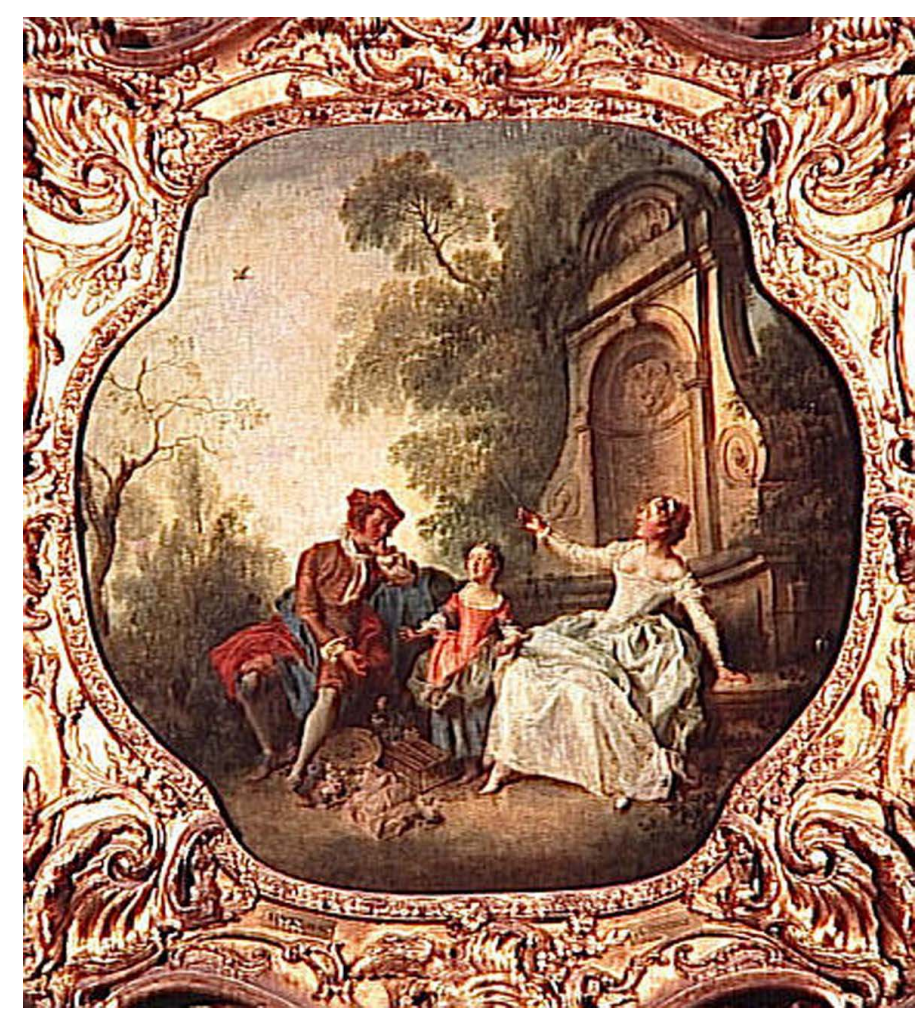

Nicolas Lancret «L'Innocence ». Paris, musée du Louvre. (c) RMN. 
Figure 38

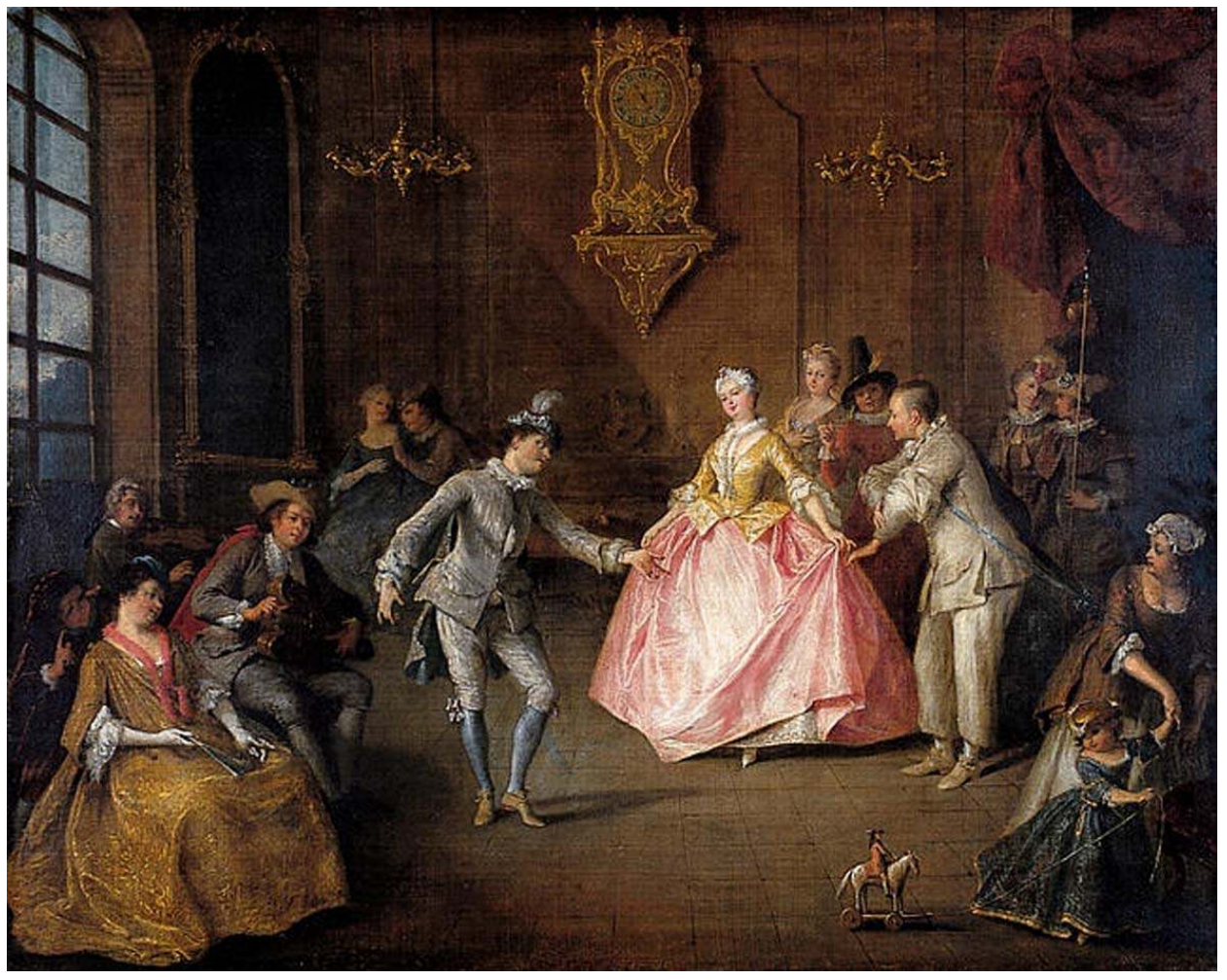

Nicolas Lancret «Avant le bal masqué ». Nantes, musée des Beaux-Arts

(c) Musée des Beaux-Arts, Nantes. (c) Direction des musées de France/Alain Guillard.

l'éphéméride, d'abord prises pour des chiffres romains et qui pourraient bien être sa signature? Nicolas Lancret signait habituellement ses œuvres en décalant le $\mathrm{N}$ (en haut) du L (en bas) ${ }^{65}$. Palais du Luxembourg, dans son sillage, d'autres artistes de la fête galante avaient eux aussi, grâce à Audran, leurs entrées dans les jardins et les collections de la résidence royale. Nicolas Lancret en était. 30 ans et commence à se faire connaître grâce au parrainage d'Audran et de La Fosse ; il le sera également par le soutien que lui offre entre autre Pierre Crozat, frère du beau-fils de Legendre d'Armény.

Nicolas Lancret a 24 ans. Comme Audran, il a appris son métier auprès d'un graveur de sa famille, son oncle en l'occurrence. Comme Watteau, il passe chez Claude Gillot quelques années - les historiens de l'art pensent d'ailleurs que Lancret assista Gillot dans la réalisation de sa toile des «Deux carrosses» (fig. n³9). Lancret fit précisément la rencontre de Watteau chez Gillot et aurait passé quelque temps au domicile de Watteau, mais la question reste cependant un sujet de controverse. Lancret fréquentait également les salons des Crozat dont il fut chargé d'en peindre la magnificence dans plusieurs tableaux dont "Le concert dans le salon ovale de Pierre Crozat à la maison de Montmorency", peint vers 1720 et conservé au L. Rosenberg Foundation de Dallas. 
Figure 39

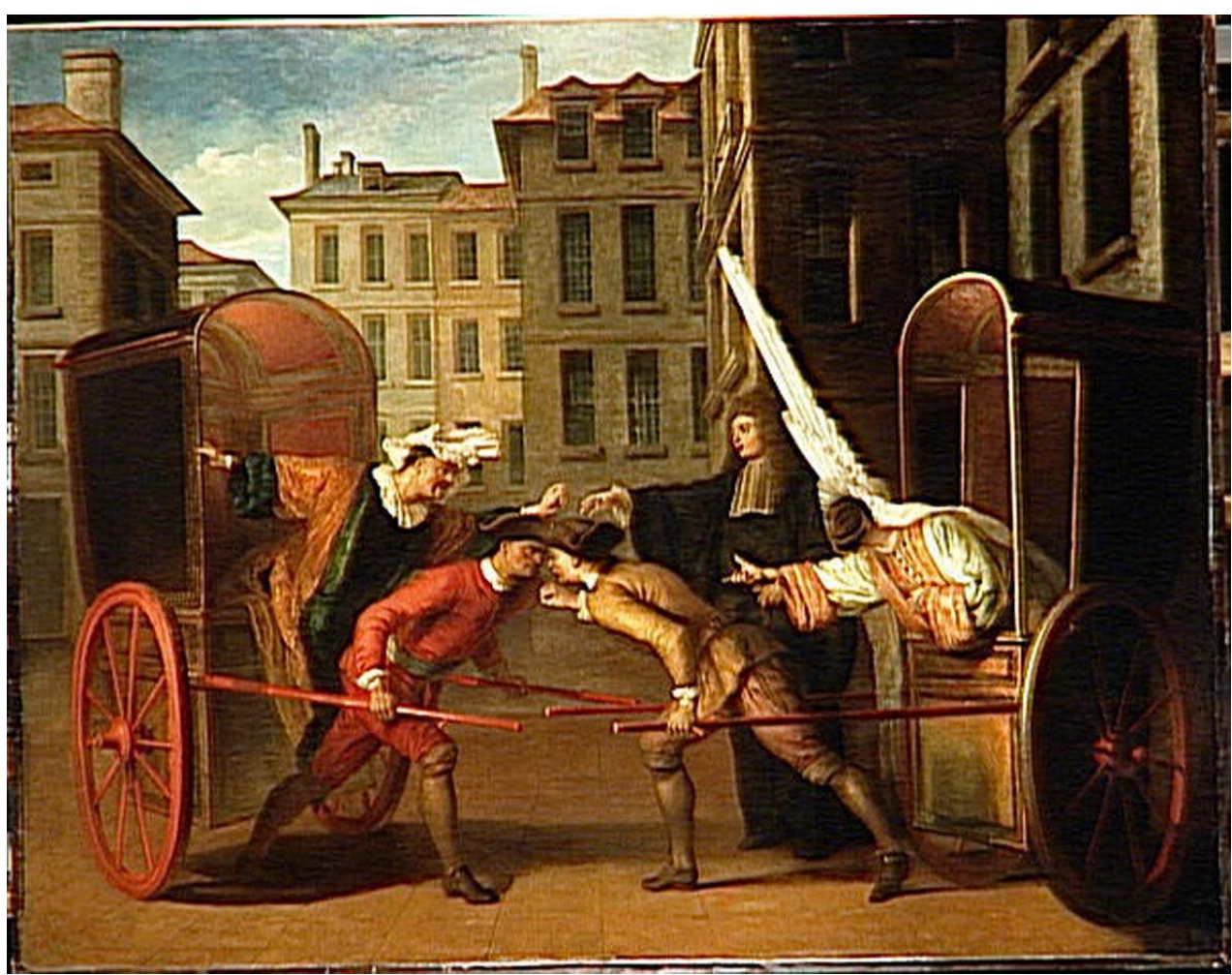

Claude Gillot « Les Deux carrosses », R.F.2405. Toile. H 126,5 x L 160,2 cm. Paris, musée du Louvre. (c) RMN/Arnaudet.

91 C'est Watteau qui conseilla à Lancret d'étudier constamment d'après nature, pratique que l'élève observa jusqu'à la fin de sa vie. Lancret avait si bien assimilé la manière de son illustre professeur que deux tableaux, "un bal " et "une dame dans un bocage ", qu'il exposa à la place Dauphine, furent pris par certains pour des œuvres de Watteau. Le pastiche étant trop flagrant, le maître de Valenciennes se fâcha et rompit avec son élève ${ }^{66}$ - La date de la brouille des deux hommes remonterait à 1714. Faute d'écrits contemporains précis concernant cette dispute, on ne peut s'avancer plus précisément sur la datation du plafond.

Quant au lien entre Audran et Lancret, il est en partie établi grâce aux travaux récents de Mary Tavener Holmes analysant notamment un tableau peint par Lancret en 1723 et conservé au J. Paul Getty Museum de Los Angeles « Danse devant une fontaine ». Le morceau d'architecture discernable en arrière fond de la toile s'avère être la grotte du Luxembourg construite par Salomon de Brosse en 1615 (aujourd'hui Fontaine Médicis et déplacée au $\mathrm{XIX}^{\mathrm{e}}$ siècle $)^{67}$. 
Figure 40

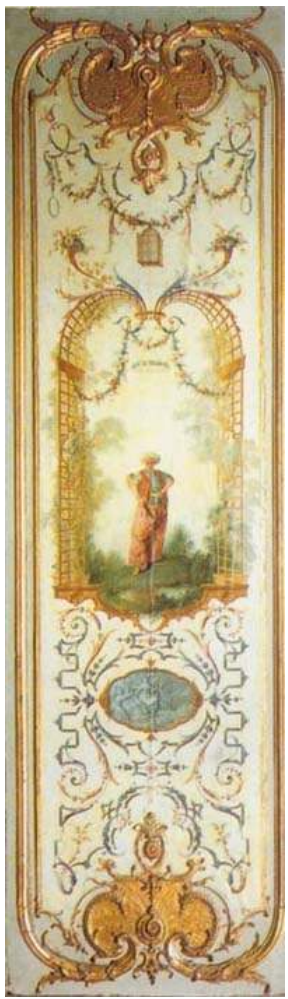

Nicolas Lancret, décors de l'hôtel de Peyrenc de Moras, 23 place Vendôme à Paris 1er ; grand panneau peint : «le Turc ». Musée des Arts Décoratifs, Paris.

(c) Les Arts Décoratifs, Paris (Tous droits réservés).

93 En 1725, Audran apparaissait déjà comme le personnage clef pour la commande des décors de l'hôtel Peyrenc de Moras (devenu hôtel de Boullongne puis hôtel de Montbreton, 23 place Vendôme à Paris 1er) ${ }^{68}$ (fig.n ${ }^{\circ}$ 40). " À Nicolas Lancret étaient revenues les compositions à figures de fantaisie disposées dans des paysages (le Gilles, une danseuse, la dame au parasol, le turc amoureux, la pélerine, l'oiseau mis en cage, le joueur de cornemuse, la bergère endormie et l'escarpolette) et à Audran les parties strictement ornementales venant encadrer les scènes ainsi que le plafond de la pièce. Comme à l'hôtel de Verrüe, Audran déploya avec talent une succession de feuilles d'acanthe, de fleurons formant d'élégants entrelacs constituant comme autant de supports aux médaillons traités en camaïeux et de berceaux de treillage autour des figures de fantaisie ${ }^{6970}$.

(fig.n ${ }^{\circ}$ 41) (fig.n $\left.{ }^{\circ} 42\right)$ 


\section{Figure 41}

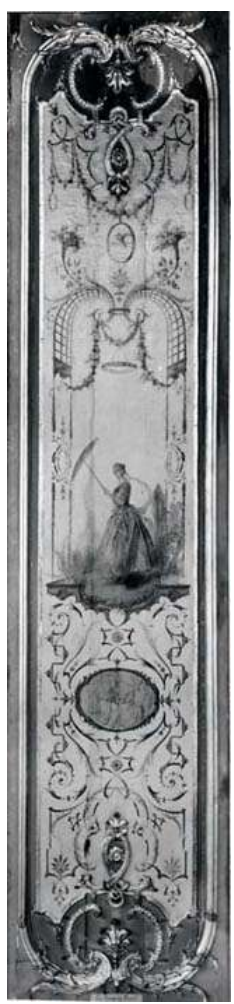

Nicolas Lancret, décors de l'hôtel de Peyrenc de Moras, 23 place Vendôme à Paris 1er ; grand panneau peint : « l'Actrice ou la femme au parasol ». Musée des Arts Décoratifs, Paris.

(c) Les Arts Décoratifs, Paris (Tous droits réservés). 


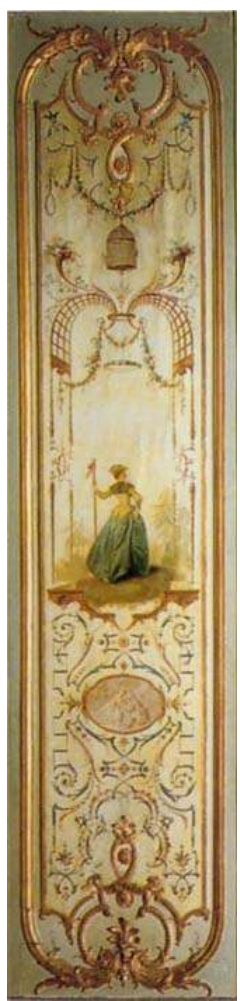

Nicolas Lancret, décors de l'hôtel de Peyrenc de Moras, 23 place Vendôme à Paris 1er ; grand panneau peint : «la Pélerine ». Musée des Arts Décoratifs, Paris.

(c) Les Arts Décoratifs, Paris (Tous droits réservés).

Une photographie de ce salon prise avant son démantèlement et consultable à la documentation du département des peintures du Louvre, nous montre ces panneaux en place et les vantaux de porte peints. Ce décor complet offre une synthèse des éléments décoratifs présents chez Audran et Watteau : arabesques et rinceaux, éventail déployé, cartouche avec saynette peinte en camaïeu, rosace de fleurs et lambrequins.

\section{Le plafond aux singes de la rue de Condé : œuvre d'un triumvirat d'exception}

En l'état actuel de cette étude, on peut avancer l'hypothèse d'une commande de décor passée à Claude III Audran qui supervise et délègue à Antoine Watteau, lequel se serait fait aider à son tour de son élève Nicolas Lancret.

Audran, Watteau, Lancret : trois signatures de référence du décor parisien de ce premier quart du XVIII siècle.

La datation de 1713 peut être proposée. Cette année est celle de l'achat de la maison par Legendre d'Armény pour Mademoiselle d'Aulnay et correspond à la période durant laquelle Watteau se présentait à l'Académie espérant obtenir une pension et se rendre à Rome pour y achever ses études. Elle corroborerait l'avis de certains spécialistes pour qui la collaboration entre Watteau et Audran se serait prolongée bien au-delà de 1708-1709. 

l'époque où ce dernier travaillait chez Audran et permet d'établir un lien direct entre les tapisseries des « Douze mois grotesques » réalisées pour le château de Meudon et un décor peint. date de réalisation supposée du plafond de l'hôtel de Nointel (1709-1710) et d'un certain nombre d'œuvres matures de Watteau qui semblent malgré tout encore influencées par la collaboration avec Audran. triomphe des motifs d'arabesques et s'achevèrent avec le déclin de la rocaille. C'est au Château de Marly que Claude III Audran introduisit ses populaires singeries dès 1690 . Rappelons-nous que «les décors de singeries aujourd'hui appréciés comme de véritables œuvres d'art, étaient à leur création considérés comme de purs éléments de fantaisie, et n'étaient pas même mentionnés dans les guides du temps $»^{71}$. Aussi sommes-nous si mal renseignés sur ces réalisations décoratives qui connurent un franc succès durant toute la première moitié du $\mathrm{XVIII}^{\mathrm{e}}$ siècle. La rareté des «singeries " préservées à Paris, et plus largement en France ${ }^{72}$, ajoute à l'intérêt de ce décor malheureusement tronqué de ses habillages muraux. Ce plafond pourrait même être le plus ancien décor parisien «aux singes» conservé en place.

\section{NOTES}

1. - Mes remerciements vont à Mesdames Isabelle Gallimard des Éditions Gallimard, Corinne Fortin de la Maison des Polytechniciens, à Monsieur Dominique Cerclet, conservateur régional des Monuments historiques d'île-de-France et Messieurs François Macé de Lépinay, inspecteur général des Patrimoines et Serge Pitiot, conservateur général des Monuments historiques, pour leur relecture critique.

2. - Charles Testu, capitaine du guet, serait le maître d'ouvrage de la maison. En ont été propriétaires successivement:

- sa veuve, Louise Coutelle. Archives Nationales, Minutier central des notaires, étude XVIII, carton 403 ;

- la sœur de celle-ci, Charlotte Coutelle (de 1697 à 1700). A.N./M.C./XVIII/415 ;

- un ancien lieutenant des gardes françaises, Adrien du Bosc (de 1703 à 1710). A.N./M.C./VI/631 A.N. S 2849 - déclaration terrier du 20 décembre 1710 ;

- un avocat, Antoine Auger (de 1710 à 1713). A.N., Centre de topographie, fichier propriétaires, fiche 208 ;

- un directeur général de l'île de Saint-Domingue, Joseph Le Gendre d'Armény ou d'Armigny qui y installa sa présupposée maîtresse Marie Angélique de la Motte d'Aulnay (de 1713 à 1740) ;

- A.N./M.C./XXII//648.

- le marquis du Perrier (de 1740 à 1763). A.N./Sentence des décrets du Châtelet de Paris du 6/07/1740 : série Y;

- l'écrivain Pierre Augustin Caron de Beaumarchais (de 1768 à 1785). A.N./M.C./XXIII/648.

En janvier 1763, Beaumarchais achète la maison du 26 rue de Condé pour y loger son père André- 
Charles Caron (qui décédera en octobre 1775) et ses deux sœurs cadettes (Jeanne-Marguerite, morte en 1772, et Julie, décédée en mai 1798). Il s'y serait remarié en 1768 avec la veuve d'un garde général des Menus-Plaisirs et y aurait écrit «Le barbier de Séville » en 1773. En avril de la même année, Beaumarchais se trouve ruiné. Sortant de prison en mai, il est chassé de sa maison de la rue de Condé et doit se réfugier chez son beau-frère Lépine.

- Octobre 1776: Beaumarchais loue un hôtel particulier pour y installer les bureaux de sa compagnie de commerce. À partir de 1778, Beaumarchais n'aurait plus occupé la maison, sa sœur Julie y serait restée. En 1786, Beaumarchais épouse Marie-Thérèse de Willer-Mawlaz, avec qui il vivait depuis douze ans, et un an plus tard achète un terrain près de la Bastille pour y faire construire une somptueuse demeure, par l'architecte Lemoyne. Le 5 juillet 1794, sa femme, sa fille Eugénie (future épouse Delarue) et sa sœur Julie sont emprisonnées à Paris. C'est la chute de Robespierre qui sauve de l'échafaud la famille Beaumarchais.

Résumé de l'ouvrage de LARTHOMAS, Pierre. Biographie de Beaumarchais (Collection la Pléiade). Paris : Gallimard, 1988.

- la famille Faure occupe la maison durant la presque totalité du XIXe siècle (de 1809 à 1879).

- la maison d'édition le Mercure Galant s'y installe à partir de 1887 et les éditions Gallimard achètent finalement l'immeuble en 1968.

3. - Par exemple les numéros 14,28 et 30 de la rue de Condé.

4. - Numéros 11,13, 15 de la rue de Condé.

5. - Une grande maison aux proportions régulières, dans l'environnement immédiat du Palais du Luxembourg: La façade agrémentée de bandeaux se déploie sur quatre travées et comporte trois niveaux. Le dernier étage est consécutif à une surélévation entreprise entre 1710 et 1763 . Nous possédons une brève présentation de l'édifice en 1710: "une grande maison à porte cochère consistant en un grand corps de logis sur rue et sur cour composée de deux étages, de chambres et antichambre et grenier au-dessus. Les écuries et autres petits bâtiments étaient partagés avec la maison voisine" (A.N./M.C./VI/631). Le soubassement est en pierre de taille. À gauche de la porte principale, aux vantaux d'origine très remaniés, trois baies éclairaient la loge du portier et les anciennes cuisines. Au second étage, les fenêtres à chambranle rectangulaire sont soulignées par des appuis saillants sur consoles à modillons parées d'écailles, courantes au XVII ${ }^{\mathrm{e}}$ siècle. Une lucarne double à gauche et une ancienne lucarne fourragère animent le dernier étage. L'ensemble des garde-corps de la maison peut être daté du premier quart du XVIII ${ }^{\mathrm{e}}$ siècle. Sur deux niveaux, ceux-ci accueillent le monogramme A.C.L. Intérieurement, le passage cocher a été supprimé pour faire place à une seule et même grande salle. Dans le fond, l'escalier principal développe une rampe à simples arcades à tenons. Il date du XVIII ${ }^{\mathrm{e}}$ siècle. Au rez-de-chaussée toujours, les anciennes cuisines servent aujourd'hui de réserves. La cour, de faible surface, a été condamnée et vitrée. S'y trouve un rare petit escalier en serrurerie réalisé dans les années 1660-1670 (rampe en forme de balustres et aux motifs adossés en rouleaux, feuilles d'eau au centre, qui se termine en simple barreaudage à fer carré. Pour l'heure, dans le corpus sur les escaliers parisiens, il n'existe aucune rampe de ce type - s'en rapprochent les escaliers du 28 rue Charlot, inscrits au titre des Monuments historiques, 12 rue de l'Odéon ; 23 rue Cassette). Au rezde-chaussée toujours, une dernière pièce semble avoir appartenu à une autre parcelle. Elle fait cependant partie de cette entité depuis le début du XIX siècle. Au premier étage se trouve une grande pièce, aujourd'hui cloisonnée, décorée d'une corniche en stuc certainement contemporaine des garde-corps. Des faunes y jouent de la flûte de pan, se balancent sur des arabesques. Masques de comédie et palmettes, trompettes entrecroisées. C'est probablement l'ancien salon de musique. Le petit cabinet aux singes (ou boudoir) devait déboucher originellement sur ce salon et être ainsi éclairé par la lumière de la rue en second jour. Ce cabinet se place conformément aux recommandations prescrites à l'époque pour l'implantation de ce type de pièce (même disposition du petit cabinet de l'hôtel de Nointel, 12 rue de Poitiers à Paris 7e) : dans le corps de bâtiment central, double en profondeur, en retrait par rapport aux belles 
pièces donnant sur rue, le plus souvent placé côté cour, à la jonction d'une aile. Le petit cabinet est aujourd'hui aveugle et communique par deux portes, l'une desservant l'aile, l'autre conduisant à l'étroit couloir menant de l'escalier principal vers une fenêtre sur cour. Il est aujourd'hui totalement dépourvu de décor hormis une cheminée à manteau en marbre rouge surmontée d'une glace meublant l'une des encoignures de la pièce (la tablette chantournée du manteau, le motif de médaillon central défoncé et sur les chambranles de plates-bandes moulurées évoquent le début du XVIII ${ }^{e}$ siècle. On retrouve ces mêmes motifs dans les boiseries du second étage). À ce même niveau, trois autres pièces plus modestes. Quelques éléments épars, du $\mathrm{XVIII}^{\mathrm{e}}$ siècle, subsistent. Le second étage comprend trois pièces principales sur rue, une grande côté cour. Elles conservent, outre leurs volets intérieurs, des poutres maîtresses avec motifs en plate-bande moulurée divisant en deux le plafond encaissé. L'une d'entre elles, la mieux préservée, est entièrement boisée, avec compartimentation à panneaux superposés de platesbandes simplement moulurées, médaillon central. Ce type de boiseries est typique de la fin du $\mathrm{XVII}^{\mathrm{e}}$ siècle ou du début du XVIII ${ }^{\mathrm{e}}$ siècle (décor similaire visible au musée Carnavalet, dans la galerie dite de Sévigné, salle $n^{\circ} 21$ ). À cet étage encore, des vantaux de porte à cadres d'époque.

6. - Mentionné en 1717 dans le Journal de la Régence : 1715-1723, retranscrit par BUVAT, J. Tome I. Paris : Plon, p. 224.

7. - Le Gendre d'Armeny, famille originaire du Languedoc, dont était Joseph Le Gendre, seigneur d'Armeny, secrétaire des finances du duc d'Orléans, en 1735, puis fermier général. JULLIEN de COURCELLES, Jean Baptiste Pierre. Histoire généalogique et héraldique des pairs de France, vol. 6. Paris : éd. l'auteur et Arthus Bertrand, 1826, p. 4. Joseph Le Gendre d'Armeny eut pour fille Marguerite Le Gendre d'Armeny (décédée le 6 septembre 1742) qui épousa en 1690 Antoine Crozat (1655-1738) l'un des plus puissants financiers de France qui fit sa fortune par la traite négrière. Ce dernier redressa les finances du duc de Vendôme, cousin du Roi, devint secrétaire du monarque en 1705 puis son banquier. En 1715, Antoine Crozat fut nommé commandeur et grand trésorier des ordres de Saint-Michel et du Saint-Esprit. En 1724, accusé de s'être enrichi aux dépens de l'état, il est démis de ses fonctions. DURAND, Yves. Les fermiers généraux au XVIIII ${ }^{\mathbf{e}}$ siècle. Paris : éd. Maisonneuve et Larose, avril 1996.

8. - Saint-Domingue fut, de 1627 à 1804 , la principale colonie française installée sur la partie occidentale de l'île d'Hispaniola. Les produits coloniaux de Saint-Domingue représentaient un tiers des exportations françaises. En 1701, le roi relance la compagnie de Guinée, avec de nouveaux actionnaires. L'un d'eux est le financier Antoine Crozat. Cette compagnie avait pour mission de livrer au moins 1000 esclaves par an aux colonies; chiffre bientôt porté à 3000 . Elle obtint même le monopole de livraisons d'esclaves aux Espagnols et prit le nom de Compagnie de l'Asiento.

9. - Archives Nationales, Minutier central des notaires, étude XXIII, carton 648.

10. - Angélique Françoise Maxime de la Motte d'Aulnoy (1677-?) est la troisième des filles de Marie Catherine le Jumel de Barneville (1651-1705 Paroisse Saint-Sulpice) et de François de la Motte, baron d'Aulnoy, contrôleur général de la maison de César de Vendôme - son amant-, et à la fin de sa vie pourvoyeur et contrôleur du prince de Condé. La mère d'Angélique est cette femme à la vie mouvementée qui, pour avoir accusé son mari de crime de lèse-majesté et voulu l'assassiner fut contrainte par Louis XIV à jouer les espionnes dans les cours anglaise, flamande et espagnole. Elle est surtout l'auteur de nombreuses œuvres à succès, entre 1690 et 1691, qui fixèrent par écrit un genre oral en faveur à la cour : le conte de fées. Angélique Françoise aurait suivi durant sa jeunesse sa mère et sa grand-mère à la cour d'Espagne. La disgrâce de sa mère dans ce pays et l'impossibilité de récupérer sa pension là-bas la contraignit certainement à revenir vivre en France.

11. - Roman sur la vie de Marie Catherine le Jumel de Barneville par: GONTIER, Fernande. Histoire de la comtesse d'Aulnoy. Paris : éd. Perrin, 2005. 
12. - LA FONTAINE de, Jean. Fables choisies, mises en vers par M. de la Fontaine (5e partie). Figures gravées par François Chauveau. Livre VII, fable XXI. Paris : éd. C. Bardin, 1694, p. 95-98. 13. - Voir la comédie de MOLIÈRE. Amphitryon (dédicacé au Grand Condé). Paris : éd. J. Ribou, 1668.

14. - Il est intéressant de souligner l'existence d'une espèce de reptile endémique de l'île d'Hispaniola : l'iguane de Ricord, qui ressemble fortement à celui représenté sur le plafond.

15. - CHEVALIER, Jean et GHEERBRANT, Alain. Dictionnaire des symboles. (Collection Bouquins). Paris : Robert Laffont, 1982.

16. - Cardinal rouge également peint sur le plafond de l'hôtel de Verrüe, exposé au musée des Arts Décoratifs, Paris.

17. - Ces couples d'oiseaux se retrouvent trait pour trait sur le plafond de la chambre à coucher située au premier étage de l'hôtel de Darnay, 21 place Vendôme à Paris 1er, plafond réalisé par Claude III Audran en 1723-1724 (Inscrit au titre des Monuments historiques).

18. - Dans «Les Héroïdes ", Ovide fait référence au personnage d'Itys - ou Ityle - qui fut égorgé par sa mère Progné (Épître XV. Sapho à Phaon, le chant des pleurs) "Seul celui de Daulis, mère éplorée, qui se vengea cruellement de son époux, à des chants pour Itys l'ismarien ». Un grand nombre de poètes feignent qu'il fut métamorphosé en faisan ou en chardonneret; Servius croit de son côté qu'il fut changé en pigeon ramier.

19. - Dans les Scènes françaises de la comédie italienne intitulée la foire Saint-Germain. Grenoble, 1696, Jean-François REGNARD propose une pièce intitulée « Le Cap Vert » où Arlequin apparaît en empereur du Cap Vert. Scène I. «Je suis Prince de la verdure; Le teinturier en vert de toute la nature; On ne me prend jamais sans vers; singes et perroquets sont sous ma seigneurie, roy des serins de Canarie ; je m'appelle en un mot l'Empereur du Cap Vert (...)».

20. - OVIDE parle encore d'Itys dans la quatorzième élégie du second livre des Amours et de "Thérée, roi de Thrace, qui fut changé en huppe ", huppe que l'on retrouve sur le plafond de Verrüe. Rappelons-nous que Watteau dans son tableau Jupiter et Antiope peint vers 1715-1716 (Paris, Louvre, M.I. 1129) s'était inspiré d'un autre épisode mythologique extrait des Métamorphoses d'OVIDE.

21. - «Pendant que nous parlons, le temps jaloux a fui : jouis de ce jour, sans trop compter le suivant». HORACE. Odes. Livre I, Ode XI, vers 7-8.

22. - OVIDE. Les Métamorphoses. Livre X, Atalante et Hippomène.

23. - OVIDE. Les Amours. Livre II, Élégie 9.

24. - Claude III Audran avait pris l'arabesque au point où l'avait amenée Berain, son âné d'une vingtaine d'années, et la transforma complètement en lui insufflant un esprit nouveau. Les jeux de bandes chers à Berain sont ainsi retournés aux angles en méandres et incurvés en souples enroulements décrivant des $\mathrm{S}$ ou des C (...). En renonçant au cadre ou en le remplaçant par des éléments décoratifs empruntés au règne végétal, Audran sut donner « de l'air » à l'arabesque. Aux baldaquins abstraits que Berain construisait avec des éléments le plus souvent pleins, succédèrent des portiques aux montants fleuris, des berceaux de treillage. Dans des proportions très justes, on trouve des danseurs et des musiciens, équilibristes et baladins qui semblent échappés de la Foire Saint-Germain, des volatiles. Auparavant Berain proposait des entrelacs, des volutes et leurs retours auxquels s'accrochaient des guirlandes et des vrilles, soulignant le canevas. Chez Audran en revanche, les plafonds sont plus dégagés, avec rosace centrale et entourage décoratif. Les arabesques de Pineau et de Gillot doivent beaucoup à celui qui fut aussi le maître de Watteau pour ce genre d'ornement. Mais Watteau s'affranchit très vite de l'influence de son maître en centrant ses arabesques avec des personnages ou des groupes de personnages empruntés à son répertoire. WEIGERT, Roger Armand. Dessins du National Museum de Stockholm: Claude III Audran, dessins d'architecture et d'ornements, catalogue d'exposition. Paris : éd. Presses artistiques, 1950. 
25. - Voir la fameuse note manuscrite en marge du projet de Mansart pour le décor de la Ménagerie (8 septembre 1699) : "Il me parait qu'il y a quelque chose à changer, que les sujets sont trop sérieux et qu'il faut qu'il y ait de la jeunesse mêlée dans ce que l'on fera...Il faut de l'enfance répandue partout (...)».

26. - Au déclin du XVII ${ }^{\mathrm{e}}$ siècle, diverses circonstances bien connues des historiens avaient modifié le décor des appartements dans le sens de la simplicité. Les plafonds furent dégagés de la peinture mythologique, les lambris de la dorure. Les surfaces ainsi libérées devinrent dès lors disponibles à la fantaisie de l'ornemaniste sur lesquelles triomphera l'arabesque d'Audran. Selon les habitudes communes à ses confrères, Audran se contentait d'imaginer l'ensemble de la composition du plafond, de peindre certains motifs et il confiait le reste aux soins de ses collaborateurs habituels (...) WEIGERT, Roger Armand. Quelques travaux décoratifs de Claude III Audran. Bulletin de la Société de l'histoire de l'art français, 1956, p.85-93.

27. - Voir les décors peints de l'hôtel de Verrüe et l'hôtel de Nointel.

28. - MICHEL, Edmond. Les Audran, peintres et graveurs. Orléans : éd. H. Herluison, 1884, p. 16. 29. - WEIGERT, Roger Armand. Dessins du National Museum de Stockholm : Claude III Audran, dessins d'architecture et d'ornements, catalogue d'exposition. Paris : éd. Presses artistiques, 1950.

30. - BRICE, Germain. Description de la ville de Paris et de tout ce qu'elle contient de plus remarquable. Tome III. Paris, 1752, p. 404-405 (réédition de la Nouvelle description de la ville de Paris et de tout ce qu'elle contient de plus remarquable. Tome III. Paris : édition J. M. Gandouin, 1725, p. 347-348).

31. - L'hôtel de Verrüe, dépendance de la communauté des Bénédictines de la rue du Cherche Midi (actuel 8 rue d'Assas), dans le couvent duquel Madame de Verrüe logea de 1701 à sa mort en 1736.

32. - L'Hôtel de Flesselles se trouvait rue Couture Sainte-Catherine, c'est-à-dire au nº 52 de la rue de Sévigné. Cet édifice fut démoli en 1908.

33. - « Décor de plafond, pour le château de Meudon ou la Ménagerie de Versailles », gouache sur fond or, vers 1700 (inv. 5482 A), musée des Arts Décoratifs, Paris.

34. - Après la mort d'Audran en 1734, Daniel Cronstedt, ambassadeur de Suède, acheta ses dessins. En 1949, les descendants de Cronstedt donnèrent cette collection au musée de Stockholm qui, un an plus tard, organisa une exposition à Paris à la Bibliothèque Nationale.

35. - WEIGERT, Roger Armand. Dessins du National Museum de Stockholm : Claude III Audran, dessins d'architecture et d'ornements, catalogue d'exposition. Paris : éd. Presses artistiques, 1950.

36. - Dans sa composition, le plafond du 26 rue de Condé se rapproche de l'ébauche du dessin d'un projet de plafond composé pour la duchesse de Bouillon, conservé au National Museum de Stockholm. Dessin aquarellé bleu, rouge et or, lignes directrices au crayon noir, 37,8 X 52,3 cm, conservé au National Museum de Stockholm, collection Cronstedt, et provenant de la succession de Claude III Audran. "Il s'agit de la représentation d'un demi plafond (deux angles, rose centrale). Son dessin est très élaboré. Il suffisait ensuite aux assistants de le compléter et de le transférer in situ. D'où l'importance de la couleur dans ces projets dessinés, l'exécution n'étant pas nécessairement sous le contrôle du créateur. Ce modèle se caractérise par un ornement en surcharge, où l'arrière-plan se distingue à peine. Découpage marqué, jeu de bandes constituant un véritable encadrement, et un étonnant mélange d'animaux, de végétaux et de motifs décoratifs variés avec silhouettes de femmes oiseaux debout ». MILLION, H.A. The Triumph of the Baroque: architecture in Europe, 1600-1750, catalogue exposition. Turin, Palazzo di Caccia di Stupinigi, 4 july-7 november 1999, p. 512.

37. - C'est en 1699, sous la direction de Jules-Hardouin Mansart, que sort la première tenture des "Nouvelles Portières des Dieux». Elle comporte des sujets pouvant être scindés en deux parties : les quatre saisons et les quatre éléments (les « Trois portières » appartiennent à la série la plus célèbre 
du genre). Si Claude III Audran est bien à l'origine des cartons et du dessin des élégants portiques, il laissait à d'autres le soin d'imaginer les figures des dieux et des enfants. Desportes se consacra par exemple aux oiseaux.

38. - GERSAINT, Edme François. Catalogue raisonné des diverses curiosités du cabinet de feu M. Quentin de Lorangère composé de tableaux originaux des meilleurs maîtres de Flandres, d'une très nombreuse collection de dessins \& d'estampes de toutes les écoles. Paris : Jacques Barois, 1744.

39. - DUPLESSIS, Georges. Les Audran. Paris : Libraire de l'art, 1892.

40. - MARTIN, Élisabeth, SINDACO-DOMAS, Claudia. La technique picturale des peintres des fêtes galantes dans le contexte du XVIII ${ }^{\mathrm{e}}$ siècle. Techne, 2009-2010, n³0-31, p. 28.

41. - FOURCAUD de, Louis. Antoine Watteau, peintre d'arabesques. Revue de l'Art ancien et moderne, 1908, tome XXIV, p. 431-440 et 1909, tome XXV, p. 49-59, 129-140.

42. - $\mathrm{N}^{\circ} 28$ «Gillot... le produisit chez M. Audran, excellent peintre d'ornements, qui l'occupa à faire des petites figures dans ses ouvrages. Cependant Watteau dégoûté de Paris s'en retourna en son pays... Il revint à Paris et rentra chez M. Audran ». LECLERC, Laurent Josse. Le grand dictionnaire historique ou le mélange curieux de l'histoire sacrée et profane de Louis Moreri. Tome VI. Paris : Libraires associés, 1725, cité par ROSENBERG, Pierre. Vies anciennes de Watteau. Paris : RMN, p. 9.

43. - Ce plafond orne, au premier étage, un petit cabinet en retrait donnant sur la cour des anciennes écuries aujourd'hui surmontées d'une terrasse. Cette œuvre décorative majeure, encore en place, ne bénéficie, elle non plus, d'aucune protection au titre des Monuments historiques.

44. - «La vivacité de son coup de pinceau et de la couleur suggèrent sa touche. La couleur magenta, les lambrequins bleus, les couleurs vives des costumes se retrouvent tout à fait dans les panneaux à motifs d'arabesques de Valenciennes ». ROSENBERG, Pierre, GRASSELI, Margaret Morgan, PARMANTIER, Nicole. Catalogue de l'exposition Watteau. Paris : RMN, 1984, p. 248.

45. - GONCOURT de, Edmond. Catalogue raisonné de l'Cuvre peint, dessiné et gravé d'Antoine Watteau. Paris : éd. Rapilly, 1875, p. 206-208.

46. - EIDELBERG, Martin. Watteau and Audran at the Hotel de Nointel. Apollo, the International magasine of the arts. London, January 2002, p. 10-16.

47. - Un second plafond de même facture (rouleaux d'acanthe, bouquets de fleurs, oiseaux et couronne de fleurs centrale) provenant de l'hôtel de Nointel a été mis en vente chez Sotheby's à New York le 14 janvier 1988, lot 196 (correspond-il au petit plafond peint sur bois passé en vente le 30 novembre 1971, lot 29 ?).

48. - LECLERC, Laurent Josse. Le grand dictionnaire historique ou le mélange curieux de l'histoire sacrée et profane de Louis Moreri. Tome VI. Paris : éd. Libraires associés, 1725.

49. - Eidelberg présume encore une relation de travail complexe entre les deux artistes. En confrontant les différentes réflexions menées par Parker et Mathey, Grasseli, Rosenberg et Prat, Per Bjurström, il lui semble nécessaire de reconsidérer l'attribution des peintures des huit arabesques figuratives de l'hôtel de Nointel gravées par Julienne et signées « Watteau pinxit » en une participation active d'Audran à leur composition.

50. - WEIGERT, Roger-Armand. Quelques travaux décoratifs de Claude III Audran. Bulletin de la Société de l'Histoire de l'art français. Paris, 1956, p. 85-93.

51. - EIDELBERG, Martin. Watteau and Audran at the Hotel de Nointel. Apollo, the International magasine of the arts. London, January 2002, p. 15.

52. - « Si Crozat prit le jeune Watteau sous son aile, ce n'est pas tant qu'il sut reconnaître en lui le futur artiste des Fêtes Galantes, mais plutôt parce qu'il avait été introduit à l'hôtel de Crozat par le célèbre peintre d'histoire Charles de La Fosse ». HATTORI, Cordelia. Contemporary drawings in the collection of Pierre Crozat. Master Drawings. London, 2007, vol. 45, n¹, p. 38-53. 
53. - HANSON, Craig. Doctor Richard Mead and Watteau's comediens italiens. Burlington Magazine, London, April 2003, $\mathrm{n}^{\circ} \mathrm{CXLV}$, p. 265.

54. - Et portant la mention " peint par Watteau et tiré du cabinet de Mgr le Duc de Cossé ».

55. - Mezzetin, de son vrai nom Angelo Constantini (1654-1729), fut le principal acteur de la Comédie italienne après la mort de Dominique. Il fut une source d'inspiration importante pour Watteau qui réalisa une étude de son visage, gravée par B. Audran, aujourd'hui conservée au Musée de l'Ermitage à Saint-Pétersbourg, et deux peintures célèbres: Mezzetin visible au Metropolitan Museum of Arts de New York, et Sous un habit de Mezzetin à la Wallace Collection de Londres.

56. - Depuis 1697 et jusqu'en 1716, la troupe de la Comédie Italienne qui s'était installée à l'hôtel de Bourgogne, est interdite de séjour à Paris et la tradition italienne se réfugie dans les théâtres des foires de Saint-Germain-des-Prés et de Saint-Laurent. La foire Saint-Laurent était le rendezvous des artisans, des commerçants et des bourgeois, et se déroulait en plein air, tandis que la foire Saint-Germain, abritée des intempéries, servait plutôt de vitrine au commerce de luxe (bijoux, porcelaine, instruments de musique, estampes). De nombreux artistes et troupes de la foire Saint-Germain s'y produisaient aussi, puisque l'une avait lieu au printemps et l'autre en été. Cette alternance permettait au public de suivre ses spectacles préférés. Peu à peu, s'installait une sorte de véritable "feuilleton " théâtral, une pièce commencée à Saint-Germain pouvait être continuée à Saint-Laurent.

\section{La concurrence aux " grands théâtres "}

Des marionnettes et danseurs de cordes, les acteurs forains en vinrent progressivement à jouer de véritables petites comédies, souvent écrites par des auteurs de renom et de talent. Après l'expulsion des comédiens italiens en 1697, les acteurs forains s'enhardirent et ils s'emparèrent de leur répertoire. La professionnalisation des spectacles de la foire commença à inquiéter la Comédie Française, qui y vit une dangereuse concurrence. Elle essaya par tous les moyens de conserver ses privilèges et, après de nombreux procès menés devant le Châtelet et le Parlement de Paris, elle obtint l'interdiction pure et simple des pièces dialoguées. Mais c'était sans compter sur les ruses que les acteurs forains étaient capables de déployer pour déjouer les interdictions dont ils étaient victimes. Ainsi, se voyant interdire tout dialogue sur les tréteaux, les forains imaginèrent d'abord, en 1707, de ne jouer leurs pièces que sous la forme de monologues, ou encore de parler à un muet, à un interlocuteur placé dans les coulisses, voire à un animal ; plus tard, ils inventèrent un jargon évoquant un bas latin quelconque (Pendao le medicinao!: pendons le médecin), mais qui n'entrait bien entendu pas en concurrence avec la langue française dont les Comédiens Français revendiquaient seuls l'usage; ensuite, ils en vinrent à inscrire tous les dialogues sur des " écriteaux", sortes de rouleaux de papier sur lesquels on se contentait d'inscrire les paroles.

\section{La foire Saint-Germain à ses débuts}

Les Comédiens Français n'eurent dès lors plus de raisons objectives de s'acharner contre les acteurs forains puisque leurs revendications étaient satisfaites. Ce fut alors au tour de l'Académie Royale de Musique de crier à la concurrence : elle était en effet détentrice unique du droit de chanter, de danser et d'accompagner les pièces en musique dans tout le royaume de France. Le rapport de force se joua différemment ici et, très vite, les directeurs de l'Opéra, en proie à des déroutes financières grandissantes, tentèrent de sauver la mise en vendant à deux exploitants forains le droit de donner des spectacles chantés. C'est ainsi qu'en 1714 naquit l'Opéra-Comique. $\mathrm{Au}$ vu du succès grandissant des spectacles de la foire, l'opéra exigea des redevances de plus en plus exorbitantes qui mirent en difficulté les directeurs forains. Alliée objective de l'Opéra, la Comédie Française en profita pour assener un coup fatal en 1719 : elle obtint la suppression de tous les spectacles forains, à l'exception des marionnettes et danses de corde.

\section{Le théâtre de Foire}

(...) Le monde de la «bâtardise » joue avant tout sur le visuel et le rire, il est saisonnier de foire 
en foire, sans subventions, sans salles officielles, le plus souvent sans le relais de la librairie. Seul le succès de la pièce assure sa relative pérennité, sa publication éventuelle ne reproduisant qu'un texte expurgé pour satisfaire la censure royale : comparant les différences entre les manuscrits et les imprimés de Lesage, peut-on uniquement conclure à sa volonté de faire de l'opéra-comique une arme de réforme morale débarrassée de sa gangue rabelaisienne ? Usant de la pantomime, de l'acrobatie, des monologues, des tableaux, de l'improvisation, des marionnettes et des chants populaires, satirique et moraliste, le théâtre de Foire prend sa source dans l'actualité (la faillite de Law suscitera plusieurs textes sur le bon usage de l'argent), dans les emprunts aux auteurs classiques (la tragédie grecque, la commedia dell'arte, Molière, La Fontaine) comme dans les mythes populaires et aristocratiques, remontant souvent au Moyen Âge (...). Le tout pour mieux dessiner, au-delà des inévitables intrigues amoureuses dans lesquelles se glissent Arlequin, Scaramouche, Pierrot, Mezzetin, Polichinelle, Léandre, Pantalon ou Colombine, un monde manichéen et volontiers allégorique, dénoncer les privilèges, le jeu, défendre une certaine homogamie sociale dans le mariage, et exalter les vertus du travail, de l'honnêteté, de l'égalité devant la loi, selon une morale qui doit rarement au christianisme et marque au contraire une laïcisation des esprits. (...) Parmi les protecteurs du théâtre de Foire : l'Archevêché de Paris, soucieux des revenus pécuniaires des foires, relevant du domaine ecclésiastique, l'administration et la magistrature dont sont issus plusieurs auteurs - la plupart, au demeurant, préférant protéger leur réputation derrière l'anonymat -, voire la Cour, qui n'hésitera pas pour ses amusements à inviter plusieurs troupes à Versailles, sans compter un public divers (du noble à l'étudiant en passant par l'artisan ou le voleur à la tire) qui finit par faire sienne la lutte contre les privilèges (...). MARTIN, Isabelle. Le théâtre de la Foire : des tréteaux aux boulevards. Oxford : Voltaire Foundation, 2002.

57. - Voir BIANCOLELLI, Pierre-François. Nouveau théâtre italien contenant: le prince généreux, la femme infidèle, Arlequin, comédies. Paris : éd. Jacques Édouard, 1712. REGNARD, Jean-François. Scènes françaises de la comédie italienne intitulée la foire Saint-Germain. Grenoble, 1696.

58. - « Les Goncourt avaient bien senti l'importance de la nouvelle façon de traiter la mythologie dans l'art du siècle et compris que les dieux à la mode reflétaient les idées nouvelles (...) Le genre mythologique n'était pas dépassé. Il n'avait fait que prendre une figure riante (...) La Régence apporta une conscience accrue des possibilités psychologiques de la mythologie, de la façon dont les dieux pourraient figurer le conflit de forces internes - le bellum intestinum - (...) Sous la forme, en apparence frivole et ornementale de beaucoup d'œuvres mythologiques de la Régence, se cache une signification plus profonde. En dépit d'éventuelles valorisations « décoratives » les dieux gardent toujours une partie de leur valeur symbolique. Mais la Régence se différencie encore davantage de l'époque précédente par sa façon de percevoir ce monde mythologique. Celui-ci n'est saisi qu'à travers une convention théâtrale. H. Bauer est un des rares critiques à analyser ce phénomène. Dans son excellente étude « Wo liegt Kytera? » il fait ressortir le fait que dans l'art de Watteau et de ses contemporains la mythologie n'est plus représentée directement mais par un détour de l'imagination théâtrale (...) L'allusion théâtrale et l'allusion mythologique s'entremêlent d'une façon symbiotique (...) Cette introduction de la qualité théâtrale en tant que point médian entre le mythe et la réalité, cette poétisation du procédé allégorique se retrouve chez Watteau (...) Le Grand siècle avait voulu élever l'homme au niveau des dieux. La Régence rabaissa ces derniers au niveau de l'homme (...) À travers leur déchéance et leur inefficacité, ils sont un commentaire ironique sur la faillite de ce monde (...) La satire des financiers et de l'amour vénal est un thème banal à l'époque (...) Désormais les qualités divines ne s'expriment qu'à travers un mythe théâtral (travestissements mythologiques courants à la Foire et aux Italiens) (...) Pour la génération de la Régence, le mythe ne peut plus être représenté directement, il faut le traduire en termes scéniques, créer pour des spectateurs légers et sceptiques des fables symboliques auxquelles ils puissent ajouter foi ironiquement (...) Pour cette société les fictions 
théâtrales sont des masques transparents dont ils se servent pour des raisons personnelles, selon une vision du monde où le jeu est miroir de la réalité et la réalité une sorte de jeu (...) Chez Crozat - mélange de financiers, de haute bourgeoisie, d'artistes et d'hommes de lettres) on se donne en spectacle. Ces comédiens amateurs trouvent leur image dans le théâtre et plus particulièrement dans le théâtre qui s'inspire de la commedia dell'arte (...) Avec le bannissement de l'ancienne troupe de Ghérardi, l'habit italien était passé sur les tréteaux forains et dans les salons. On sait que ces habits étaient couramment utilisés dans les divertissements mondains (Watteau luimême en avait un stock dont il revêtait ses amis). Ce que Watteau emprunte à la tradition italienne est beaucoup plus que le pittoresque des costumes (...) Il y trouve les possibilités esthétiques et thématiques du déguisement (...) Le jeu théâtral lui permet de se définir à travers une variété de rôles. Qu'importe si la route de l'authenticité passe par le travestissement, le but est toujours d'atteindre à sa vraie personnalité ». TOMLINSON, Robert. La fête galante : Watteau et Marivaux. Genève, Paris : Libraire Droz, 1981.

59. - MARTIN, Élisabeth, SINDACO-DOMAS, Claudia. La technique picturale des peintres des fêtes galantes dans le contexte du XVIII ${ }^{e}$ siècle. Techne, Paris, 2009-2010, n³0-31, p.25-36.

60. - DEZALLIER d'ARGENVILLE. Abrégé de la vie des plus fameux peintres. 1ère éd. 1745 , t. II ; 2e éd. 1762, t. IV.

61. - MARTIN, Élisabeth, SINDACO-DOMAS, Claudia. La technique picturale des peintres des fêtes galantes dans le contexte du XVIII ${ }^{\mathrm{e}}$ siècle. Techne, Paris, 2009-2010, nº30-31, p. 33-34.

62. - ÉVENO, Myriam, LAVAL, Éric, MARTIN, Élisabeth, BARTOLL, Jens. La palette de Watteau et de ses épigones : l'analyse des pigments. Techne, Paris, 2009-2010, n³0-31, p. 41.

63. - MARTIN, Élisabeth, SINDACO-DOMAS, Claudia. La technique picturale des peintres des fêtes galantes dans le contexte du XVIII ${ }^{\mathrm{e}}$ siècle. Techne, Paris, 2009-2010, n³0-31, p. 28.

64. - DEZALLIER d'ARGENVILLE. Supplément à l'abrégé de la vie des plus fameux peintres, $3 e$ partie. Paris, 1752, p. 291.

65. - CAPLAN, H. H. Symbols and monograms: the classified directory signatures of artists. London : ed. George Prior, 1976.

66. - BENEZIT, E. Dictionnaire des peintres, sculpteurs, dessinateurs et graveurs. Tome 6. Paris : Librairie Gründ, 1976, p. 414-416.

67. - «Dans ce début du XVIII ${ }^{\mathrm{e}}$ siècle, le Palais du Luxembourg, avec ses œuvres d'art et ses jardins, était comme une deuxième académie pour les artistes de la fête galante, qui fixèrent dans ce lieu plusieurs éléments importants de ce genre nouveau. Le directeur de cette seconde académie était Claude III Audran (...), conservateur du Luxembourg depuis 1704 et qui avait toutes ses entrées dans cette résidence royale.(...) Audran, nous le savons, laissait Watteau évoluer librement dans les jardins du palais et dans les salles de peintures (en particulier devant la série de toiles illustrant la vie de Marie de Médicis peinte par Rubens, artiste comme on l'a souvent souligné qui influença fortement les artistes de la fête galante (...). Nicolas Lancret aussi était bien connu d'Audran ». TAVENER HOLMES, Mary. Nicolas Lancret : Île de France ou île de Cythère ? Techne, Paris, 2009-2010, n³0-31, p. 211-212.

68. - EIDELBERG, Martin. Watteau and Audran at the Hotel de Nointel. Apollo, the International magasine of the arts. London, January 2002, p. 13.

69. - FORRAY-CARLIER, Anne. Du destin de quelques décors d'arabesques conservés au musée des Arts décoratifs. Techne, Paris, 2009-2010, n³0-31, p. 110.

70. - Des décors du salon de cet hôtel subsistent mais ont été dispersés dans différentes collections : trois grands panneaux peints : "le turc ", "l'actrice », " la pèlerine » sont conservés au musée des Arts décoratifs de Paris; le Metropolitan Museum of Arts de New York possède un trumeau de boiserie, dessus-de-cheminée ; enfin le 16 juin 2000 furent mis en vente à Richelieu Drouot (vente Piasa - Maîtres Picard Audap Solanet et Associés) deux grands panneaux ("la Danseuse " et "le Gilles») et deux dessus-de-porte ("l'oiseau mis en cage» et "le joueur de cornemuse »). La place Vendôme. Coll. Paris et son patrimoine. Paris : éd. DAAVP, 2002, p. 283. 
71. - GARNIER, Nicole, SORAN-STEDMAN, Véronique, PASQUALI, Cinzia. La restauration de la grande singerie de Christophe Huet à Chantilly. Techne, Paris, 2009-2010, n³0-31, p. 117.

72. - Les réalisations de Christophe Huet sont plus tardives: la grande et petite singerie de Chantilly ont été réalisées en 1735-1737 et le cabinet des singes de l'hôtel de Rohan à Paris en 1750.

\section{RÉSUMÉS}

La récente découverte d'un plafond peint à décor de singeries est venue enrichir notre connaissance de l'art décoratif parisien de la fin du règne de Louis XIV. L'étude de cette œuvre de grande qualité artistique, admirablement conservée, bien que modeste de proportion, a permis d'identifier deux des peintres: Claude III Audran et Antoine Watteau, et de proposer une troisième main : Nicolas Lancret. La date avancée de 1713 éclaire d'un jour nouveau la période de collaboration de ces artistes et replace cette réalisation décorative dans le contexte politique, culturel et artistique du quartier Saint-Germain, deux ans avant la Régence.

The recent discovery of a rare ceiling painting in the way of the "décor de singeries " has enriched our knowledge of the ornemental Parisian art dating of the end of the Louis XIV's reign. The study of this work, with great artistic quality, perfectly perserved, though modestly sized, allows us to identify two of the painters: Claude III Audran and Antoine Watteau; and enables us to put forward a third hand: Nicolas Lancret. The suggested date of 1713 provides us with a new theory on the period of theses artistes' collaboration and replaces this decorative creation in the political, artistic and cultural context of Saint-Germain's district, two years before Regence.

\section{INDEX}

Mots-clés : Paris, art décoratif, plafond, 18e siècle, singerie, ornemaniste, arabesque, commedia dell'arte, Watteau, Audran, Lancret

Keywords : ornemental art, ceiling, monkeys, eighteenth century, Louis XIV's reign

\section{AUTEUR}

\section{CHRISTELLE INIZAN}

Chargée d'études documentaires, Conservation régionale des Monuments historiques, Direction régionale des affaires culturelles d'île-de-France christelle.inizan@culture.gouv.fr 